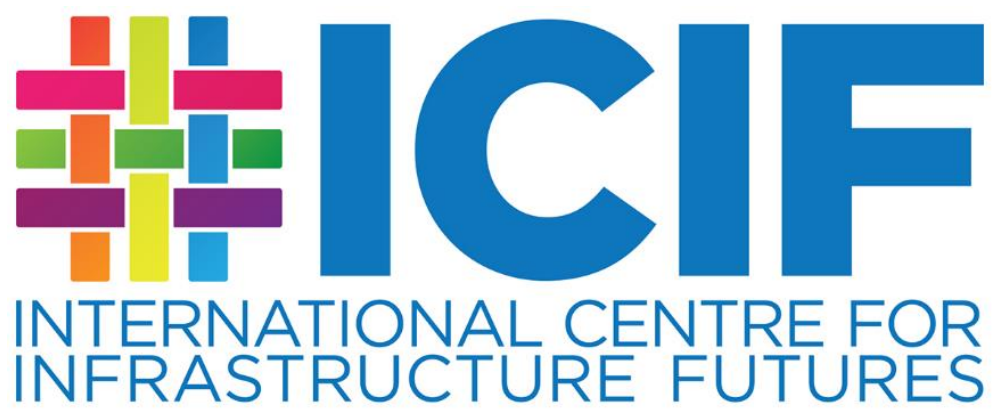

Investigation into the Development of a Framework for the Identification and Appraisal of Infrastructure Interdependencies with Application to Critical UK Infrastructure:

Case Study Report for Infrastructure UK.

\title{
Identification of High-level Infrastructure Interdependencies for the Lower Thames Crossing
}

Final Report Published 30th October 2014

DOI: $10.14324 / 20141455371$ 


\section{Report Author}

Dr Neil Carhart, Research Associate, Systems Centre \& Department of Civil Engineering, University of Bristol, Bristol BS8 1TR, United Kingdom. (Email: neil.carhart@bristol.ac.uk).

\section{Acknowledgement}

This report comprises a case study for a programme of research entitled 'The Development of a Framework for the Identification and Appraisal of Infrastructure Interdependencies with Application to Critical UK Infrastructure', completed on behalf of Infrastructure UK. The research was led Prof. Brian Collins ${ }^{1}$ and Prof. Patrick Godfrey ${ }^{2}$ as Principal Investigators, and was funded by Infrastructure UK, University College London and the University of Bristol. The author would like to acknowledge the additional contribution of The Bartlett Faculty of the Built Environment at UCL to this case study report, and is grateful to the International Centre for Infrastructure Futures for publishing the final report.

\section{Disclaimer}

This report comprises a review of publicly available documents relating to the proposed Lower Thames Crossing conducted by The Systems Centre, University of Bristol. The views and recommendations expressed in this report are solely those of the author and do not represent Government policy.

\footnotetext{
1 Professor of Engineering Policy, UCL; Director, International Centre for Infrastructure Futures (ICIF).
}

2 Professor of Systems Engineering; Director of the Systems Centre, University of Bristol. 


\section{Contents}

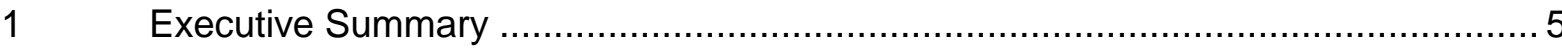

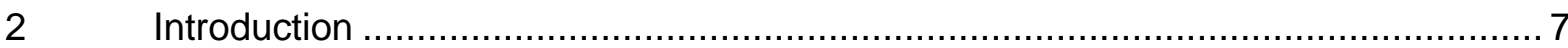

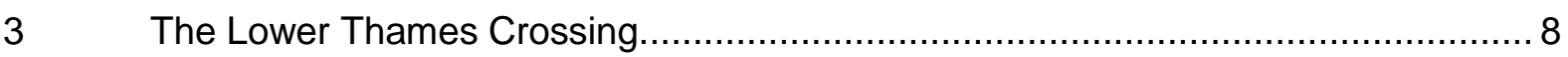

Purpose of the Lower Thames Crossing........................................................ 9

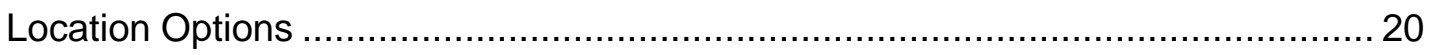

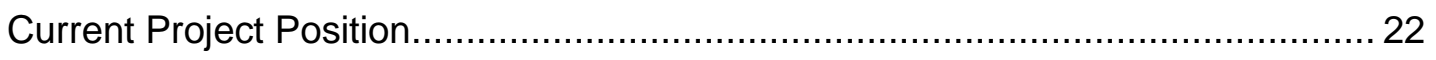

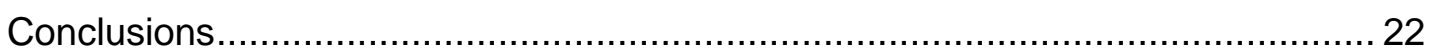

$4 \quad$ Local and Regional Infrastructure and Regeneration Projects ............................ 24

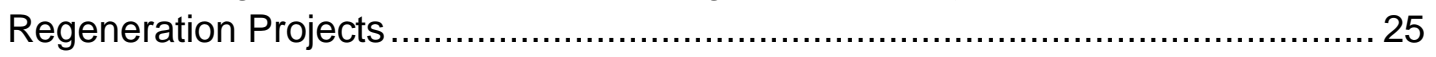

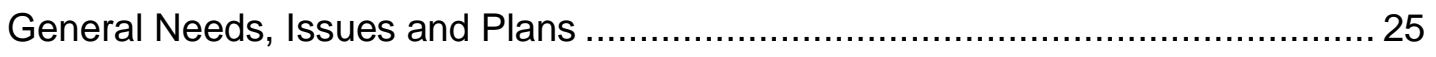

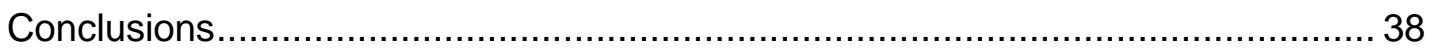

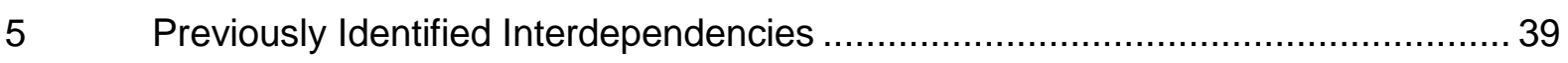

$6 \quad$ Key Stakeholders ............................................................................ 42

7 Resonance of OMEGA Lessons and Case Study Findings to LTC Project ............ 45

$8 \quad$ Method for Application of IP\&MF Associated Tools ........................................... 54

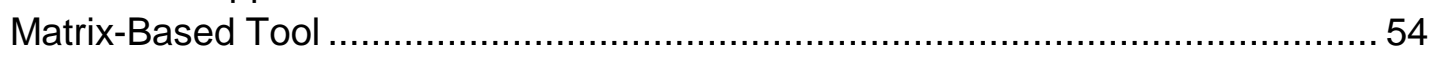

Characterising and Evaluating Interdependencies............................................. 55

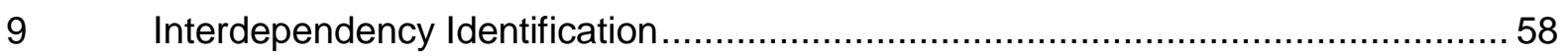

Energy Infrastructure \& the Lower Thames Crossing ………………………..... 59

ICT Infrastructure \& the Lower Thames Crossing ………………………........... 60

Transport Infrastructure \& the Lower Thames Crossing........................................ 60

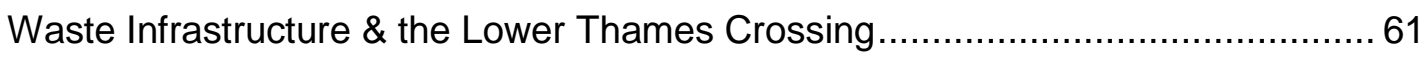

Water Infrastructure \& the Lower Thames Crossing ............................................. 62

The Wider Community and Environment \& the Lower Thames Crossing............... 63

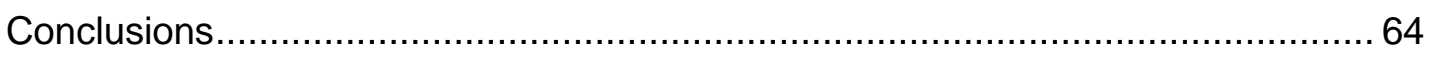

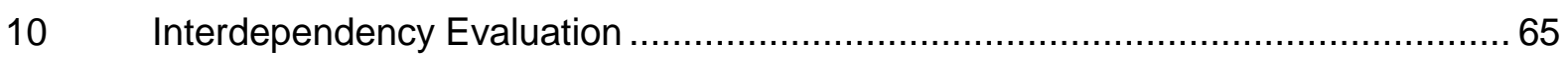

Energy Infrastructure \& the Lower Thames Crossing ......................................... 65

ICT Infrastructure \& the Lower Thames Crossing ……………........................... 65

Transport Infrastructure \& the Lower Thames Crossing....................................... 66

Waste Infrastructure \& the Lower Thames Crossing ............................................. 66

Water Infrastructure \& the Lower Thames Crossing ............................................. 66

The Wider Community and Environment \& the Lower Thames Crossing ................ 66

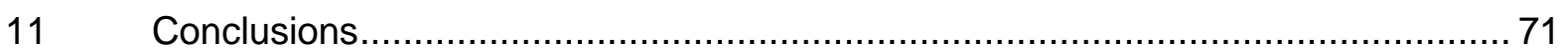

Appendix A - Lower Thames Crossing Document Roadmap ......................................... 72

Appendix B - Desk Study Output Matrix ................................................................... 75 


\section{List of Figures}

Figure 1 - The Dartford Crossing Strategic Context (Figure 1 in Jacob Babtie, 2004).......... 11

Figure 2 - 2007-2008 Dartford Road Improvements (from 2010 Atkins Transport

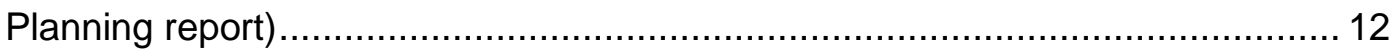

Figure 3 - LTC Policy Area (from Fig 2.3 in Aecom 2013 Final Review Report).................. 17

Figure 4 - Crossing Options considered (Left: Appendix 10A of 2009 PB Study,

Right: Figure 1.1 of 2013 Aecom Study) ............................................... 22

Figure 5 - Kent Thameside Transport Schemes (from Figure 1-1 in 2007 Jacobs report).... 26

Figure 6 - Conservation Areas (Figure 2.12 from 2009 MVA Study) ................................. 28

Figure 7 - Kent Thames Gateway Sub-regional Strategy Area (Diagram KTG1 in 2009

South East Plan) ..................................................................................... 30

Figure 8 - Option A 2030 Employment Impacts (Figure 10-14 in 2009 PB Study) ............... 31

Figure 9 - Option B 2030 Employment Impacts (Figure 10-19 in 2009 PB Study) ............... 31

Figure 10 - Option C 2030 Employment Impacts (Figure 10-22 in 2009 PB study) .............. 32

Figure 11 - Key Swanscombe and Northfleet Land Use Diagram (from David Lock

Associates, 2010) ..................................................................... 33

Figure 12 - Development Clusters in Dartford Area (from Figure 5.1 in URS, 2012)........... 35

Figure 13 - Development Clusters in Gravesham Area (from Fig 5.2 in URS, 2012) ........... 36

Figure 14 - Development Clusters in Thurrock Area (from Fig 5.4 in URS, 2012)................ 36

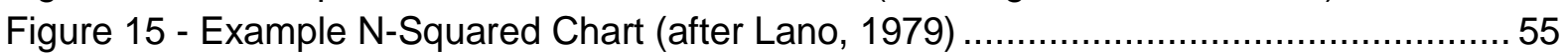

Figure 16 - Generic Sector-Level Infrastructure Interdependency Matrix............................. 58

Figure 17 - Energy Infrastructure \& LTC Interdependencies......................................... 59

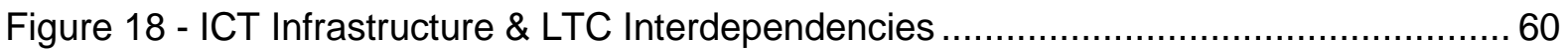

Figure 19 - Other Transport Infrastructure \& LTC Interdependencies ...............................61

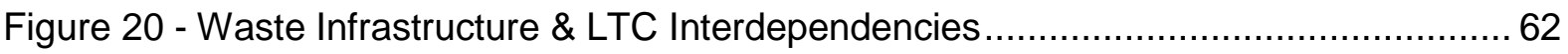

Figure 21 - Water Infrastructure \& LTC Interdependencies ............................................. 63

Figure 22 - Wider Society, Regeneration and Environment Infrastructure

\& LTC Interdependencies

\section{List of Tables}

Table 1 - Aecom Appraisal Impact Areas (Table 2.1 in Aecom, 2013)............................... 19

Table 2 - Lower Thames Crossing Location Options ....................................................... 21

Table 3 - SELEP Strategic Transport Infrastructure Schemes.......................................... 34

Table 4- Average Congestion Delays by Selected Districts (seconds per vehicle km) with New Crossings, 2041 (Table 4.1 in 2013 Aecom study) ............................. 37

Table 5 - Main Stakeholders involved in the LTC project................................................ 42

Table 6 - Energy Infrastructure \& LTC Interdependencies Characterisation and Evaluation 67

Table 7 - ICT Infrastructure \& LTC Interdependencies Characterisation and Evaluation ..... 67

Table 8 - Other Transport Infrastructure \& LTC Interdependencies Characterisation and Evaluation

Table 9 - Waste Infrastructure \& LTC Interdependencies Characterisation and Evaluation. 69

Table 10 - Water Infrastructure \& LTC Interdependencies Characterisation and Evaluation 69

Table 11 - Wider Community and Environment \& LTC Interdependencies Characterisation and Evaluation. 


\section{Executive Summary}

Existing and planned infrastructure can be interconnected in many different ways with each other and with the natural, political and socio-economic systems in which they are located. Current planning, appraisal and design process for major infrastructure projects tend not to identify and capture all of the valuable or hazardous interdependencies that could be exploited or need to be managed. Many potential interdependencies which could deliver benefits or costs to the project and the wider natural/social/economic/political systems are identified too late into the process to take appropriate action.

The approach to infrastructure both old and new is often fragmented, projects are treated as relatively closed systems and the boundaries around them are drawn too early and too narrow. This report applies elements of an Interdependency Planning and Management Framework $(\mathrm{IP} \& M F)^{3}$ to an important emerging infrastructure project, the proposed Lower Thames Crossing (LTC). The IP\&MF, as applied here, aims to identify necessary and potential interdependencies between the LTC and other infrastructure in order to evaluate any prospective benefits or hazards they may present.

The existing Dartford to Thurrock Thames River crossing is an important part of the national, regional and local road networks. Studies have found that during peak times the existing crossing can act as a bottleneck in the network, and traffic forecasts have indicated a need for increased future river crossing capacity in the region and as such the National Infrastructure Plan 2012 has identified the LTC as one of 40 projects of national significance.

There are many complex issues surrounding the capacity problem, the needs for a new crossing and delivery of a solution. The literature concerning the LTC indicates that it is broadly conceived as a transport problem; albeit one that can influence regional and national economies. This perspective can influence the way in which a solution is developed and the way in which interdependencies with other infrastructure systems are identified and valued.

There are a large number of urban regeneration projects proposed for the area around the LTC. These can have an impact on the need for a new crossing and the demands that will be placed upon it. In turn, the existing and new crossing can impact on the delivery and success of these regeneration activities. Desirable and undesirable interdependencies may emerge between the LTC project and these regeneration projects either by design or by accident. The IP\&MF is applied here to better understand the potential interdependencies.

The application of a Matrix-Based Tool for the systematic identification of cross-sector interdependencies highlights a number of necessary and potential interdependencies. These can then be evaluated in terms of Political, Environmental, Social, Technological and Economic factors. Additional, potentially valuable interdependency opportunities include:

\footnotetext{
${ }^{3}$ Rosenberg, G; Carhart, N; Edkins, AJ; Ward, J; (2014), Development of a Proposed Interdependency Planning and Management Framework. International Centre for Infrastructure Futures: London, UK. http://dx.doi.org/10.14324/20141455020
} 
- Using the crossing to generate electricity;

- Using the crossing to carry electricity, telecommunications, water and waste infrastructure elements;

- Using the crossing as a flood defence;

- Using recycled materials in the construction of the crossing; and

- Sharing resources between the construction of the crossing and local regeneration projects. 


\section{Introduction}

This report explores the interdependencies between the proposed Lower Thames Crossing (LTC) and other local, regional and national infrastructure (both existing legacy infrastructure and planned future infrastructure). This will help in the ongoing planning and management of the LTC infrastructure project.

It applies element of an Interdependency Planning and Management Framework (IP\&MF) for the identification and appraisal of infrastructure interdependencies. This is currently under development by the University of Bristol (UoB) and University College London (UCL). This wok was commissioned by HM Treasury and Infrastructure UK who identified the proposed Lower Thames Crossing project as a suitable Case Study for the development of the framework.

This report has several aims:

- To examine the available documents relating to the proposed Lower Thames Crossing and extract the identified characteristics, purpose, need and issues;

- To examine the available documents relating to the desired regeneration of the geographical areas arround the proposed sites for the new Lower Thames Crossing;

- To identify the main Lower Thames Crossing stakeholders;

- To apply the IP\&MF Matrix-Based Tool in order to systematically identify and catalogue the existing and postential interdependencies between the proposed Lower Thames Crossing and other infrastructures, in particular other infrastructure projects; and

- To evaluate the identified interdepdnencies using the IP\&MF PESTLE-based assessment method.

This report does not assess the strength of the case for a Lower Thames Crossing, nor does it provide an appraisal of the potential crossing options. It does not evaluate or pass judgement on the options in terms of their ability to reduce congestion on the local, regional or national strategic road networks, their environmental impacts, social impacts, economic impacts or their regenerative abilities These assessments have been considered elsewhere and are described here only in the context of fully understanding the potential interdependency risks and opportunities presented by a new Lower Thames Crossing.

The following chapter review the relevant literature surrounding the Lower Thames Crossing. It attempts to identify the way in which the problem has been defined and the way in which it is perceived. It looks at the implied and defined purpose of the LTC and the proposed solutions. The third chapter looks at the proposed local and regional regeneration schemes and the wider social and environmental context for the existing and new crossing. These are considered in relation to the LTC. The interdependencies already identified in the literature and the relevant stakeholders are then described in chapters four and five respectively.

Chapter six looks at the LTC project in regards to the OMEGA Lessons derived from a set of OMEGA studies into Mega Transport Projects (MTPs).

Chapter seven sets out the method for the application of the IP\&MF and it associated tools for this case study, while chapters eight and nine describe the output of this application. Finally chapter ten draws together a number of conclusions from this study. 


\section{The Lower Thames Crossing}

The existing Dartford to Thurrock Thames River crossing is an important part of the national road network. It is also of regional and local importance. The existing crossing links international ports, major distribution centres and large urban areas. The crossing, comprising two tunnels (opened in 1963 and 1972) and a cable-stayed bridge (opened in 1991) links the North and South as part of the M25 (via the A282).

In 2002 it was recommended that further consideration be given to an additional multi-modal Lower Thames Crossing ${ }^{4}$. This was endorsed by the Secretary of State for Transport who initiated work re-examining the case.

The National Infrastructure Plan $2012^{5}$ sets out 40 projects and programmes of national significance, the focus on deliver communicated in this plan has resulted in a commitment to build a new crossing. Pressures at Junction 30 of the M25 and on the A13 corridor will also be considered as part of the investigation into a new crossing. The focus on infrastructure has also cemented support for the development of the new London Gateway Port which is also of great importance to the existing and potential new Lower Thames Crossing (LTC).

During peak times the existing crossing can act as a bottle neck in the network ${ }^{6}$. This is of particular concern in an area forecast to experience significant economic growth, home to the current Purfleet, Tilbury and Sheerness Ports as well as the proposed London Gateway Port. Despite this, figures actually show a 6-7\% drop in traffic using the existing crossing between 2003 and 2008, made up of a 9-10\% drop in light vehicles, but an $11-12 \%$ increase in $\mathrm{HGVs}^{6}$. This demonstrates the impact from freight traffic, the importance of the new port developments in the area, and the related effects on local personal/business travel. The cost of delays at the exiting Dartford crossing has been estimated to be in the region of $£ 40$ million per annum ${ }^{6}$.

This chapter summarises the main studies looking at reducing congestion on the existing Dartford crossing and the potential construction of a new Lower Thames Crossing. The first section identifies the issues, perceived needs and purpose ascribed to the LTC. This is followed by a summary of the potential options for fulfilling this purpose, including locations for a new LTC.

There are many complex and interacting issues involved in assessing the need for and impact of a new crossing as detailed in the documents referenced here. This chapter, along with the following chapter, focuses on the main issues specifically in relation to the interaction and interdependency between a new LTC and other infrastructure elements and projects.

\footnotetext{
${ }^{4}$ Kellogg, Brown \& Root Ltd, 2002, Orbit: Transport solutions around London, A report for The Government Office for the South East

${ }^{5}$ HM Treasury \& Infrastructure UK, 2012, National Infrastructure Plan 2012

6 Parsons Brinkerhoff, 2009, Dartford River Crossing Study, Parsons Brinkerhoff for Depart for

Transport
} 


\section{Purpose of the Lower Thames Crossing}

A number of studies have been conducted to understand the need and therefore purpose for a Lower Thames Crossing. These have also examined the wider issues affecting the project. A list of these documents can be found in Appendix A.

Consideration of a new Lower Thames Crossing essential began in $\underline{1990}$ when a report by the Department for Transport entitled 'Private Finance Road Schemes - Information on Proposed Options' described how a it could:

- "increase the opportunity for journeys between Kent and Essex downstream of the Dartford Crossing";

- "improve communications between the fast growing areas of East Anglia and Essex and Kent";

- "and for traffic bound for the Continent via the Channel Tunnel or the Haven Ports"; and

- "would assist M25 in dealing with orbital traffic in this sector"

This led to a $\mathbf{1 9 9 4}$ report by $\mathbf{G}$. Maunsell and Partners (later acquired by Aecom) which included a Feasibility Study into the LTC for the Highways Agency. It identified four potential crossing locations: Swanscombe, Tilbury, Canvey and Sheerness.

Variations at these four locations resulted in a total of 25 different possible routes. The report concluded that a new Lower Thames Crossing would:

- Reduce congestion on the existing Dartford crossing, including the approaches to the north and south;

- Promote economic and development opportunities;

In addition to this, it made some location specific conclusions:

- A crossing at Swanscombe or Tilbury would influence a relatively large area of development;

- Swanscombe would not provide the same user benefits as the other locations;

- A crossing at Tilbury would integrate with existing highway proposals and improve the strategic network, and;

- A crossing at Tilbury is the only location that would be financially viable, and may be privately fundable.

The 1998 Dartford Local Crossing Study by Halcrow Fox and Associates again investigated the feasibility of a new crossing in the Dartford area.

Following the 1998 'New Deal for Transport', the Orbit Multi Modal Study was conducted in 2002. This aimed to develop a long-term sustainable management strategy for the M25 which meets the Government's transport objectives and resolves or relieves current and future problems. It sets out a specific area objective to:

"Examine the role of additional road and rail cross-river capacity east of Dartford to assist regeneration and improve accessibility in Thames Gateway, particularly for freight movement."

It identifies the existing Dartford crossing as one of four particularly congested areas, assessing it in more detail they add:

"Where there is no satisfactory public transport alternative, particularly at the Dartford crossing, then the level of social exclusion is even more of a concern" 
As it is the only crossing for some distance, it is described as being "inelastic" to tolls It also notes lack of real-time information, local bans on night-time freight movement and single occupancy cars as increasing the problem of congestion on the M25. The Orbit report quotes Highways Agency figures (in Table 12.1, p152) that conclude the Dartford Crossing itself will reach capacity in less than 10 years (i.e. by 2012) while some of the surrounding junctions will reach capacity before then. It summarises the main conclusions of the pre-2002 investigations, stating that the LTC:

- would reduce traffic congestion on North and South approaches to the existing Dartford crossing, reducing bottlenecks at points of strategic importance to freight;

- could promote development;

- would provide local and international freight to by-pass London and connect to the national road network; and

- would provide better links between Europe and UK cities.

The study concludes that an initial economic appraisal suggests a new crossing would have a low benefit to cost ratio, adding:

"We believe that a new Lower Thames Crossing should be seen as a local facility to aid regeneration in the Thames Gateway and not primarily as a means of relieving the M25."

Ultimately, further investigation into the LTC is recommended by the study on the grounds it would relieve M25 congestion and aid regeneration in the Thames Gateway. They do not rule out rail infrastructure being part of the crossing to ease difficulties with rail freight circumnavigating London.

Jacobs Babtie produced a report at the end of $\underline{2004}$ for the Highways Agency entitled 'Getting the most out of the Dartford Crossing'. It concludes that possible future demand pressures on the crossing may arise from improvement measures adjacent to the crossing; national, regional and local regeneration plans; M25 Motorway policies, and; tunnel safety and air quality legislation and EU directives. It quotes data from October 2003 that $61 \%$ of journeys using the crossing are longer than $100 \mathrm{~km}$.

It uses data from the Highways Agency's NAOMI traffic model (which include assumptions about provision from the DLR extension, Thames Gateway Bridge, Crossrail and the CTRL) to predict a more than $20 \%$ increase in daily flows by 2016 . This is equal to the highest ever throughput measured at the time on two occasions in 2004. It notes that these were marked by congestion for 14 hours of the day and therefore predicts this to become a common occurrence by 2016 . It concludes from this data that:

"the existing Dartford Crossing and its approaches will be unable to accommodate the NAOMI predicted demand without extensive congestion and frequent demands for significant improvement".

As a result the levels of service for the M25 would not be achieved, a greater proportion of freight than originally identified would need to move to alternative modes or overnight movement and the demand for movement and regeneration opportunities will be "frustrated by a lack of capacity".

It investigates short and medium term proposals such as removing the southbound toll plaza and changes to charging but ultimately suggests that "It would appear timely to examine further both the engineering practicality and full business case for significant enhancement to 
the Crossing that will match the inherent capacity of the M25 ring" itself projected to increase as a result of a Rapid Widening Project.

The report places the crossing into the wider context of the area (Figure 1), the developments within which are discussed further in the following chapter.

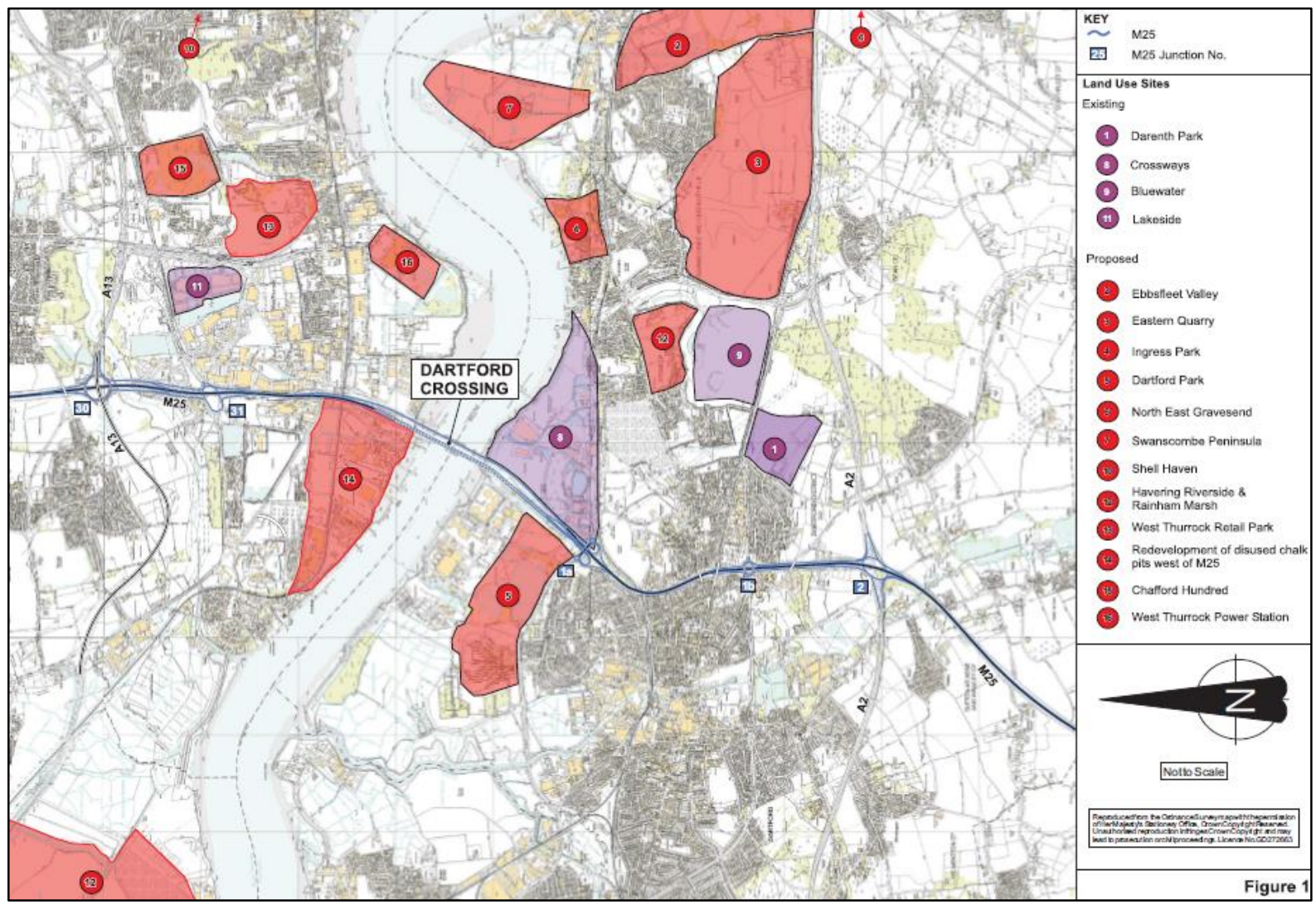

Figure 1 - The Dartford Crossing Strategic Context (Figure 1 in Jacob Babtie, 2004)

Their assessment of 13 different measures for dealing with the predicted growth in congestion concludes that none will have a significant impact in the short term, though some may limit disruptions due to accidents.

They also note that the crossing is part of the local and regional road network, that its importance in this context is likely to increase (due to increased housing, employment and business developments), and that this will have an impact on congestion and journey time reliability which will ultimately impact the local and national economy. Furthermore, they recognise that opportunities to safeguard land for a new crossing are shrinking as the regeneration of the region continues.

In December 2007 a set of improvements to the A2/A282, on the south approach to the existing crossing, were opened. This involved the construction of three free-flow links at J2 of the M25 and the widening of $2 \mathrm{~km}$ of the A2 to the east of the junction. Part of the objectives of this was to reduce journey times, improve reliability and improve access to the regeneration local areas. In July 2008 widening of Junction $1 \mathrm{~b}$ to Junction 3 of the M25 was opened. This too aimed to improve journey time and reliability, as well as creating jobs in the area through 
increased labour markets. Figure 2 taken from a post project review by Atkins Transport Planning ${ }^{7}$ depicts these improvements.

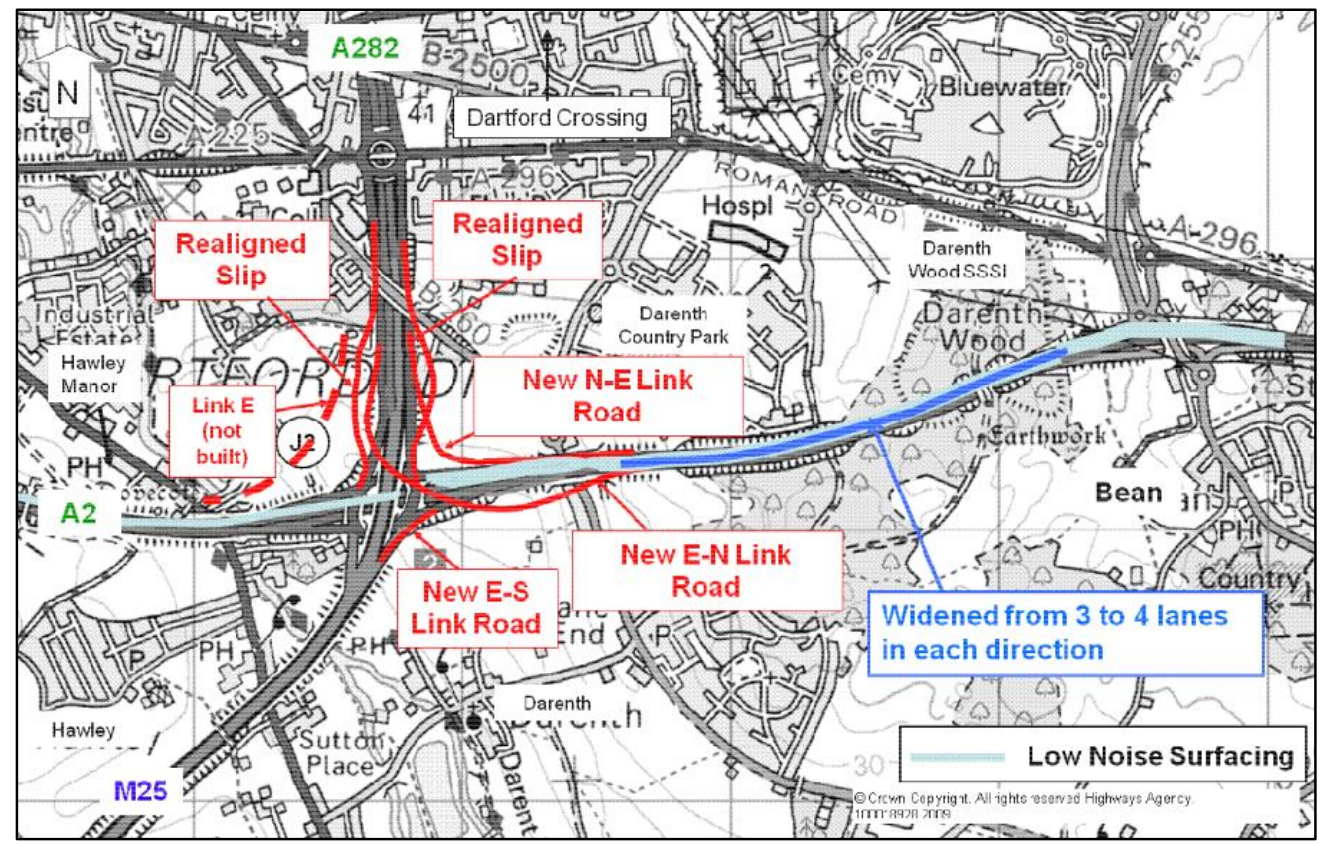

\section{Figure 2 - 2007-2008 Dartford Road Improvements (from 2010 Atkins Transport Planning report)}

In $\underline{2008}$ the East of England Plan recognises the link between the Essex Thames Gateway and the Kent Thames Gateway as being a key inter-regional infrastructure connection. Also in 2008 the Department for Transport published 'Delivering a Sustainable Transport System' (DaSTS) ${ }^{8}$. This set out five high-level goals against which the options for a new Lower Thames Crossing were assessed. These goals are:

1) to support national economic competitiveness and growth, by delivering reliable and efficient transport networks;

2) to reduce transport's emissions of carbon dioxide and other greenhouse gases, with the desired outcome of tackling climate change;

3) to contribute to better safety, security and health and longer life expectancy by reducing the risks of death, injury or illness arising from transport, and by promoting travel modes that are beneficial to health;

4) to promote greater equality of opportunity for all citizens with the desired outcome of achieving a fairer society; and

5) to improve quality of life for transport users and non-transport users, and to promote a healthy natural environment.

In 2009 Parsons Brinkerhoff were commissioned by the Department for Transport to investigate ways of addressing capacity constraints at the existing Dartford crossing ${ }^{6}$. It looked at capacity requirements up to 2037 , the role of other transport modes (e.g. rail) in meeting the capacity demands, the impacts of meeting the demand with new infrastructure

\footnotetext{
${ }^{7}$ Atkins Transport Planning, 2010, Post Opening Project Evaluation: A2/A282 Dartford Improvement and M25 J1b - 3 Widening: One Year After, September 2010

${ }^{8}$ Department for Transport, 2008, Delivering a Sustainable Transport System, November 2008
} 
and how to improve traffic flow in the short/medium term. The analysis uses data from Le Crossing, the Dartford Crossing operators and the Highways Agency (HATRIS database).

The report identified that the "planning, economic, regional and national transport issues in the vicinity of the existing Dartford Crossing are inextricably linked to the relevant Regional Spatial Strategies (RSS) and the emerging Local Development Frameworks (LDF)".

The study conducted transport modelling to establish a base case for future use of the Dartford Crossing, assessed the current and likely future performance of the existing crossing based on this, investigated the option of rail provision, investigated options for making better use of the existing crossing, undertook stakeholder engagement activities and identified preliminary designs for a possible new crossing.

Using the available data the report concludes that the existing crossing experiences "high levels of flow and congestion on a daily basis" adding that total flows had actually decreased, but HGV crossings had increased. The crossing experiences the third highest delays in the strategic road network. Almost half of users in either direction experience a significantly reduced level of services (quantified as "more than nine minutes of additional delay"). Of the journeys using the crossing:

- $40 \%$ of light vehicles are journeying relatively long distance (>80km)

- $50-60 \%$ of light vehicles are travelling between the urban areas either side of the crossing

- $30 \%$ of the HGV journeys are to or from the port of Dover over long distances

- $50 \%$ of the HGV journeys are centred around elsewhere in the East and South East

- $20 \%$ of the HGV journeys are over short distances between centres on either side.

It is certainly of interest that "There is specific evidence, drawn from the Census data, which suggests that interactions between the local authority areas to the north and south of the Thames on either side of the Crossing are lower than would be expected, given the proximity of the areas." It is suggested that as these areas grow, this disconnect could restrict employment opportunities and therefore wider economic prosperity.

Using figures for 2007 the report calculates that the cost of the delays at the existing crossing cot in the region of $£ 40$ million per annum (para 5.101). Demand on the existing crossing is forecast to increase by $38 \%$ to 2031 by the East of England Model (para 7.41), assuming the congestion would not affect this growth. The Trip End Model Presentation Program (TEMPRO) forecasts $19 \%$ of the total number of hours in a year would see flows exceeding the current 6,000 vehicles per hour capacity. Disruption to journey time reliability is already seen when demand exceeds 4,000 vehicles per hour. This is projected to occur for $43 \%$ of the available hours in a year. The South Essex Land Use and Transport Model (SETLUM) also predicts the crossing to be beyond capacity by 2030 . These projections seemingly provide a strong case for the consideration of improved capacity management and additional capacity.

The PB report dismissed the option for a rail crossing, identifying a lack of demand from passengers for a North-South crossing, and a limited need for alternative freight carrying rail infrastructure. The report concludes:

"It is acknowledged that there will be rail freight capacity issues by 2031 around much of London. That said, the inclusion of rail freight provision as part of any new 
Lower Thames Crossing would not appear to address these issues and may even lead to a deterioration in rail congestion at certain points in the network."

Adding:

"Overall, taking into account both passenger and freight provision, the inclusion of rail infrastructure within the scheme is not considered to have a reasonable initial business case."

The consultation highlighted two constraints perceived to be of particular importance by the stakeholders:

- The issue is more to do with a general infrastructure deficit than a specific crossing constraint

- The need for a new crossing was frequently linked to the challenges created by the existing crossing

The conclusions strongly link the need for providing additional river-crossing capacity to the economic growth of the region:

"It is therefore reasonable to assume that without cross-Thames capacity
enhancements in the Lower Thames area, increased delays resulting from
forecast increases in demand within the study area will have several effects. It will
not only worsen journey time reliability but will also generate negative economic
effects at local, regional and national scales as well as more localised social
impacts."

In terms of rail freight, the Parsons Brinkerhoff study looks at the 'Great Britain Freight Model' forecasts up to 2031. These forecasts suggest there would be minimal growth in the areas served by a new crossing in the Lower Thames region, and little scope for modal shift away from road freight. It would not serve the routes forecast to experience significant growth. They conclude that "Overall, taking into account both passenger and freight provision, the inclusion of rail infrastructure within the scheme is not considered to have a reasonable initial business case." The inclusion of a freight crossing was therefore discounted from the options considered in the study. There is of course an argument that 2031 timescales may be too short for such an infrastructure investment.

Parsons Brinkerhoff identified five potential location options (referred to as A. B, C, D and E, as described in Table 2 below) which were assessed with respect to the DaSTS goals in terms of their corridor description and alignment, their traffic impacts, their wider economic benefits, their environmental impacts, their integration and accessibility with other transport infrastructure, and stakeholders views. The integration of the LTC with other transport infrastructure relates mainly to the SERT and Fastrack Bus Rapid Transport schemes, along with cycling and pedestrian facilities.

While these options are described in greater detail in the following section, it is of note that two potential crossing sites ( $D$ and $E$ ) were recommended for elimination from further consideration. Option D performed generally positively against the DaSTS goals, but significantly worse than Options A, B and C. It would benefit the London Gateway Port and local traffic movements but would provide limited relief to the existing Dartford Crossing, leaving it over capacity, increasing greenhouse gas emissions compared to the 'do nothing' case, and causing significant adverse environmental impacts. Option E would also provide only limited relief to the existing crossing, again leaving it over capacity and ultimately 
increasing greenhouse gas emissions. It is also a site forecast to experience only a low level of traffic demand.

Also in 2009 the Gifford, MVA Consultancy and Capita Study 9 sought to help the Essex and Kent County Councils to better understand how additional crossing capacity might change land use on either side of the estuary and how it might bring economic regeneration into the area.

Phase 1 of this report looks at the need for intervention, identifying two points:

- A need to improve the level of reliability and dependability of journey times across the river for European (TEN-T), national and local traffic

- A need to improve the connectivity between the growth areas in North Kent and South Essex

The regeneration plan for these areas identify the need for and benefit of a new crossing, "but currently the plans are predicated only on the exiting Dartford - Thurrock Crossing". The potential is to unlock additional benefits and to further facilitate growth.

They state that "Any intervention will need to facilitate the achievement of the planning objectives relating to the economic, environmental, social and employment needs of the area" adding that it should also facilitate other improvements that would reduce the effect of traffic and benefit the community. To this end, they identify six requirements for a new crossing extending the two points above:

- To reduce congestion and improve the reliability and dependability of journey times;

- To ease local traffic congestion and associated problems;

- To result in a safer and more efficient corridor;

- To cater for future planned growth;

- To assist in enabling future regeneration and economic growth;

- To support public transport and other sustainable modes.

The study looked at nine possible locations, considering the feasibility of bridges and tunnels at each. Each option was appraised based on congestion relief, economic vitality, environmental impact, engineering (feasibility, acceptability and impact on existing network), affordability (capital costs and funding sources), enabling of development and regeneration and travel sustainability (e.g. promoting sustainable transport modes, share of sustainable modes, improving safety and reducing demand).

In term of reducing congestion alone, their modelling indicates that a crossing between West Thurrock and Swanscombe would be the best option, followed by the Grays to Swanscombe option (similar to Option B in the PB study), Chadwell to Gravesend option (similar to Option $\mathrm{C}$ in the PB study) and Wennington to Dartford option.

In 2010 KPMG produced a report ${ }^{10}$ for Kent County Council into the Lower Thames Crossing. This looked at potential funding options for the project along with the likely regeneration impacts. It underlined this link between the crossing and regeneration concluding productivity benefits of $£ 2$ and $£ 15$ million per annum depending on the chosen location. Importantly, it

\footnotetext{
${ }^{9}$ Gifford, MVA Consulting and Capita, 2009, Assessment of Lower Thames Crossing Capacity, November 2009

10 KPMG, The Lower Thames Crossing - KPMG Regeneration and Funding Report, August 2010
} 
indicates that Kent County Council has concluded that a crossing between Stanford-le-Hope and the East of Gravesham (known as Option C) is its preferred route.

The existing Dartford Crossing is beyond the boundary of the Greater London area, but as part of the Strategic Road Network and a by-pass to central London, its efficiency can have a significant impact on the city. In May 2010 the Mayor's Transport Strategy for London for the period up to 2031 states in Proposal 39 f) "Support for Government proposals to reduce congestion at the Dartford crossing".

This was followed by the London Plan published in July $\underline{\mathbf{2 0 1 1}}$ by the Greater London Authority reiterates the need for additional river crossings in the east sub-region of London in Policy 6.4, Policy 6.12 and Table 6.1. Policy 6.4 'Enhancing London's Transport Connectivity' is generally concerned with ensuring "effective transport policies and projects to support the sustainable development of the London city region and the wider south east of England" as well as "efficient and effective cross-boundary transport services". Policy 6.4, Part B which refers to improving the public transport system, includes (clause k) "providing new river crossings". Paragraph 6.20 expand on this but does not specifically mention the Dartford Crossing or any plans to increase its capacity, the focus instead being on additional crossings east of the existing Dartford Crossing. Policy 6.11 addresses smoothing traffic flow and tackling congestion, while Policy 6.12 addresses road network capacity. It is stated that:

\begin{abstract}
"[The Mayor] is committed to improving cross-river pedestrian, cycle and public transport links, to promoting a shift from private cars to more sustainable modes, and to encouraging freight journeys to avoid peak hours through improved journey planning, supply chain measures and support for consolidation centres and modal shift to rail and water in order to reduce pressure on congested crossings. There will, however, continue to be a need for some journeys to be undertaken by vehicle, in particular commercial traffic, the movement of goods and the provision of services to support a growing economy in east London"
\end{abstract}

Here, the Dartford crossing is specifically mentioned as regularly operating at, or close to, capacity. It is recognised as having little resilience and being important to local businesses in south east London. The report argues that projected increases in jobs and population in the Thames Gateway will make the situation worse, and "The Mayor is therefore supportive of additional road-based river crossings in east London as part of a package of transport improvements."

On the $21^{\text {st }}$ May 2013 the Government launched a consultation into location options for the Lower Thames Crossing, supported by the release of a new review of crossing options completed by Aecom for the Department for Transport ${ }^{11}$.

It is perhaps of note that as part of the methodology for this study (as described in para 2.5.2) the report's authors contacted statutory bodies responsible for environmental issues, the Port of London Authority, Network rail and major public utilities in order to understand constraints imposed on the various location options, particularly by their infrastructure assets.

${ }^{11}$ Aecom, 2013, Review of Lower Thames Crossing Options: Final Review Report, April 2013 
The policy area, defined as "the area where the provision of new capacity at one of the location options might have particular impacts" (para 2.7.4) is shown in the diagram below.

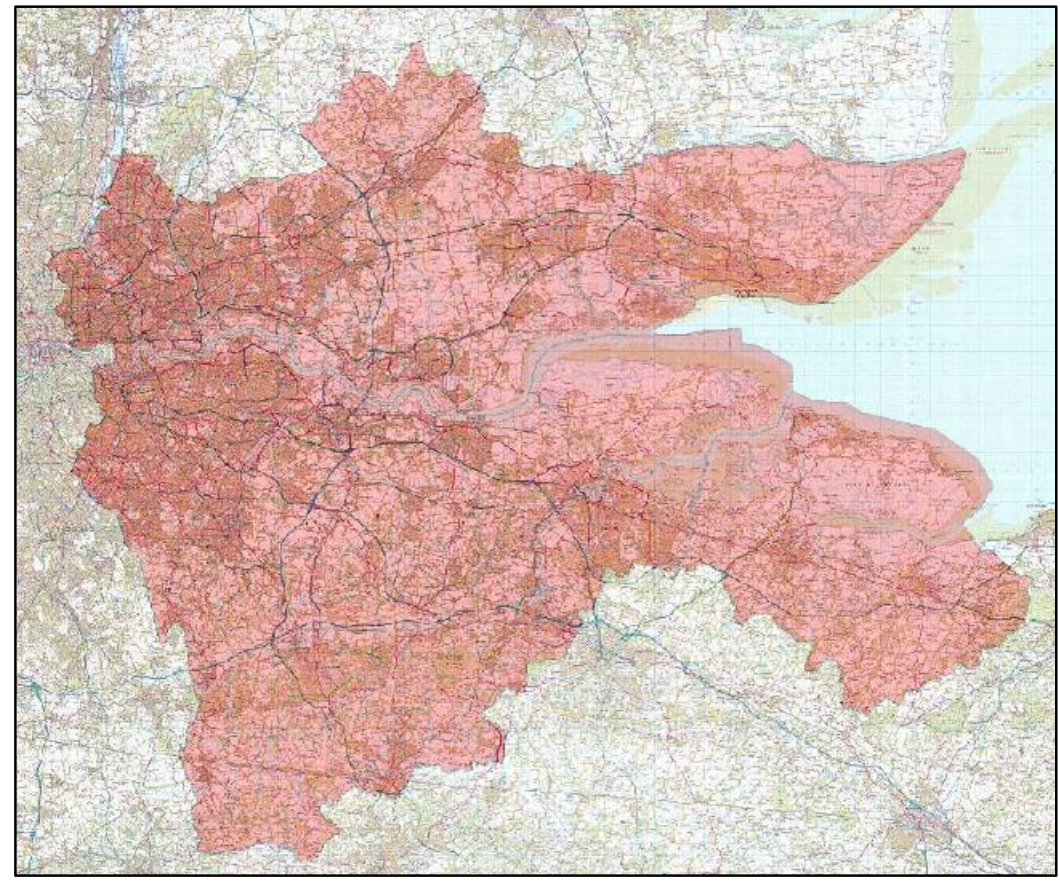

Figure 3 - LTC Policy Area (from Fig 2.3 in Aecom 2013 Final Review Report)

Section 3.2 describes the Business Strategy through reference to several key government publications. In addition to the general points of the National Infrastructure Plan (facilitate economic growth and private investment, and improve quality, sustainability and capacity), at the highest level this refers to a vision for "dynamic, sustainable transport that drives economic growth and competitiveness" (para 3.2.1). This is interpreted from a 2012 Department for Transport document ${ }^{12}$. The report then references a speech from the Prime Minister in March 2012 which links transport to business investment, economic growth and protection of the environment, and the Department for Transport Business Plan ${ }^{13}$ for investment in roads to promote growth while reducing congestion and carbon emissions. Finally it references Highways Agency Business Plan's ${ }^{14}$ goals to tackle bottlenecks and increase capacity.

Section 3 sets out the Strategic Case and the need for change, summarising the problem in para 3.3.8:

"The lack of capacity and resilience result in consequential problems: delays;
longer journey times and reduced journey time reliability. These impacts in turn
reduce business productivity and ultimately produce an adverse impact on the
national economy. A further consequence of congestion is higher vehicle
emissions, which has consequences for local air quality."

In other words; (1) lack of capacity at the existing crossing, which causes; (2) delays in both directions; (3) reduced resilience (i.e. higher rate of incidents that at other parts of the strategic

\footnotetext{
12 Department for Transport, 2012, The High Level Output Specification (HLOS) 2012: Railway Act 2005 Statement, July 2012

${ }_{13}$ Department for Transport, 2011, Business Plan 2012-2015

14 Highways Agency, 2011, HA Business Plan 2012-2013
} 
road network; (4) reduced journey time reliability and; (5) reduced connectivity. In addition to this are a number of adverse environmental impacts (primarily in terms of air quality). As stated in the above quote, these combine to reduce productivity and economic activity. It is therefore suggested that providing additional capacity will resolve these problems. It is suggested that the short-term measures will not address long term traffic forecasts.

This conclusion is drawn from the supporting Aecom report into demand forecasts ${ }^{15}$ that traffic flows will increase from 2009 to 2041 by around $30 \%$. This prediction includes road schemes considered likely to already be implemented by 2041 . Flows across the existing Dartford Crossing are predicted to increase by $10-20 \%$ in the southbound direction and $2-10 \%$ in the northbound direction by 2041. Growth in the northbound direction will be constrained by lack of capacity. The main driver for this growth is identified as the forecast increase in population.

Having established that the need is "to add capacity to the strategic road network to alleviate congestion at the existing crossing" Paragraph 3.5.3 outlines the way in which the impacts of a new crossing at each of the proposed locations were judged:

"This involved considering the extent to which a new crossing at each location would:

- contribute to the national economy, through improving journey times and connectivity of the strategic road network, both to and within the Thames Gateway and the South East;

- reduce congestion at the existing crossing and improve the resilience of the strategic road network;

- contribute to reducing greenhouse gas emissions;

- avoid unacceptable impacts on environmentally sensitive areas and improve quality of life; and

- avoid unacceptable impacts on committed development. “

From this statement of need and appraisal framework it is clear that the LTC Project is firmly conceived as a transport solution. Its benefit to the national and regional economy arises from reducing congestion and therefore reducing journey times, improving connectivity and reducing harmful emissions. The success of the project is to be measured through changes in: (1) the level of delay; (2) journey times; and (3) journey time reliability. Environmental appraisal will look to measure: (1) incidents and accidents; (2) noise and air quality; and (3) traffic volumes.

The report claims that stakeholders are particularly concerned with the congestion and lack of resilience of the current crossing. The Thames Gateway South Essex Partnership for example are cited as being concerned that this may affect growth in the area, while the Thames Gateway Strategic Group state that it is critical to Britain's economic future. The South East Local Enterprise Partnership (SELEP) are reported to also be very concerned with these issues, and that they consider the LTC to be the second highest priority national

\footnotetext{
${ }^{15}$ Aecom, 2013, Review of Lower Thames Crossing Options: Central Forecasts and Sensitivity Report. April 2013
} 
road scheme. It is also quoted that proposal 39 in the Mayor of London's Transport Strategy ${ }^{16}$ indicates support for the Government proposals to reduce congestion at the existing crossing.

The direct impacts of the new crossing at each of the location options is carried out using the LTC Model ${ }^{15}$. The focus is very much on the direct traffic impacts, congestion and journey times. These are then interpreted to understand the key impacts they may have. This is done in accordance with DfT Transport Analysis Guidance (WebTAG). The impact areas are split into four areas with associated sub-topics, these are shown in the table below, which also indicates whether they were monetised in the appraisal process, whether social and distributional impacts have been analysed, and the relevant WebTAG reference.

Table 1 - Aecom Appraisal Impact Areas (Table 2.1 in Aecom, 2013)

\begin{tabular}{|c|c|c|c|c|}
\hline Key Impacts & Sub-Impacts & Monetised? & $\begin{array}{c}\text { SDI } \\
\text { Analysis? }\end{array}$ & WebTAG Unit \\
\hline \multirow{4}{*}{ Economy } & $\begin{array}{l}\text { Business users \& } \\
\text { transport providers }\end{array}$ & $\checkmark$ & $x$ & $3.5 .1-3.5 .4$ \\
\hline & $\begin{array}{l}\text { Reliability impact on } \\
\text { business users }\end{array}$ & $x$ & $x$ & $\begin{array}{c}3.5 .7 \\
\text { Appendix } \mathrm{F}\end{array}$ \\
\hline & Regeneration & $x$ & $x$ & 3.5 .8 \\
\hline & Wider impacts & $\checkmark$ & $x$ & 3.5 .14 \\
\hline \multirow{8}{*}{ Environmental } & Noise & $\checkmark$ & $\checkmark$ & 3.3 .2 \\
\hline & Air quality & $\checkmark$ & $\checkmark$ & 3.3 .3 \\
\hline & Greenhouse gases & $\checkmark$ & $x$ & 3.3 .5 \\
\hline & Landscape & $x$ & $x$ & 3.3 .7 \\
\hline & Townscape & $x$ & $x$ & 3.3 .8 \\
\hline & $\begin{array}{l}\text { Heritage of historic } \\
\text { resources }\end{array}$ & $x$ & $x$ & 3.3 .9 \\
\hline & Biodiversity & $x$ & $x$ & 3.3 .10 \\
\hline & Water environment & $x$ & $x$ & 3.3 .11 \\
\hline \multirow{10}{*}{ Social } & $\begin{array}{l}\text { Commuting and other } \\
\text { users }\end{array}$ & $\checkmark$ & $\checkmark$ & $3.5 .1-3.5 .4$ \\
\hline & $\begin{array}{l}\text { Reliability impact on } \\
\text { commuting and other users }\end{array}$ & $x$ & $x$ & $\begin{array}{c}3.5 .7 \\
\text { Appendix F }\end{array}$ \\
\hline & Physical activity & $x$ & $x$ & 3.3 .12 \\
\hline & Journey quality & $x$ & $x$ & 3.3 .13 \\
\hline & Accidents & $\checkmark$ & $x$ & 3.4 .1 \\
\hline & Security & $x$ & $x$ & 3.4 .2 \\
\hline & Access to services & $x$ & $x$ & 3.6 .3 \\
\hline & Affordability & $x$ & $\checkmark$ & 3.6 .4 \\
\hline & Severance & $x$ & $x$ & 3.6 .2 \\
\hline & Option values & $x$ & $x$ & 3.6 .1 \\
\hline \multirow{2}{*}{$\begin{array}{l}\text { Public } \\
\text { Accounts }\end{array}$} & $\begin{array}{l}\text { Cost to broad transport } \\
\text { budget }\end{array}$ & $\checkmark$ & $x$ & 3.5 .1 \\
\hline & Indirect tax revenues & $\checkmark$ & $x$ & 3.5 .1 \\
\hline
\end{tabular}

WebTAG Unit 3.5.14 describes how wider impacts resulting from transport interventions are a result of:

- Changes in labour supply;

- Move to more/less productive jobs;

- Agglomeration (third party spin off benefits from businesses being brought closer together); and

${ }^{16}$ Greater London Authority, 2010, Mayor's Transport Strategy, May 2010 
- Changes in output in imperfectly competitive markets.

In each case, 'Regeneration' impacts are linked to the new crossing shifting employment opportunities, while 'Wider Impacts' are described as the agglomeration benefits of improved connectivity. In the appraisals 'Access to Services' are seemingly only interpreted as "public transport services", perhaps reinforcing the perceived project boundary as being a transport project. For each of the potential locations it is noted that there would be no impact on public transport services or access to them.

Appendix D1.26 to the Aecom report does explicitly recognise that the crossing could impact on land use in the area, in relation to regeneration, adding that "In transport appraisal, regeneration refers specifically to the redistribution of economic activity or employment that results in an increase in employment" of the residents in the defined area. A means for calculating this impact is set out in WebTAG Unit 3.5.8. However, given the complexity and uncertainty, it was not felt appropriate to conduct a Regeneration Report consistent with WebTAG Unit 3.5.8 (or Unit 2.8). Instead a qualitative approach is used.

It is recognised (in Table 5.2 of the Aecom report) that a risks to the Commercial Case for the new crossing could result from "Poor integration with supporting infrastructure" leading to increased congestion. Additionally, under the heading "Integrated Infrastructure", the case suggests:

"A maintenance plan could be established to minimise disruption and congestion whilst maximising economic performance of the new crossing and supporting infrastructure"

On a regional scale "additional capacity could only be expected to limit the economic growth within the Thames Gateway in the future" (para 3.3.16). The LTC project is seemingly conceived as a solution to the forecast lack of capacity at the existing Dartford Crossing, and the follow on problems this presents. The appraisal framework described above reinforces this view. However, there is also a strong argument for considering such large transport projects as proactive agents for change and not just passive solutions. The LTC Project does not appear to be perceived in this way, instead being a passive solution to a perceived barrier. It could benefit greatly, particularly in terms of identifying and leveraging beneficial interdependencies, from adopting a more open-systems view and being framed as a proactive agent for change.

\section{Location Options}

Several locations have been considered for the Lower Thames Crossing in the studies between 1994 and 2013. The 1994 Maunsell study looked at the feasibility of 25 different routes, while the Gifford, MVA, Capita study in 2009 looked into 9 different locations. The Parsons Brinkerhoff study identified 5 which were assessed and narrowed down to the 3 options taken forward to the public consultation in 2013.

For the purposes of this report, the focus will be on the three options reported in the 2013 Aecom report. These can be summarised as:

- Option A - Additional capacity at the existing Dartford Crossing

- Option B - New crossing at the Swanscombe Peninsula link A2 to the A1089

- Option C - New crossing East of Gravesend and link to the M20 
For completeness, the 2009 PB report also investigated:

- Option D - M2 link to Canvey Island (two variants)

- Option E - Isle of Grain link to East of Southend.

These are shown in Figure 4 below, reproduced from the PB report.

Table 2 - Lower Thames Crossing Location Options

\section{Gifford, MVA (2009) \\ Parsons Brinkerhoff \\ Aecom (2013)} (2009)

\begin{tabular}{|l|l|l|}
\hline $\begin{array}{l}\text { Wennington - Dartford } \\
\text { Connecting the A13 to the A206 }\end{array}$ & \\
\hline Existing Dartford - Thurrock & Option A & Option A \\
\hline $\begin{array}{l}\text { West Thurrock - } \\
\text { Swanscombe } \\
\text { Connecting A126 to A206 }\end{array}$ & \\
\hline $\begin{array}{l}\text { Grays - Swanscombe } \\
\text { Connecting A1089 to A206(west of } \\
\text { Gravesend) }\end{array}$ & $\begin{array}{l}\text { Option B } \\
\text { Connecting A1089 to A2 (west of } \\
\text { Gravesend) }\end{array}$ & $\begin{array}{l}\text { Option B } \\
\text { Connecting A1089 in vicinity of } \\
\text { Tilbury Docks to A2 near Dartford }\end{array}$ \\
\hline $\begin{array}{l}\text { Chadwell - Gravesend } \\
\text { Connecting A1089 to A2 (east of } \\
\text { Gravesend) }\end{array}$ & Slight variation on Option C & \\
\hline $\begin{array}{l}\text { Stanford-le-Hope - } \\
\text { Gravesend } \\
\text { Connecting the A13 to A2 (east of } \\
\text { Gravesend) }\end{array}$ & $\begin{array}{l}\text { Option C } \\
\text { Connecting the M25 to the M2 }\end{array}$ & Option C \\
\hline $\begin{array}{l}\text { Canvey - Grain } \\
\text { Connecting A130 to A228 }\end{array}$ & $\begin{array}{l}\text { Option D } \\
\text { Connecting A13/A130 to the A228 }\end{array}$ & \\
\hline $\begin{array}{l}\text { Canvey - Halstow } \\
\text { Private Metro tidal plan for multi- } \\
\text { modal tunnel, tidal power plant and } \\
\text { flood defences }\end{array}$ & $\begin{array}{l}\text { Similar to Option D location but } \\
\text { Optro tidal have also considered }\end{array}$ & \\
\hline $\begin{array}{l}\text { Shoeburyness - Sheerness } \\
\text { Private plan for bridge linking man } \\
\text { made islands }\end{array}$ & Option E & \\
\hline
\end{tabular}



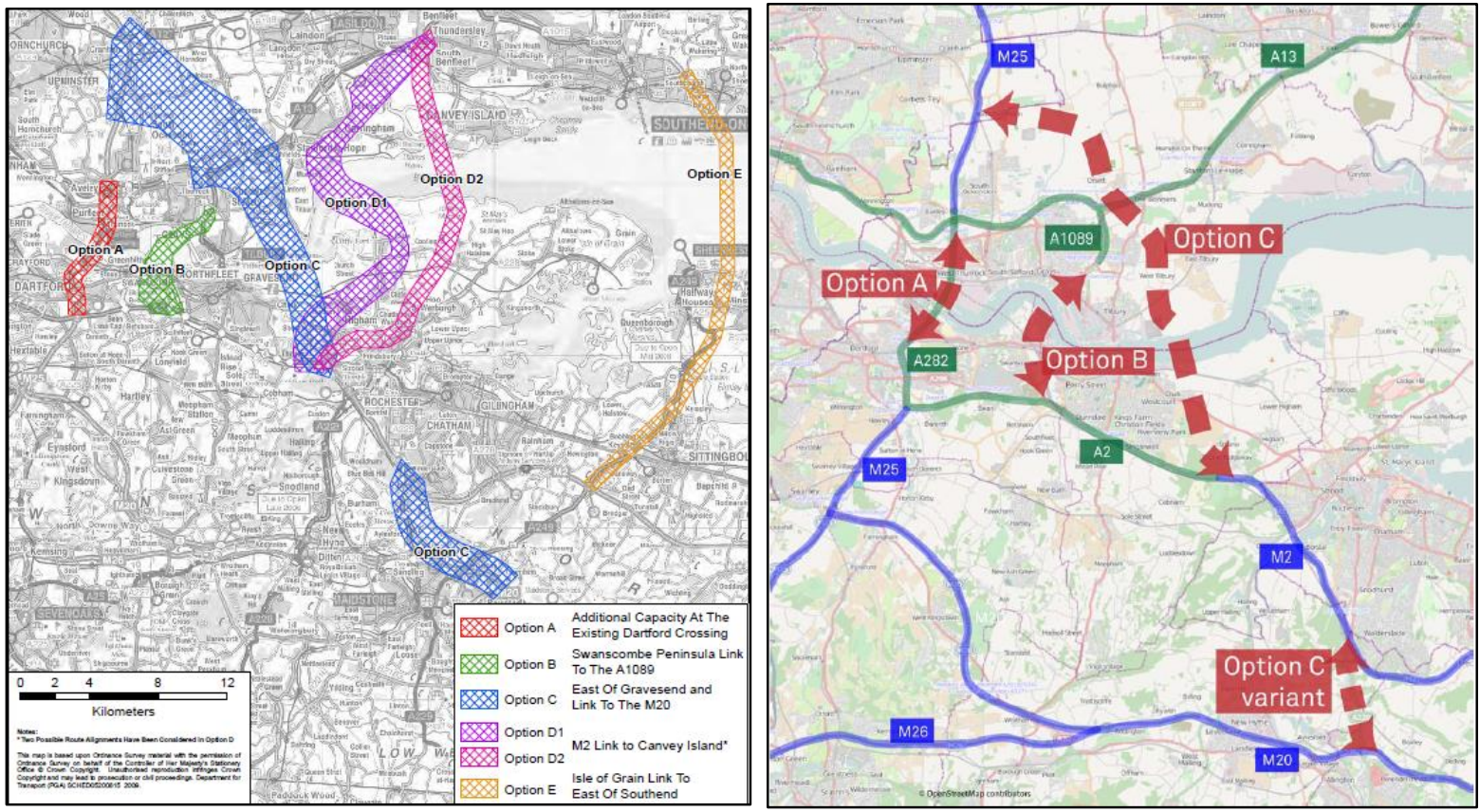

Figure 4 - Crossing Options considered (Left: Appendix 10A of 2009 PB Study, Right: Figure 1.1 of 2013 Aecom Study)

The 2010 KPMG report ${ }^{17}$ indicates that although they have not officially stated a preference, it is suspected Kent County Council favour a bridge at the site of Option C. Subsequent news reports have speculated that the route may not connect with the M25, but will instead bypass this and connect to the $M 11^{18}$.

The situation is complicated by the announcement of a new theme park in the area, with indications that this is leading to serious consideration of Option B, a crossing at Swanscombe Peninsula ${ }^{19}$.

\section{Current Project Position}

At the time of preparing this case study report the Lower Thames Crossing project is undertaking a public consultation on the location of the crossing. No detailed engineering has been conducted on the design of the crossing, its exact route or its interface with any existing or planned infrastructure. Construction of a new crossing is expected to begin in 2021.

\section{Conclusions}

\section{What is the problem the Lower Thames Crossing is trying to address?}

The evidence presented by the various traffic forecast models (as reported by Jacobs Babtie, Parsons Brinkerhoff and Aecom) clearly predict that the existing Dartford Crossing will regularly be operating at pressures beyond its capacity within the next two decades. This will

\footnotetext{
17 KPMG, 2010, The Lower Thames Crossing - Kent County Council - KPMG Regeneration and Funding Report (Page 7)

18 BBC NEWS, 2010, "New bridge over Thames 'should link with M11' in Essex", [Online: http://www.bbc.co.uk/news/uk-england-11617685], Accessed: 23/04/2013

${ }^{19}$ Kent Online, 2012, "Reaction to "2bn theme park for Kent", [Online: http://www.kentonline.co.uk/kentonline/news/2012/october/8/reaction to paramount park.aspx], Accessed: 23/04/2013
} 
impact on the predictability of journey time and overall resilience at an important point of the national strategic road network.

Short and medium term measures can be implemented to mitigate the forecast growth, but this is thought to have little impact in the long term. The increased congestion and reduced reliability will have a knock-on effect on local communities who use the crossing and surrounding roads, but it will also impact the national economy due to its importance to freight traffic.

With this as the accepted problem, the boundary of the project has been firmly drawn around a new river crossing and its supporting infrastructure (e.g. new junctions with existing roads). It is primarily perceived as a transport project, with a focus on road traffic. That is not to say that the assessment of the new options (in line with national policy such as DaSTS) have not taken into account the wider economic, social and environmental impacts or its integration with public transport. Indeed it has been recognised that the regions around the existing and proposed new crossing are the focus of many regeneration initiatives. These will not only have an effect on the demand on river crossings, but will also be significantly affected by the location of the crossing and overall crossing capacity. Ultimately, despite being an important part of the new crossing's assessment, the regeneration projects and the Lower Thames Crossing project are treated as being relatively loosely coupled. That is to say the need for a new crossing is driven by a forecast increase in traffic (albeit partially caused by regional regeneration) and not to directly facilitate the regeneration. While it is recognised that problems with the existing crossing can negatively impact the planned regeneration, many of the regeneration projects (again, as shown in the following chapter) are planned to proceed independently from and regardless of the development of a new river crossing.

The Lower Thames Crossing Project is therefore somewhat different from, for example, the Northern Line Extension Project where the transport infrastructure element is tightly coupled to local regeneration in terms of its explicit and perceived need.

Also of interest, though far more subjective, is how the solution to the problem is conceived. The problem has a number of soft and hard causes which influence the level of congestion on the existing crossing, along with its finite capacity. Measures have been considered to address the soft and hard causes of congestion, but ultimately it seems additional capacity is required. With this in mind, it is important not to limit the conception of the solution simply to a hard physical asset (i.e. a bridge or tunnel) which provides additional crossing capacity. It is arguably advantageous to keep a broader conception of what the solution to the capacity problem could be and what it could do, even if in reality it exists as a large physical asset. 


\section{Local and Regional Infrastructure and Regeneration Projects}

The coupling of the proposed LTC with regional economic and social regeneration has been explicit since at least the 1994 Maunsell Study, and is also implied in the 1990 Department for Transport report. The proposed Lower Thames Crossing's ties to regeneration in the nearby areas are arguably more subtle that those at play in the Northern Line Extension case study (reported elsewhere as part of this project), as the regeneration is not tightly dependent on the construction of a new crossing, and the new crossing is not proposed primarily to serve the effects of this regeneration. Nevertheless, they are intrinsically linked as failure to address congestion at the existing Dartford Crossing may hinder growth or weaken the local, regional and national economies. Addressing congestion on the existing Dartford crossing, and providing a new LTC could facilitate the desired regeneration or present options for additional, as yet unplanned or currently unobtainable regeneration.

This chapter summarises the issues and plans relating to regeneration of the areas around the existing Dartford crossing, and potential sites for a new LTC. There are many complex needs, issues and plans interacting within the region around the proposed LTC, and as with the previous chapter, the focus here is on those most pertinent to identifying necessary and potential interdependencies between the LTC and these need, issues and plans. Accordingly, there is a focus on the proposed social and economic infrastructure regeneration plans for the region, along with the barriers and constraints thought to be involved with them. In many ways this relates to the seven micro driver mechanism for how transport impact on the economy set out in the Eddington Report ${ }^{20}$ :

- Increasing business efficiency through time savings and improved reliability;

- Increasing business investment and innovation by supporting economies of scale and new ways of working;

- Supporting clusters and agglomerations of economic activity;

- Improving the efficient functioning of labour markets, increasing labour market flexibility and access to jobs;

- Increasing competition by opening up access to new markets;

- Increasing domestic and international trade by reducing the cost of trading;

- Attracting globally mobile activity to the UK by providing an attractive business environment and good quality of life.

In most of the studies that look directly at the LTC in relation to the wider impacts on the localities and regions around the sites, the focus is on the improved connectivity rather than direct opportunities and risks of infrastructure interdependencies. The following chapter extrapolates identified interdependencies from these.

${ }^{20}$ Eddington, R, 2006, The Eddington Transport Study - The case for action: Sir Rod Eddington's advice to Government 


\section{Regeneration Projects}

The table below summarises and describes significant physical regeneration projects planned, under construction and completed in the areas surrounding the proposed crossing sites which may present necessary, potentially beneficial, or hazardous interdependencies with the Lower Thames Crossing.

\begin{tabular}{|l|l|l|l|}
\hline \multicolumn{1}{|c|}{ Project } & \multicolumn{1}{c|}{ Location } & \multicolumn{1}{c|}{ Description } & \multicolumn{1}{c|}{ Status } \\
\hline $\begin{array}{l}\text { London } \\
\text { Gateway Port }\end{array}$ & Thurrock & $\begin{array}{l}\text { A large port and business park on a } \\
\text { 6km² site. }\end{array}$ & Under construction \\
\hline $\begin{array}{l}\text { Ebbsfleet } \\
\text { Valley }\end{array}$ & $\begin{array}{l}\text { Swanscombe } \\
\text { (Gravesham) }\end{array}$ & $\begin{array}{l}\text { Residential, retail and leisure } \\
\text { development on a 4.2km² between } \\
\text { Bluewater Shipping Centre and } \\
\text { Ebbsfleet International Railway } \\
\text { Station (HS1). BT set to trial high } \\
\text { speed fibre network at the site. } \\
\text { Potential site of stalled 'Angel of the } \\
\text { South' style landmark. }\end{array}$ & $\begin{array}{l}\text { Possibly not going ahead } \\
\text { because Highways } \\
\text { Agency could not provide } \\
\text { another junction to the } \\
\text { M25 }\end{array}$ \\
\hline The Bridge & Dartford & $\begin{array}{l}\text { Residential and business } \\
\text { development on 1km² site. }\end{array}$ & Open for use \\
\hline $\begin{array}{l}\text { Dartford } \\
\text { Northern }\end{array}$ & Dartford & $\begin{array}{l}\text { Residential and business } \\
\text { development on 0.026km² site. }\end{array}$ & Under development \\
\hline Stone Castle & $\begin{array}{l}\text { Swanscombe } \\
\text { (Gravesham) }\end{array}$ & $\begin{array}{l}\text { Residential, business and public } \\
\text { park. }\end{array}$ & Open for use \\
\hline $\begin{array}{l}\text { Northfleet } \\
\text { Embankment }\end{array}$ & $\begin{array}{l}\text { Northfleet } \\
\text { (Gravesham) }\end{array}$ & $\begin{array}{l}\text { O.74km² site along the river front, } \\
\text { formerly Northfleet Cement Works. }\end{array}$ & $\begin{array}{l}\text { Under } \\
\text { development/construction }\end{array}$ \\
\hline
\end{tabular}

\section{General Needs, Issues and Plans}

Several of the studies above considered the potential regeneration impacts of a new Lower Thames Crossing, but in addition to these are a number of reports looking specifically at regeneration in the localities around the proposed crossing. Collectively these include:

In 2007 Jacobs produced a 'Scoping report on Transport Schemes' along Kent Thameside for Kent County Councili ${ }^{21}$. This identified a list of potential and developing soft and hard transport schemes in the area. Those which have or are still planned to go ahead may interact with the LTC, provide or be provided with an interdependency opportunity with the LTC. These schemes include the promotion and integration of public transport, park and ride schemes at Fastrack Bus Rapid Transport stations, Fastrack stations/routes (Ebbsfleet, Eastern Quarry, Bluewater, Dartford town centre, Gravesend town centre, Ingress Park, Swanscombe Peninsula and Northfleet Embankment) and cycling/walking routes. Figure 5 below, taken from the Jacobs report, shows the planned transport schemes for the area (circa 2007). These Kent Thameside Delivery Board were identified as overseeing these schemes.

21 Jacob, 2007, Scoping Report on Transport Schemes - Final Version, February 2007 


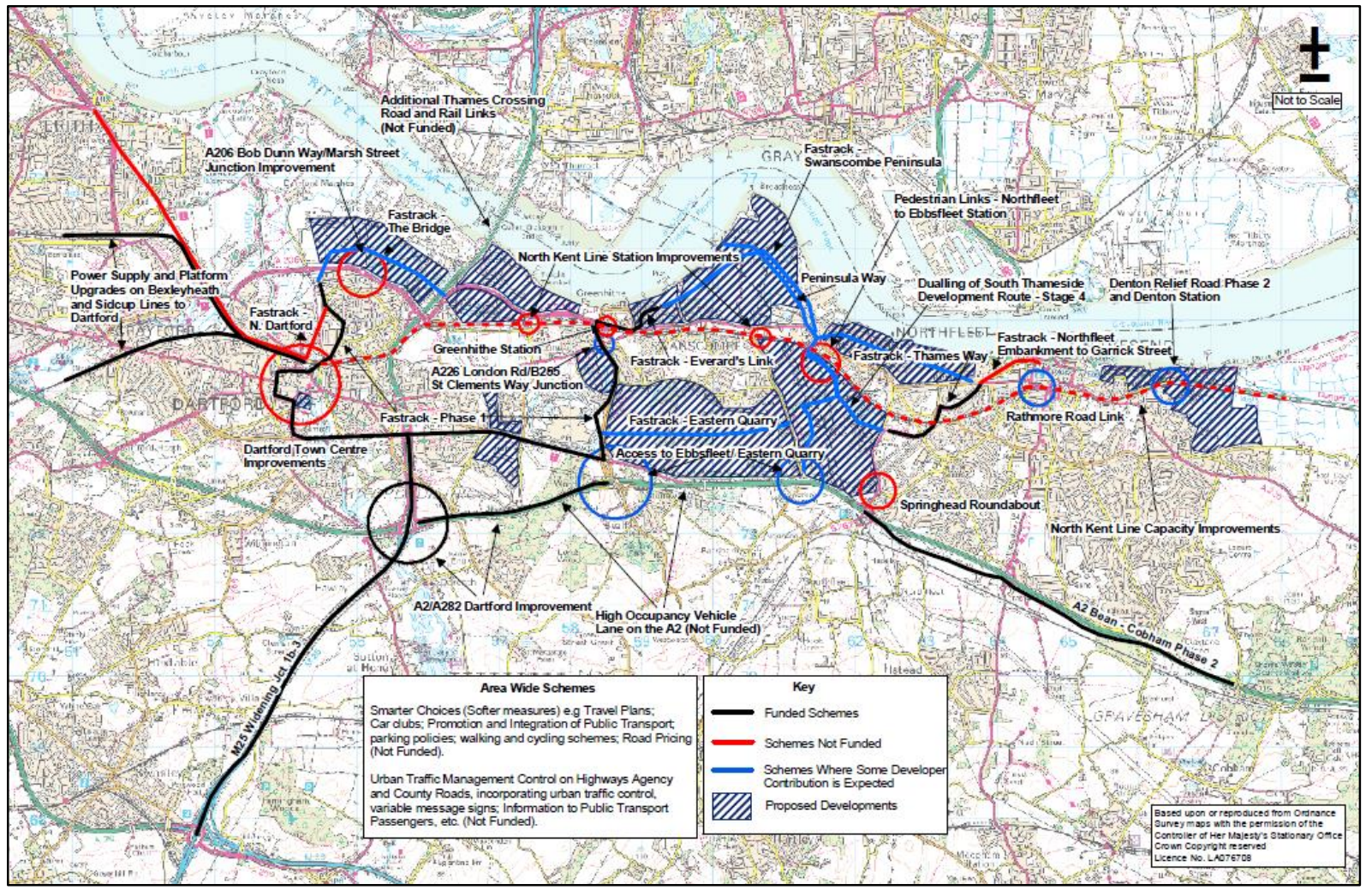

Figure 5 - Kent Thameside Transport Schemes (from Figure 1-1 in 2007 Jacobs report)

In the $\mathbf{2 0 0 7}$ Thames Gateway Delivery Plan it is stated that the Thames Gateway Growth Area from East London to North Kent and South Essex is expected to grow by 225,000 new jobs and 110,000 new homes by 2016. It is Europe's largest regeneration project. There are six strategic locations (Stratford, Lower Lea and Royal Docks, London Riverside, Greenwich Peninsula and Woolwich, Thurrock, Kent Thameside, and Medway) and five urban renewal areas (Barking, Basildon, Erith, Sittingbourne and Swale, and Southend).

The delivery plan outlines the significant projects completed or under development in the area, some of which may have or provide interdependencies with the LTC. These projects include:

- High Speed 1, stopping at Ebbsfleet (Completed);

- London Gateway deep-water park and business park;

- Eastern Quarry residential community by Ebbsfleet station;

- Barking Riverside residential area;

- New further and higher education campuses in Grays, Basildon, Swale and Medway;

- Development of J30 of the M25 (with the A13)

- Funding of 13 local transport schemes ( $£ 100$ million through the Community Infrastructure Fund);

- New flood defences at Ebbsfleet Valley (Completed);

- New flood defences and land raising at Rochester Riverside (Completed);

- Hospital refurbishment;

- Establish the region as an Eco-Region;

- Invest in a skilled workforce;

- Enable ten new priority housing areas. 
In addition to this are seven high-level regeneration outcomes desired for the Thames Gateway:

- Improvement in the performance of the Thames Gateway economy;

- Enhanced education and lifelong learning;

- Modern, responsive and efficient transport system;

- Increase in the number and quality of dwellings;

- Increase in the quality of life for communities;

- Thames Gateway Parklands programme;

- Environmental interventions.

The 2008 East of England Plan ${ }^{22}$, an update to the earlier Regional Spatial Strategy for the East of England, covers Essex and other eastern counties (but not Kent to the south). It was produced by the Government Office for the East of England, abolished in the 2010 Spending Review. With this abolishment the document was essentially revoked, but it may provide insight into the wider context for the development of the LTC. The plan set out 58 policies, ranging from sustainable development and job growth to green infrastructure and emissions reduction.

Policy $\mathrm{T} 1$ relays the regional transport strategy objective and outcomes. These include:

- Managing traffic behaviour;

- Encouraging efficient use of existing transport infrastructure;

- Improve access to jobs, services and leisure facilities;

- Improved journey times and reduced congestion;

- Increased proportion of journeys by public transport, walking or cycling;

- Increased proportion of freight movement by rail;

- Economic growth without concomitant growth in travel; and

- Improved air quality.

The Essex Thames Gateway is identified as a priority area (Policy T15) likely to come under significant transport pressures, but there is no mention specifically of the area around the existing Dartford Crossing.

As discussed in the previous chapter, Gifford, MVA Consultancy and Capita study ${ }^{9}$, published in $\mathbf{2 0 0 9}$ investigated many different options for a LTC so that Essex and Kent County Councils could better understand the potential impacts on either side of the estuary and regeneration. In conducting this appraisal of the potential sites, they identify a great deal of useful information about the wider regions. Unlike the other reports in this section it explicitly considers local and regional factor in the context of a new crossing.

\section{Special Protection Areas}

Firstly, the estuary and significant areas either side of it are of particular conservational importance. As shown in Figure 6 there are Special Protection Areas and an internationally designated RAMSAR site.

22 Government Office for the East of England, 2008, East of England Plan: The Revision to the Regional Spatial Strategy for the East of England, May 2008 


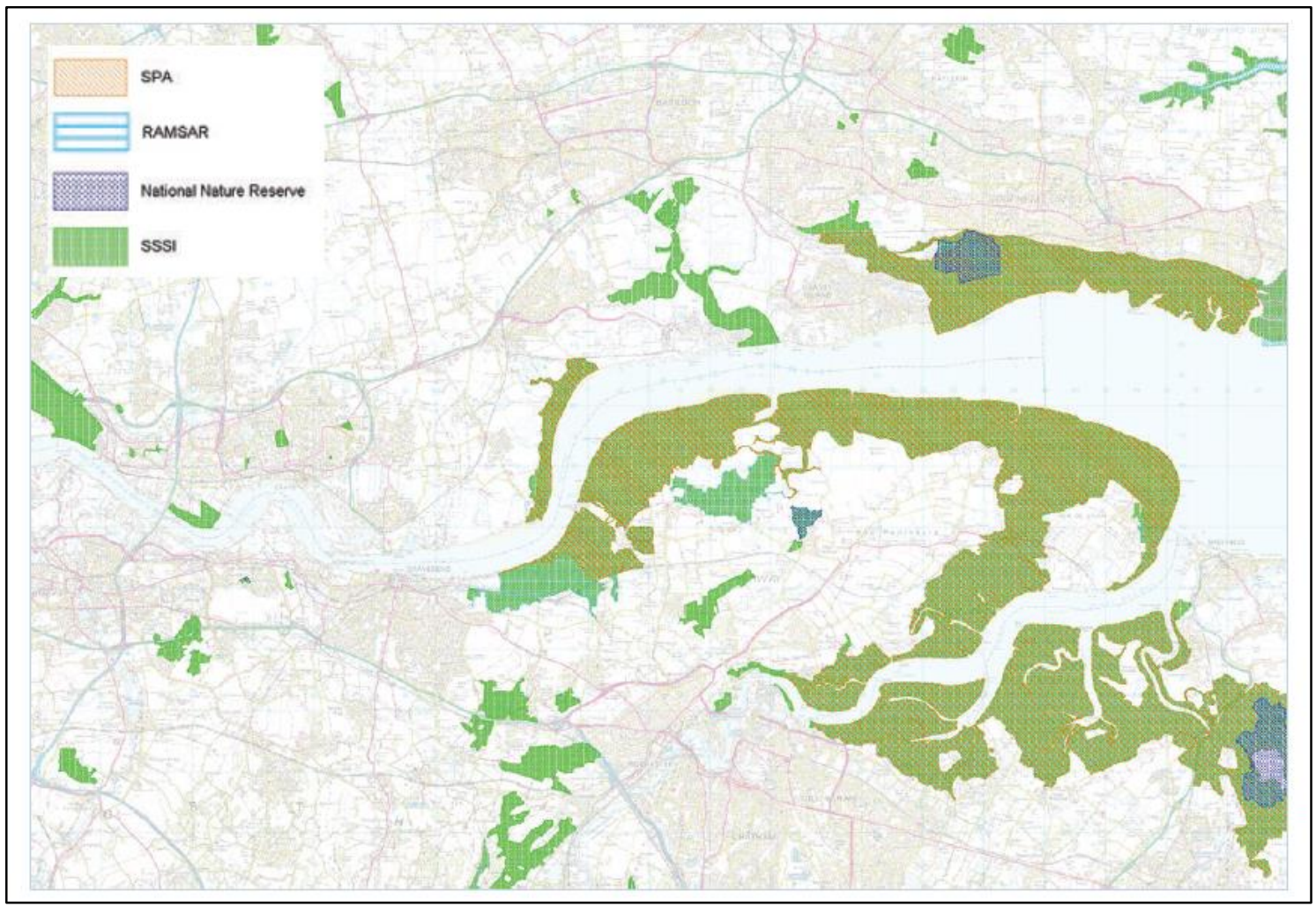

Figure 6 - Conservation Areas (Figure 2.12 from 2009 MVA Study)

If the crossing were to require any of the protected land it would be necessary to demonstrate that there was no alternative, that it was overriding public interest and that appropriate compensation was provided for lost habitats.

\section{Air Quality Management}

There are also Air Quality Management Areas in the region and while a new site for a crossing would likely improve air quality at the existing site, it would reduce air quality at the new site.

\section{Commuting Time and Regeneration}

The report states that Grays/Tilbury, South Ockendon, Southend-on-Sea, Basildon, Chatham, Gravesend, and Sheerness and Leysdown-on-Sea have particular pockets of social and economic deprivation.

Using accessibility modelling they predict crossings between Chadwell and Gravesend (similar to Option C in the PB study), Stanford-le-Hope and Gravesend (also similar to Option C in the PB study), and Canvey to Grain or Halstow (similar to Option D in the PB study) would allow $90 \%$ more jobs to be made accessible within a 20 minute commute time.

They conclude that overall the Chadwell to Gravesend option (similar to Option C in the PB study) would best enable development and regeneration, followed by the Grays to Swanscombe crossing (similar to Option B in the PB study).

While planned developments do not depend on a new crossing being built at all, the Canvey to Grain/Halstow and Shoeburyness to Sheerness crossings would open up additional development opportunities. 
The 2009 South East Plan ${ }^{23}$, also known as the Regional Spatial Strategy for the South East of England covers a wide area, including Kent (but not Essex). It was produced by the Government Office for the South East of England, abolished in the 2010 spending review. Again, with the abolishment of the Government Offices, this plan was essentially revoked. It outlines 179 policies for the region, many of which relate closely to those set out in the 2008 East of England Plan, and may again still provide context for the LTC development. As quoted in the Parsons Brinckerhoff study, the South East Plan says this specifically about the Lower Thames Crossing:

"Efficient north-south movement by public transport and by road will be of increasing importance even with the existing level of planned growth. Regional and international traffic will be affected by the congestion on the transport networks serving development in the Growth Area. Therefore, there are regional and national reasons to improve transport capacity.

While the Lower Thames crossing would form an inter-regional route it would have important implications for the local economy of the sub-region and would support the planned growth in north Kent."

Thus it is believed that the LTC is economically of sub-regional, regional, national and international importance. It is useful to note though that the Plan does not state explicitly that its reliability and growth "depends" on north-south travel as it does for east-west routes earlier in the paragraph. In terms of infrastructure (Policy CC7) the report states that "The scale and pace of development will depend on sufficient capacity being available in existing infrastructure to meet the needs of new development". To tackle this it initiates the development of an infrastructure implementation plan, where infrastructure includes: transport, housing, education, health, social infrastructure (e.g. community facilities), green infrastructure (e.g. parks, rivers and woodlands), public services, utility service and flood defences.

The transport chapter (p65) of the report forms the Regional Transport Strategy for South East England to 2026. It acknowledges evidence for an increase in travel by car and a need to rebalance this in favour of more sustainable modes, stating:

"Our vision is a high quality transport system to act as a catalyst for continued economic growth and provide for an improved quality of life for all in a sustainable and socially inclusive manner; a regional transport system that progressively reaches the standard of the best in North West Europe."

Policy T11 states that rail should be developed to carry a larger share of the freight transport, T12 concerns the safeguarding and encouragement of adjacent intermodal facilities, while Policy T13 expands this, stating that DfT rail, Network Rail, the Highways Agency, the Fright Transport Association and local authorities should work together on achieving rail and road corridors that can accommodate the anticipated levels of freight.

"The efficient movement of freight through the region is a key issue arising from its gateway function. Freight movement within the region is also a key consideration in facilitating continued economic success."

The A2, M2 and A282 (existing Dartford Crossing) corridor is also highlighted as one of three priority transport links requiring particular focus. Chapter 19 looks specifically at the Kent

${ }^{23}$ Government Office for the South East; 2009, The South East Plan: Regional Spatial Strategy for the South East of England, May 2009 
Thames Gateway Sub-regional Strategy Area, and summarises some of the important aspects of this region, as shown in Figure 7.

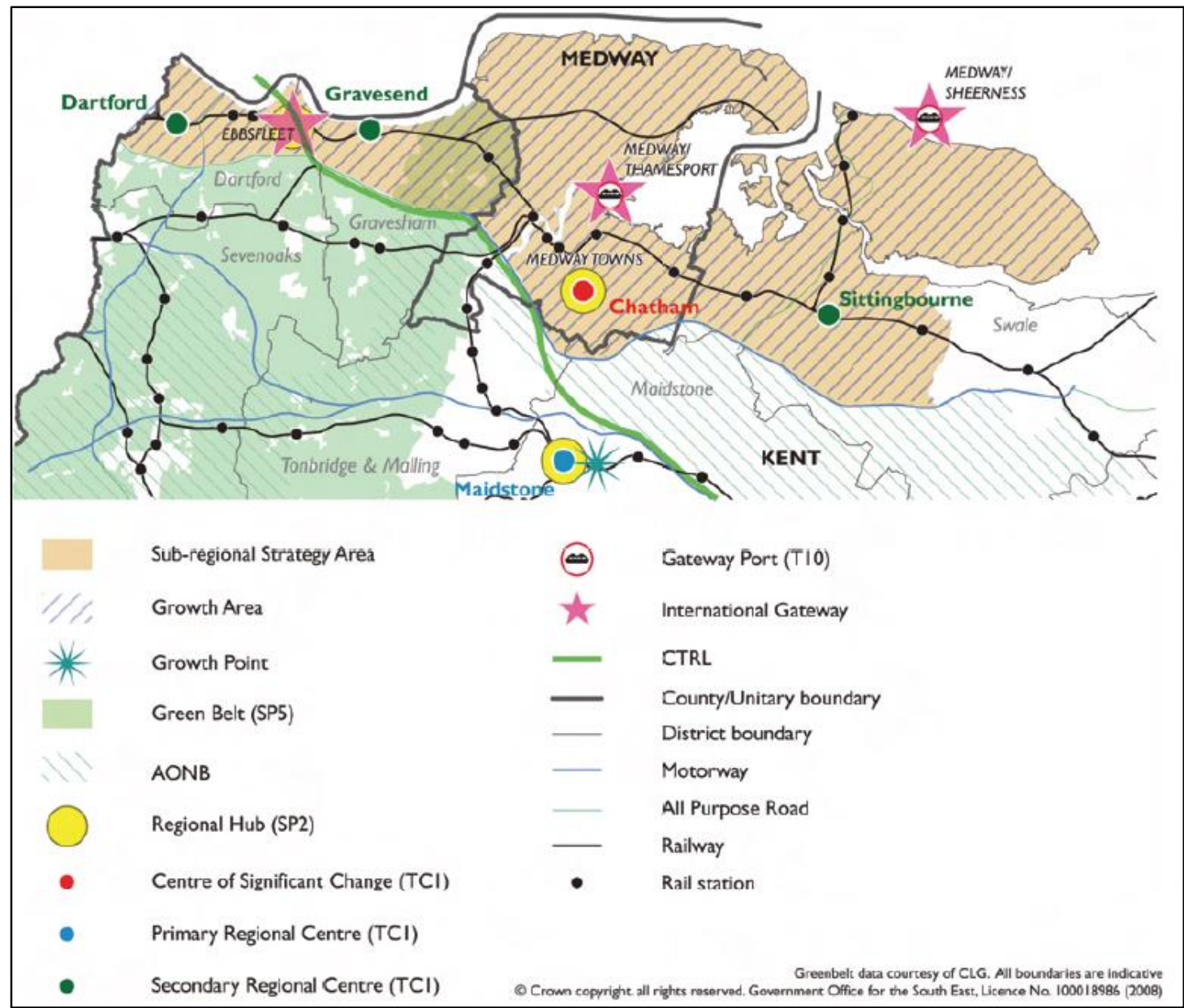

Figure 7 - Kent Thames Gateway Sub-regional Strategy Area (Diagram KTG1 in 2009 South East Plan)

Also published in 2009, the Parsons Brinkerhoff Study discussed in the previous chapter, contains some information about the regional development projects relevant to the LTC, in particular public transport and, or particular interest to the regeneration policies, employment impacts.

\section{Local Public Transport}

The PB study identifies two local bus rapid transit (BRT) projects of relevance to the LTC. The South Essex Rapid Transit (SERT) scheme would run to the north of the river, while the Fastrack scheme runs to the south. As described below, both of these could interact with the proposed crossings.

\section{Employment Impact}

The following diagrams show the results of a modelling exercise undertaken as part of the 2009 Parsons's Brinkerhoff study. The modelling, using the South Essex Transport and Land Use Model (SETLUM), looks at the effect of new crossing capacity on jobs in the neighbouring areas, for each of the main options. Green indicates a predicted increase in jobs by 2030, while red indicates a decline. The darker the colour, the more significant the change. 
Option A is shown in Figure 8, and is considered to be a relatively poor option by the stakeholders. Both the SERT and Fastrack schemes would be compatible with this crossing option.

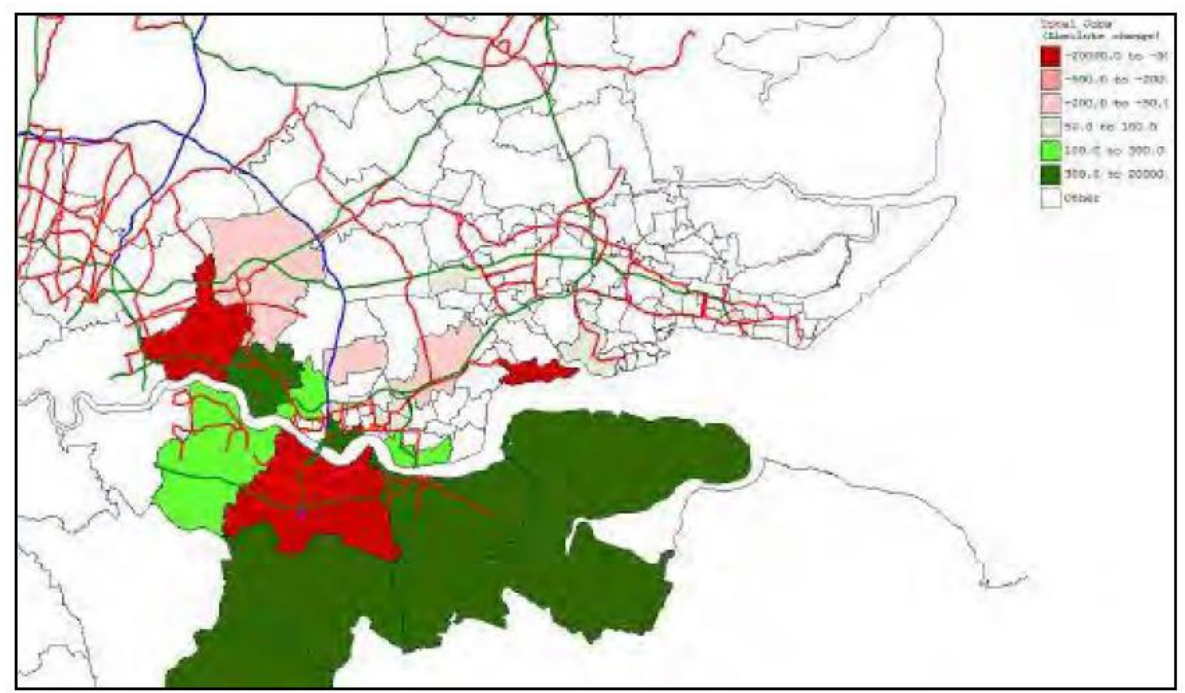

Figure 8 - Option A 2030 Employment Impacts (Figure 10-14 in 2009 PB Study)

Option B (Figure 9) is thought to generate similar wider benefits to Option A. It would enhance the development of the Ebbsfleet area, but may increase transport problems in the Thames Gateway South Essex and North Kent areas (although they would become more accessible). It would likely integrate with the SERT transport scheme. When asked though, the stakeholders felt it would be unlikely to be accepted by the local authorities and unlikely to fulfil the need for additional capacity for long distance through traffic. No stakeholders preferred this route.

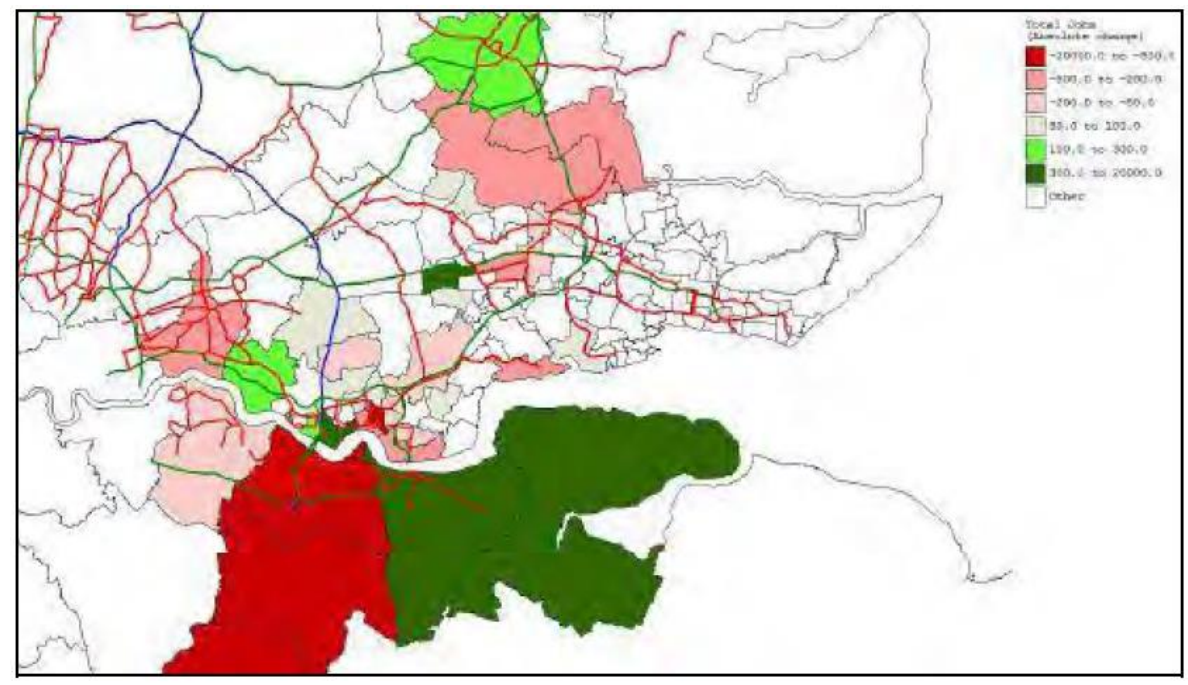

Figure 9 - Option B 2030 Employment Impacts (Figure 10-19 in 2009 PB Study)

Option $\mathrm{C}$ would provide some relief to existing crossing and offer benefits to national strategic and regional traffic similar to Options $A$ and $B$. It would relieve local roads in the Essex/North Kent area, alleviating constraints on the Thames Gateway development. Significant employment benefits are predicted for north Kent and Thurrock, but this may impact areas 
west of the M25 such as Havering. It would integrate with the SERT scheme, and Fastrack could be extended to meet Option C. Many stakeholders considered this to be the most feasible option, fulfilling regional and national objectives, although there may still be resistance from local authorities.

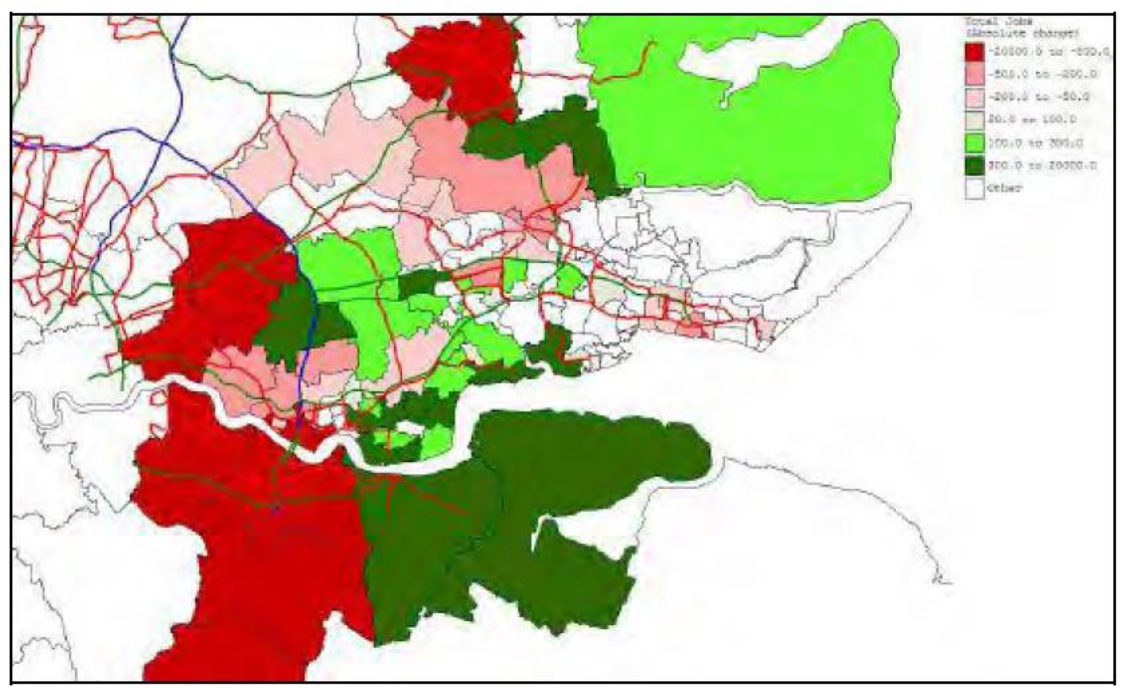

Figure 10 - Option C 2030 Employment Impacts (Figure 10-22 in 2009 PB study)

The 2010 KPMG report discussed in the previous chapter asses the wider economic and regeneration impacts of a new LTC (along with the potential funding mechanisms). It considered three location options: near the existing crossing (i.e. Option A), and two variations of Option C (Stanford-le-Hope to East Gravesham and Chadwell to East Gravesham). Like many of the other reports on this subject it concludes that a new LTC would influence the creation of additional jobs, increased productivity and economic output.

Also in $\mathbf{2 0 1 0}$ the Swanscombe \& Northfleet Riverside Study ${ }^{24}$ was produced for Kent Thameside Regeneration Partnership. This is a very useful document as it identifies potential land use options and shows the key infrastructure required to open up the area for development. This area is of most significance to a crossing at location Option B which may land on or near this area.

Figure 11, taken from this report, shows the proposed land use options in this area. Across 21 study zones it indicates scope for residential premises (low, medium and high density), park, woodlands, commercial businesses, wildlife/ecology areas and leisure facilities.

24 David Lock Associate, 2010, Swanscombe \& Northfleet Riverside Study - Revised Final Output, March 2010 


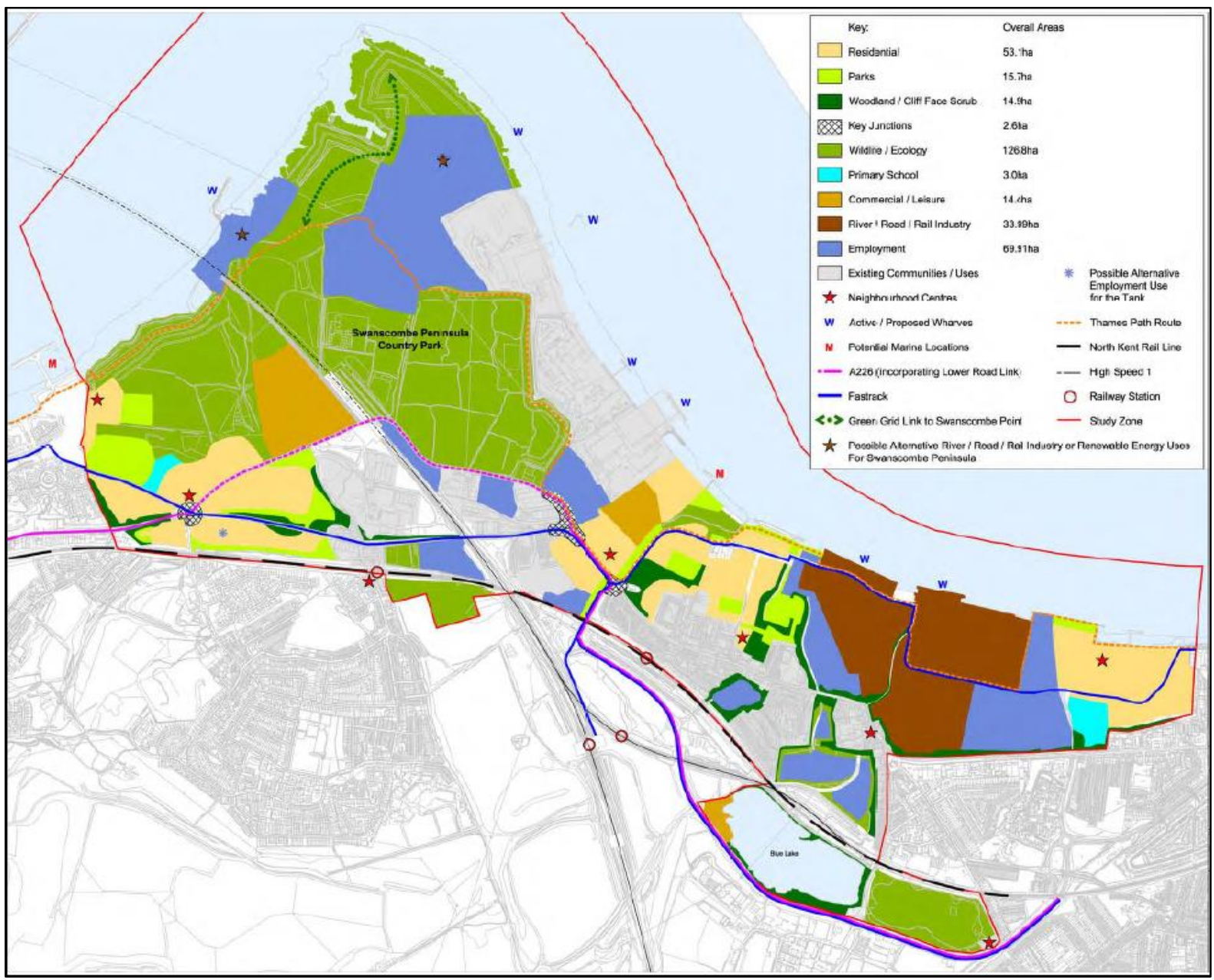

Figure 11 - Key Swanscombe and Northfleet Land Use Diagram (from David Lock Associates, 2010)

The Thames Gateway Kent Growth Plan was prepared by the Thames Gateway Kent Partnership in 2012. It sets out the Partnership's economic priorities for the area along with the key investment opportunities to achieve their objectives. The Partnership list their economic objectives as:

- Raise Gross Value Added (GVA) productivity per head in North Kent to that of the average for the greater south east of England;

- Support the creation of at least 58,000 jobs between 2006 and 2026, particularly in high-value sectors;

- Attract and grow the number of knowledge-based companies in North Kent's economy;

- Improve the skills of North Kent's workforce and tackle unemployment;

- Increase the rate of new business start-ups;

- Maximise the economic benefits of universities by strengthening the links with industry and retaining more graduates in the area;

- Attract and retain investment in priority employment locations, ensuring development of new employment sites and provision of high-quality marketable business premises;

- Continue to lobby government for the necessary investment in transport and infrastructure to assist sustainable economic growth across North Kent; 
- Support the delivery of up to 52,000 new homes between 2006 and 2026;

- Ensure that all new development is of the highest possible quality.

They identify ports and logistics, advanced manufacturing and sustainable construction as existing strong sectors and environmental technologies, business and financial services, creative industries and tourism and leisure as sectors with growth opportunities.

Access to high-quality employment and housing sites, and "The necessary infrastructure and transport routes to unlock key employment sites and markets" are recognised as requirements for attracting and retaining investment.

Paragraphs 5.15 to 5.20 deal with enhancing connectivity, noting:

"Efficient connectivity that enables the free flow of goods, information, services and people is essential for sustainable economic growth. The infrastructure necessary to unlock key employment sites is a prerequisite for bringing forward development and this includes both physical infrastructure - road and rail - as well as digital infrastructure for high-speed broadband, to enable businesses to be highly competitive."

To improve this connectivity the Partnership states a need to strengthen transport links locally, regionally, nationally and internationally; relieve congestion on local routes and; invest in local physical and digital infrastructure.

Following the closure of several regional development agencies, the South East Local Enterprise Partnership (SELEP) was established. It covers East Sussex, Essex, Kent, Medway, Southend and Thurrock. The SELEP aims to bring together leaders in business and local government as well as further and higher education, in order to promote growth. In 2012 the SELEP Business Plan covering the period up to 2015 set out the objectives for the group:

- Secure growth for the Thames Gateway;

- Promote investment in coastal communities;

- Strengthen the rural economy; and

- Strengthen the competitive advantage of strategic growth locations.

They set out to do this through strategic transport infrastructure, universal super-fast broadband, skills, and new financial instruments. Within the SELEP is a Strategic Transport Infrastructure Group tasked with identifying the transport and infrastructure developments of greatest importance to growth in the region. This led to the publication of a report by SKM $\mathrm{CB}^{25}$ detailing a framework for prioritising strategic transport infrastructure projects. A number of short and long term transport infrastructure schemes were assessed via this framework. Some of the short term road schemes may have some minor relevance in terms of LTC interdependency (Table 3). None of the long term schemes appear to be in the region of the proposed crossing, though they may have some impact on traffic flows.

Table 3 - SELEP Strategic Transport Infrastructure Schemes

\begin{tabular}{|l|l|l|}
\hline Short Term Road Scheme & Location & Rank \\
\hline A13 Widening Link 1 M25 to Lakeside & Thurrock & 4th \\
\hline A13 Widening Link 2 M25 to A126 & Thurrock & $5^{\text {th }}$ \\
\hline
\end{tabular}

25 SKM Colin Buchanan, 2012, Framework for Prioritising Strategic Transport Infrastructure in the SELEP area, May 2012 


\begin{tabular}{|l|l|l|}
\hline A13 Widening Link 5 & Thurrock & $10^{\text {th }}$ \\
\hline A 13 Link 1-8 Management & Thurrock & $11^{\text {th }}$ \\
\hline Kent Thameside Strategic Transport Programme (Homes and Roads) & Kent & $21 \mathrm{st}$ \\
\hline
\end{tabular}

At around the same time, URS produced a report for Kent County Council, Essex County Council and Thurrock Council entitled Third Thames Crossing Regeneration Impact Assessment ${ }^{26}$. This looked at Options A, B and C to assess how they could bring about job creation and new housing in the area. This assessment involved stakeholder consultation with the councils' planning, transport and regeneration departments. Their key findings include that "demand for jobs and homes is lower than the potential capacity available", all three options would bring significant growth of jobs and homes, these result from improved economic conditions which in turn arise from improved accessibility. They identify a number of important assets and development opportunities in the region. These may be relevant to this study of interdependencies with the LTC. These include:

- $\quad$ The existing Port of Tilbury;

- The DP World London Gateway Port currently under construction;

- Southend Airport;

- A concentration of logistics operations;

- A concentration of science based industries;

- Established transport links to London and mainland Europe; and

- Over 400 hectares of brownfield land.

Figure 12, adapted from the URS report, shows the development clusters in the Dartford area.

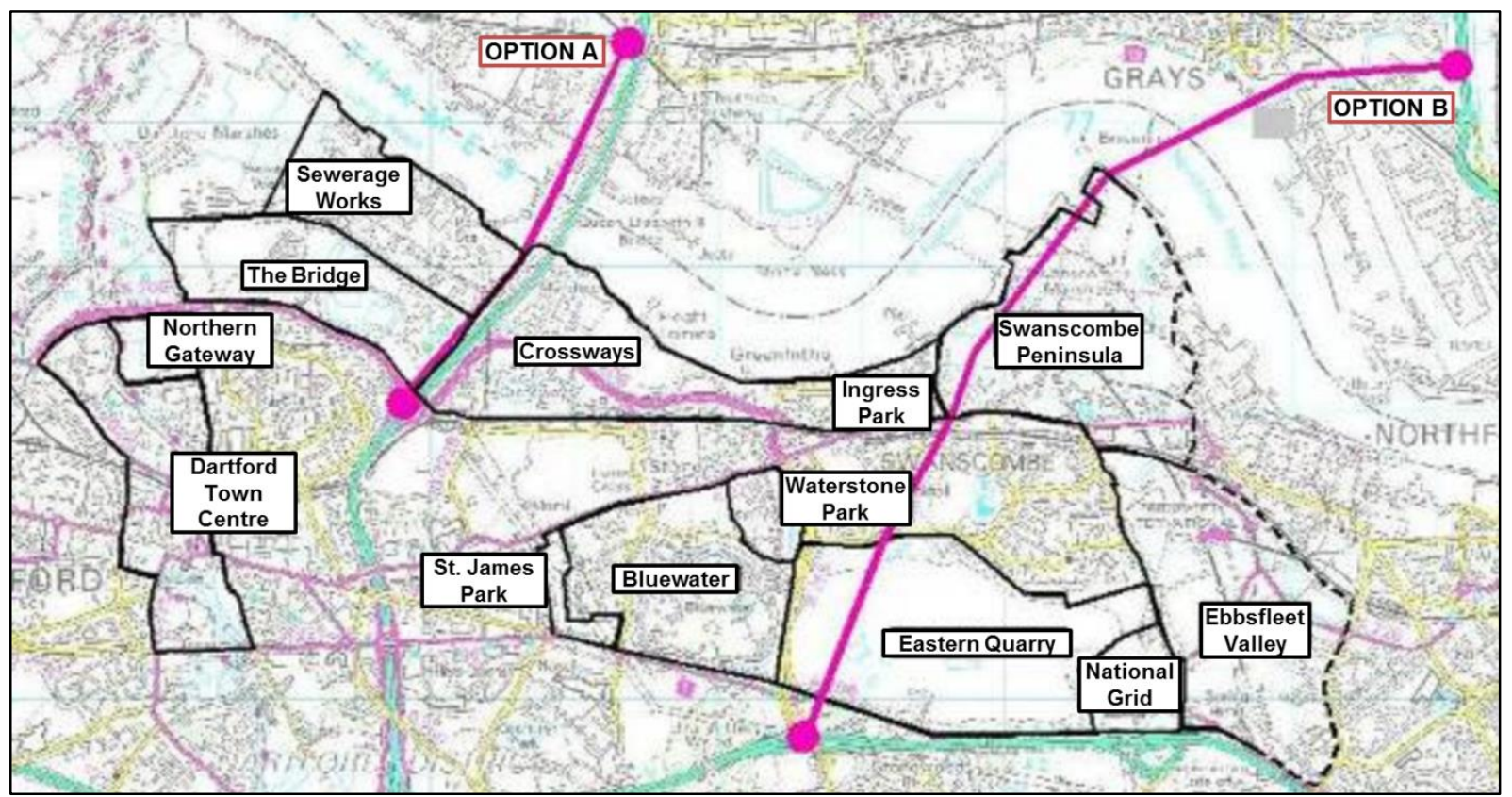

Figure 12 - Development Clusters in Dartford Area (from Figure 5.1 in URS, 2012)

26 URS, 2012, Third Thames Crossing Regeneration Impact Assessment - Final Report, May 2012 
Figure 13 shows the development clusters in the region to the east of Dartford area above, in Gravesham.

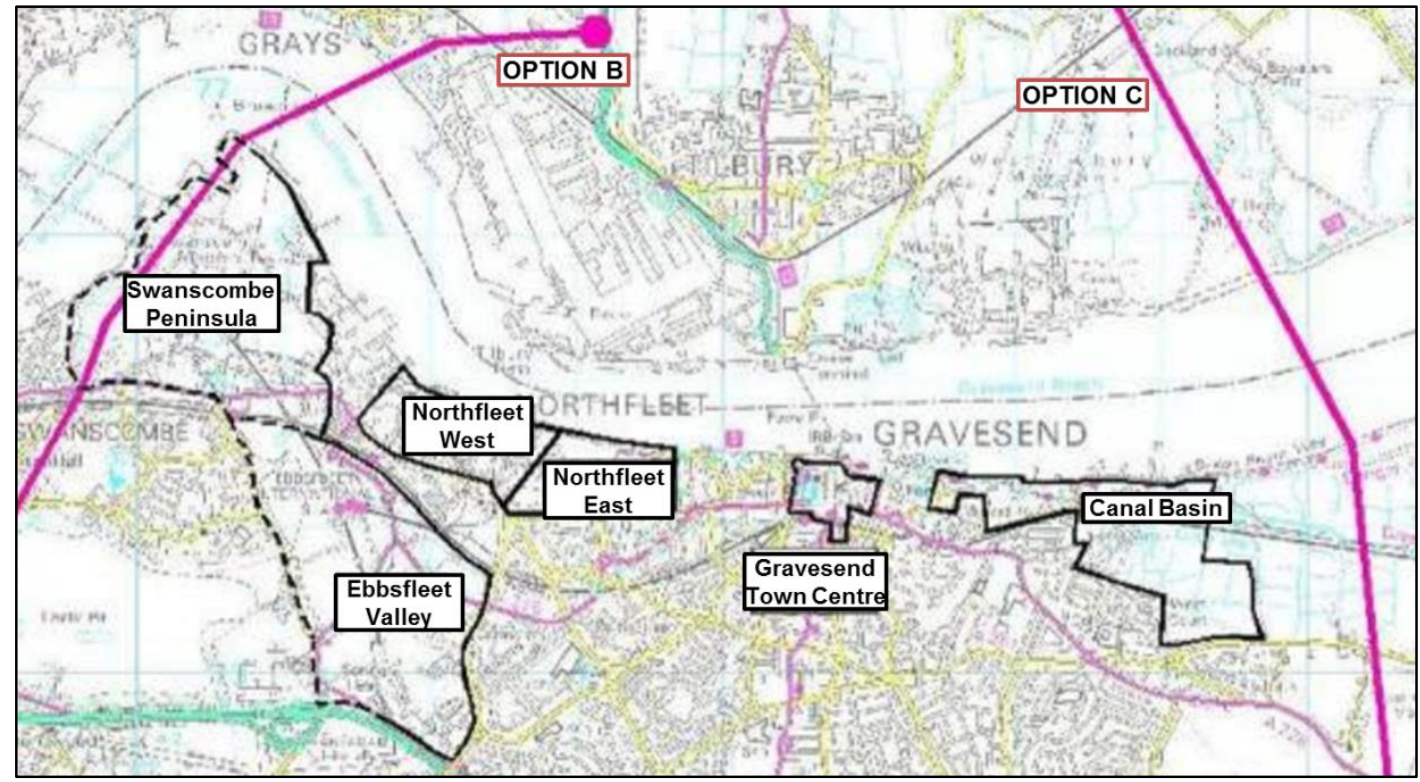

Figure 13 - Development Clusters in Gravesham Area (from Fig 5.2 in URS, 2012)

Finally, Figure 14 shows the development clusters to the north, in the Thurrock area. Each of these development clusters, and projects within them, have the potential for interdependencies with the LTC.

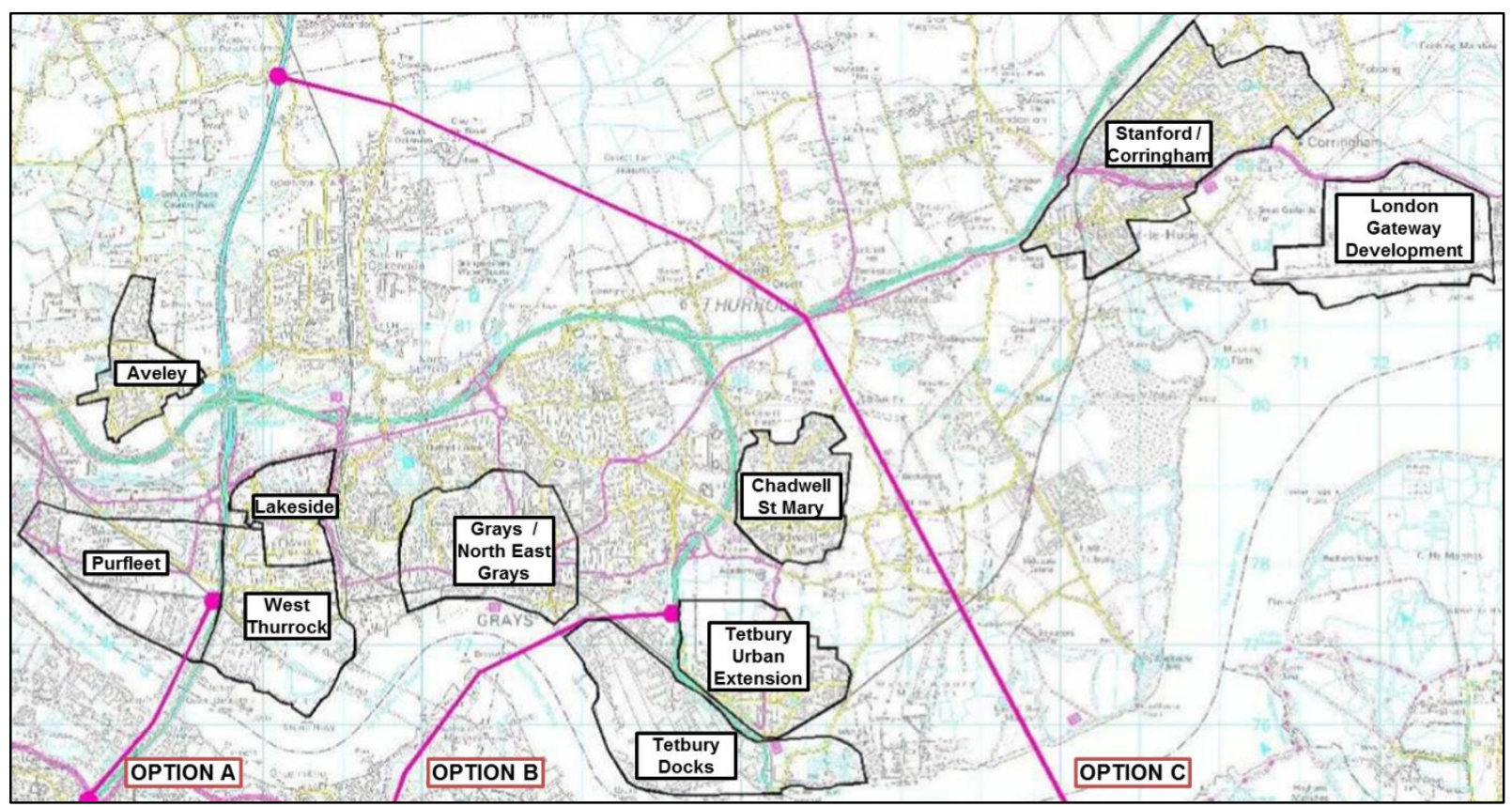

Figure 14 - Development Clusters in Thurrock Area (from Fig 5.4 in URS, 2012)

In some cases, it is noted that Option B may reduce development capacity in some of these clusters. The report assumes (para 5.5.3) that Option B, if it were a bridge, would result in a $20 \%$ reduction at Eastern Quarry, and slightly confusingly a 30\% reduction at Swanscombe Peninsula (Dartford Thames Waterfront) and a 10\% reduction to Swanscombe Peninsula 
(Gravesham). A tunnel would have less impact on the development capacity. As with the majority of the other reports, the focus is on the impact of better connecting these area, opening up access to labour market and therefore making the area a more attractive investment opportunity. There is scope to identify and better understand any specific interdependencies between the purpose, needs, inputs and outputs of the many regeneration schemes and the LTC.

The 2013 Aecom Study into the Lower Thames Crossing, like the early Parsons Brinkerhoff report, does consider some aspects of the LTC's impact on local regeneration and vice versa. In particular it looks at the local journeys and the effects of congestion and journey time reliability, all of which are thought to impact on the local and regional economies.

\section{Local versus Long Distance Journeys}

The LTC model reported in the Aecom study indicates that any of the new crossings would increase traffic across the Thames by between 1,000 and 2,000 vehicles per hour. They would not affect the distribution of local versus national trip usage on the existing crossing, Option B would attract mainly local traffic, while option $\mathrm{C}$ would attract more long distance traffic.

\section{Congestion Delays and Journey Time Reliability}

Table 4.1 in the Aecom report summarises the impact of each of the options on delays in the areas around the existing and potential new crossing in terms of seconds per vehicle $\mathrm{km}$ for the 2041 base case. This is reproduced in Table 4 below.

In terms of reliability, it is reported that the new crossing options would reduce stress on the existing Dartford crossing relative to 2041 projections. Option A would reduce stress on the existing crossing the most, as well as providing additional flexibility in terms of network management.

Table 4- Average Congestion Delays by Selected Districts (seconds per vehicle km) with New Crossings, 2041 (Table 4.1 in 2013 Aecom study)

\begin{tabular}{|l|c|c|c|c|c|}
\hline Delay (s/km) & $\begin{array}{c}\text { No new } \\
\text { crossing }\end{array}$ & Option A & Option B & Option C & Option Cvarrant \\
\hline Dartford & 40.7 & -6.5 & -7.0 & -7.6 & -8.2 \\
Gravesham & 14.7 & 0.0 & -0.2 & -0.2 & -0.0 \\
Sevenoaks & 13.2 & 0.4 & 0.3 & 0.5 & 0.6 \\
Medway & 34.9 & -0.0 & -0.2 & -0.3 & 2.6 \\
Tonbridge and & & & & & \\
Malling & 20.7 & -0.1 & 0.2 & 0.3 & -2.8 \\
Swale & 6.1 & 0.1 & 0.4 & 0.7 & -0.2 \\
Thurrock & 28.6 & 0.4 & 0.2 & -0.8 & -0.8 \\
Brentwood & 20.0 & 0.9 & 0.1 & -0.0 & -0.0 \\
Basildon & 60.8 & 0.1 & 0.3 & 0.5 & 0.5 \\
Rochford & 44.8 & 0.2 & 0.2 & -0.1 & -0.1 \\
Castle Point & 75.2 & 0.0 & -0.2 & -0.3 & -0.3 \\
\hline
\end{tabular}

As part of the 2013 consultation the SE LEP backed the proposal for a new crossing, with the chairman, John Spence stating: 
"The Lower Thames Crossing has been identified as the single greatest barrier to connectivity to businesses in our region"27

Their response ${ }^{28}$, important as they themselves questioned and represent business and local authority stakeholders, rejects Options A and B on the grounds that they are "sub-optimal in stimulating economic growth". They express regret that options further east have been ruled out, and demonstrate a preference for Option C. This view is said to be held by the majority, unanimous amongst businesses outside of Thurrock, and "primarily because it is [sic] will deliver greatest benefit to the economy". It is certainly of note that this assessment does not mention the ability to reduce congestion at the existing Dartford Crossing, seemingly perceived at the projects conception to be the driving purpose for the new crossing.

\section{Conclusions}

It is clear that a new Lower Thames Crossing is expected to have a generally positive impact on the economies of the surrounding localities and regions by creating new transport links, reducing journey times, reducing delays and congestion and improving reliability. This in turn is thought to increase employment catchment areas, broaden job opportunities and sales markets, and improve competition. It is commonly acknowledged that the regeneration of these areas does not depend on the construction of a new crossing, but this would generally help facilitate planned improvements and new improvement opportunities. However, it is also clear that very few opportunities and risks arising from potential interdependencies between these regeneration plans and the proposed LTC have been considered explicitly. Obviously without knowledge of the exact site or route for the crossing it is difficult to identify these in any detail, but it would be useful to consider in advance the types of interdependencies that could be involved, and whether these are of value or not.

The original driving force behind the LTC project was congestion at the existing Dartford Crossing, and the forecast need to provide additional crossing capacity, even though, as above, the underlying driver is arguably the desire for national economic security. The documents relating specifically to regeneration however, and the response to the 2013 consultation from the South East Local Enterprise Partnership, make the LTC decision more explicitly about the impact of the crossing on local and regional economies.

The following chapter looks at the documents cited in the previous two chapters in order to begin to catalogue the identified and implied interdependencies and interdependency opportunities between the regeneration schemes and the Lower Thames Crossing.

27 SE LEP Press Release, 2013, SE LEP make strong submission on Lower Thames Crossing, [Online: http://www.southeastlep.com/news/press-releases/279-se-lep-makes-strong-submission-onlower-thames-crossing], $15^{\text {th }}$ July 2013, Accessed $19^{\text {th }}$ July 2013

28 SE LEP, 2013, SE LEP response to the Lower Thames Crossing consultation, [Online: http://www.southeastlep.com/publications/consultation-responses/278-se-lep-response-to-the-lowerthames-crossing-consultation], $15^{\text {th }}$ July 2013, Accessed $19^{\text {th }}$ July 2013 


\section{Previously Identified Interdependencies}

The overall purpose of this report is to identify and evaluate the existing and potential interdependencies linked to the proposed Lower Thames Crossing developments. It aims to achieve this through the application of the Interdependency Planning and Management Framework. This chapter looks at interdependencies that have already been identified by the previous studies into the LTC.

Both the Parsons Brinkerhoff report and the more recent Aecom report give some explicit consideration to the interdependencies. The 2009 Parsons Brinkerhoff report broadly identifies four potential interdependencies of a new crossing, in the form of wider impacts it may have (Ch10 p94-A21):

- A LTC could reduce reliance on current distribution centres

- Shellhaven could provide an alternative distribution focus

- A LTC could be designed to also reduce or relieve flooding

- TE2100 looked at options including building a barrier/barrage across the Thames in Gravesham/Thurrock

- A LTC could create power generating opportunities

- There is no highlighted need, but there have been proposals for a tidal lagoon as part of the new crossing.

- A LTC could create an iconic structure for the region

- This could provide additional impacts on the regeneration of the area.

In relation to the interdependency between the LTC project and flood defences, the creation of a tidal lagoon was also been suggested during the 2009 consultation on the scheme (para 9.63), and the LTC could help improve air quality around the existing crossing, revealed to be a concern to local residents.

Interdependency between road and rail were eliminated by the Parsons Brinkerhoff led analysis which also notes (para 10.67) that the integration of walking and cycling networks have not been considered:

"This is because in comparison to the scale of the additional crossing capacity provided in the options, the benefits generated from the integration to walking and cycling networks are insignificant."

The reports touch on issues which reveal more intangible interdependencies with softer elements of the surrounding regions. For example, the LTC could provide larger employment catchment areas when at the moment there is little desire to commute to the areas on the opposite side of the Thames. By relieving congestion and providing better local transport facilities the LTC could reduce negative impacts on local businesses, prevent them from relocating and encourage the population to stay within the region for work.

Despite being relatively loosely coupled the potential for interdependency between the LTC Project and the regeneration project are quite complex. The previous reports on the LTC touch on these issues without explicitly investigating interdependency risks or opportunities. 
Section 3.8.5 to 3.8.8 of the report published by Aecom looks at the interdependencies with other potential major development, where they identify:

- Improvement works to tackle congestion at Junction 30 of the M25 starting in 2015

- The potential construction of a new Thames Barrier at Long Reach (1 km west of the existing crossing) as identified in the Thames Estuary 2100 plan

- The proposed Thames Estuary Airport

- Potential developments within Ebbsfleet Valley

- The proposed Paramount Park at Swanscombe Peninsula

In addition to this the Economic Case outlined by Aecom captures some common impacts of all the options (Section 4.6.2) which imply interdependencies:

- Reduce fuel and non-fuel operating costs by reducing congestion

- While benefits to freight, disbenefit to personal users due to added traffic at new sites

- Increase in accidents as proportional to increase in traffic in general

- Adverse environmental impacts on River Thames and surrounding area (i.e. habitats)

- Minor impacts on:

- Physical fitness

- Security

- Severance and access to services

And sections 3.8.2 and 3.8.3 list examples of constraints, which again imply interdependencies:

- River navigation requirements (influence design)

- Highway and junction design requirements

- Thames estuary marine environment

- Option B's potential impacts on the Ebbsfleet Valley development area

- Option C's potential impacts on the Thames Estuary and Marshes RAMSAR site

- Option C's potential impacts on the Shome and Ashenbank Woods SSSI

- Governance of development within designated Green Belt Land (particularly Option C)

It is suggested (para 4.6.7) that the new crossing locations (Options B and C) would change patterns of connectivity, and it is this which gives rise to the wider economic impacts:

\section{"Changing patterns of connectivity and relationships between businesses and their employees, customers and suppliers could in turn have significant impacts on the economy, land use and regeneration."}

Each of the options is thought to have an adverse impact on biodiversity and either or both of the landscape and townscape of the surrounding areas. Option A is felt to have the least adverse impact, Option to have a moderately adverse impact and Option $\mathrm{C}$ to have a moderate to large adverse impact if a bridge, or a moderate adverse impact if a tunnel.

As the structures would be "out of scale" (para 4.6.26) with the local townscape, they would impact on features such as school grounds and recreational spaces. Option $\mathrm{C}$ would impact "directly and indirectly" on nationally valued landscapes including Scheduled Monuments, listed buildings, conservation areas, ancient woodlands, areas of historic landscape patterns, Shorne Country Park and Thames marshland. 
As suggested in an earlier section, the Commercial Case set out in the Aecom report recognises the need for a "maintenance plan", requiring stakeholder coordination, to minimise disruption and performance resulting from integrated infrastructure. Though it does not go into any detail as to what this might be.

The Financial Case, also set out in the Aecom report, says "The successful delivery of a new Lower Thames crossing will be dependent on and affected by decisions relating to a number of other projects" and that those identified so far include:

- Thames Gateway developments

- M25 Junction 30/A13 improvements

Thus, while the provision of additional capacity will go ahead whether or not any other projects (regeneration or otherwise) occur, the success of a new crossing is not independent of these projects.

\section{Engineering the Future Infrastructure Timelines}

Engineering the Future have recently published a second report ${ }^{29}$ looking at UK infrastructure policy and plans over the next 50 years. This was presented on a timeline, together with an analysis of some of the potential interdependencies between these policies and projects. Interdependencies between the LTC project and other infrastructure policies and projects can be identified from the report as potentially arising from.

- Simultaneous construction of High Speed 2 Phase 1 and 2 (e.g. restricted access to material, equipment and human resources);

- Predicted progressive introduction of autonomous vehicles for freight between 2021 and 2030;

- Heavy reinforcement of $400 \mathrm{kV}$ network, especially if Electric Vehicles and electric heating become widespread;

- Emerging EU Supergrid;

- Solar microgeneration of electricity; and

- Flood defence projects;

${ }^{29}$ Engineering the Future, 2013, Infrastructure Interdependencies Timelines, May 2013 


\section{Key Stakeholders}

In alignment with OMEGA Centre findings, it is necessary to identify a representative selection of stakeholders, with diverse interests, to participate in the interdependency identification and appraisal process. This chapter identifies the key stakeholder organisations with an interest in the Lower Thames Crossing, identified from the relevant documents discussed in the previous chapters. Stakeholders are defined as "those people who have a vested interest in a problem by affecting it or/and being affected by it"30.

Stakeholders have been identified primarily from the Parsons Brinkerhoff led preliminary stakeholder consultation and the Aecom /DfT led Stakeholder Advisory Panel. Members of this panel are indicated in the table. Some of the stakeholders involved in the 2009 preliminary consultation no longer exist. Some have disbanded entirely while others have changed their name or had their interests and responsibilities taken on by new groups, mainly Local Enterprise Partnerships (LEPs).

As with the work conducted by the OMEGA Centre, these have been classified according to their geographical dimension (from local to international) along with their identity as a public sector, private sector or civil society organisation. They are also grouped in relation to infrastructure sector, though there is some overlap between sectors for some stakeholders.

Table 5 - Main Stakeholders involved in the LTC project

\begin{tabular}{|c|c|c|c|c|}
\hline & \multicolumn{4}{|c|}{$\begin{array}{c}\text { STAKEHOLDER CLASSIFICATION } \\
\text { Public Sector, Private Sector, Civil Society }\end{array}$} \\
\hline & LOCAL & REGIONAL & NATIONAL & INTERNATIONAL \\
\hline 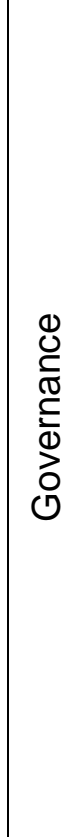 & $\begin{array}{l}\text { Dartford Borough Council } \\
\text { Thurrock Borough Council } \\
\text { Castle Point Borough } \\
\text { Council } \\
\text { Gravesham Borough } \\
\text { Council } \\
\text { Southend-on-Sea } \\
\text { Borough Council } \\
\text { Basildon District Council } \\
\text { Medway Council } \\
\text { Swale District Council } \\
\text { London Borough of } \\
\text { Havering } \\
\text { London Borough of } \\
\text { Bexley } \\
\text { Rochford District Council }\end{array}$ & $\begin{array}{c}\text { Greater London } \\
\text { Authority } \\
\text { Kent County Council } \\
\text { Essex County Council }\end{array}$ & $\begin{array}{l}\text { UK Government } \\
\text { HM Treasury }\end{array}$ & European Parliament \\
\hline
\end{tabular}

${ }^{30}$ Banville, C., Landry, M., Martel, J.M., Boulaire, C., 1998, "A Stakeholder Approach to MCDA." System Research. Vol. 15, pp. 15-32 
Table 5 continued

\begin{tabular}{|c|c|c|c|c|}
\hline \multicolumn{5}{|c|}{$\begin{array}{l}\text { STAKEHOLDER CLASSIFICATION } \\
\text { Public Sector, Private Sector, Civil Society }\end{array}$} \\
\hline & LOCAL & REGIONAL & NATIONAL & INTERNATIONAL \\
\hline $\begin{array}{l}\text { के } \\
\frac{\text { के }}{\text { ய }}\end{array}$ & & $\begin{array}{l}\text { UK Power Networks } \\
\text { Metro tidal }\end{array}$ & $\begin{array}{c}\text { Department for Energy } \\
\text { and Climate Change } \\
\text { National Grid } \\
\text { EON } \\
\text { EDF Energy } \\
\text { British Gas }\end{array}$ & \\
\hline \multirow{2}{*}{$\underline{\mathfrak{o}}$} & & & BT Openworld & IBM \\
\hline & & & & INTEL \\
\hline \multirow{7}{*}{$\begin{array}{l}\frac{5}{0} \\
\frac{0}{0} \\
\frac{0}{\sqrt{0}} \\
\text { ㄴ }\end{array}$} & SERT & Transport for London ${ }^{*}$ & $\begin{array}{l}\text { Department for } \\
\text { Transport }^{*} \\
\end{array}$ & $\begin{array}{l}\text { DP World London } \\
\text { Gateway Port }\end{array}$ \\
\hline & Fast-track & $\begin{array}{l}\text { Port of London } \\
\text { Authority }\end{array}$ & Highways Agency* & Peel Ports \\
\hline & & $\begin{array}{l}\text { Thames Gateway } \\
\text { Transport Partnership }\end{array}$ & Network Rail & Tilbury Docks \\
\hline & & & Rail Freight Group & $\begin{array}{c}\text { Individual Smaller } \\
\text { Docks }\end{array}$ \\
\hline & & & $\begin{array}{l}\text { Road Haulage } \\
\text { Association }\end{array}$ & $\begin{array}{c}\text { Individual International } \\
\text { Haulage Firms (e.g. } \\
\text { Canute Group) }\end{array}$ \\
\hline & & & $\begin{array}{c}\text { Individual National } \\
\text { Haulage Firms }\end{array}$ & $\begin{array}{c}\text { International Shipping } \\
\text { Freight Carriers }\end{array}$ \\
\hline & & & $\begin{array}{l}\text { British Ports } \\
\text { Association }\end{array}$ & \\
\hline $\begin{array}{l}\frac{1}{\mathscr{M}} \\
\stackrel{\pi}{3}\end{array}$ & & $\begin{array}{l}\text { Veolia Environmental } \\
\text { Services }\end{array}$ & & \\
\hline \multirow{2}{*}{$\frac{\bar{d}}{\frac{ \pm}{\pi}}$} & & Thames Water & & \\
\hline & & Thames Estuary 2100 & & \\
\hline \multirow{6}{*}{ 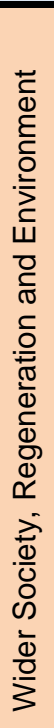 } & Renaissance Southend & $\begin{array}{l}\text { Thames Gateway Kent } \\
\text { Partnership* }\end{array}$ & $\begin{array}{c}\text { Department for } \\
\text { Environment, Food and } \\
\text { Rural Affairs } \\
\end{array}$ & Climate KIC \\
\hline & Swale Forward & $\begin{array}{l}\text { Thames Gateway } \\
\text { South Essex } \\
\text { Partnership }{ }^{ \pm} \text {(disbanded } \\
\text { April 2012) }\end{array}$ & Environment Agency & \\
\hline & $\begin{array}{c}\text { Thurrock Thames } \\
\text { Gateway Development } \\
\text { Corporation }\end{array}$ & $\begin{array}{l}\text { Thames Gateway } \\
\text { London Partnership }\end{array}$ & $\begin{array}{c}\text { Homes and } \\
\text { Communities Agency }\end{array}$ & \\
\hline & $\begin{array}{l}\text { Basildon Renaissance } \\
\text { Partnership }\end{array}$ & $\begin{array}{c}\text { South East Local } \\
\text { Enterprise Partnership }\end{array}$ & $\begin{array}{c}\text { Town and Country } \\
\text { Planning Association }\end{array}$ & \\
\hline & $\begin{array}{l}\text { Bexley Regeneration } \\
\text { Agency }\end{array}$ & $\begin{array}{l}\text { Kent Thameside } \\
\text { Delivery Board }\end{array}$ & English Nature & \\
\hline & $\begin{array}{c}\text { Woolwich Regeneration } \\
\text { Agency }\end{array}$ & GO East & $\begin{array}{c}\text { Modern Built } \\
\text { Environment KTN }\end{array}$ & \\
\hline
\end{tabular}


Table 5 continued

\begin{tabular}{|c|c|c|c|c|}
\hline & $\begin{array}{r}S \\
\text { Publi }\end{array}$ & $\begin{array}{l}\text { TAKEHOLDER CL } \\
\text { Sector, Private }\end{array}$ & $\begin{array}{l}\text { ASSIFICATION } \\
\text { ector, Civil Society }\end{array}$ & \\
\hline & LOCAL & REGIONAL & NATIONAL & INTERNATIONAL \\
\hline & $\begin{array}{l}\text { Local Residents Groups } \\
\text { (e.g. Gravesham Rural } \\
\text { Residents Group) }\end{array}$ & Connect Plus & Atkins & \\
\hline & Local Action Groups & & Balfour Beatty & \\
\hline & Paramount Park & & Skanska & \\
\hline & $\begin{array}{c}\text { Space Catapult Centre } \\
\text { Harwell }\end{array}$ & & $\begin{array}{c}\text { Egis Road Operation } \\
\text { UK }\end{array}$ & \\
\hline$E$ & $\begin{array}{l}\text { Individual Local } \\
\text { Businesses }\end{array}$ & $\begin{array}{c}\text { London Thames } \\
\text { Gateway Development } \\
\text { Corporation }\end{array}$ & Fosters \& Partners & \\
\hline $\begin{array}{l}\bar{\Phi} \\
\sum_{\overline{0}}^{\underline{0}}\end{array}$ & $\begin{array}{l}\text { Individual Local Residents } \\
\text { and Crossing Users }\end{array}$ & $\begin{array}{c}\text { Medway Renaissance } \\
\text { Partnership }\end{array}$ & Hyder & \\
\hline $\begin{array}{l}\vec{z} \\
\vec{w} \\
\text { c }\end{array}$ & No2LTC Action Group & $\begin{array}{l}\text { London Enterprise } \\
\text { Panel }\end{array}$ & Arup & \\
\hline $\begin{array}{l}\sigma \\
\tilde{\sigma}\end{array}$ & & Gateway to London & CH2MHill/Halcrow & \\
\hline 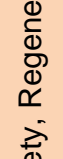 & & $\begin{array}{l}\text { East of England } \\
\text { Development Agency } \\
\text { (disbanded March } \\
\text { 2012) } \\
\end{array}$ & Aecom & \\
\hline $\begin{array}{l}\frac{1}{0} \\
\dot{0}\end{array}$ & & $\begin{array}{l}\text { Government Office } \\
\text { South East }\end{array}$ & RSPB & \\
\hline$\stackrel{\frac{0}{0}}{i}$ & & $\begin{array}{l}\text { South East England } \\
\text { Development Agency } \\
\text { (disbanded March } \\
\text { 2012) }\end{array}$ & Lloyds Register & \\
\hline & & $\begin{array}{l}\text { South East England } \\
\text { Councils }\end{array}$ & Wills $\mathrm{Re}$ & \\
\hline & & $\begin{array}{l}\text { Thames Estuary } \\
\text { Partnership }\end{array}$ & CIRA & \\
\hline & & & $\begin{array}{c}\text { TSB Transport and } \\
\text { Future Cities Catapult } \\
\text { Centres }\end{array}$ & \\
\hline & & & $\begin{array}{l}\text { Council for Protection of } \\
\text { Rural England }\end{array}$ & \\
\hline
\end{tabular}




\section{Resonance of OMEGA Lessons and Case Study Findings to LTC Project}

This chapter aims to examine the LTC project in the context of selected OMEGA Lessons derived from all OMEGA studies of Mega Transport Projects (MTPs). The LTC project thus far, as reviewed in the previous chapters is appraised against a list of project criteria and lessons extracted from the key findings of the five-year OMEGA Centre project: 'Decision making in the Planning, Appraisal and Delivery of Mega Transport Projects'31.

In the following tables the first and second columns contain the 'OMEGA Lessons and Insights' and 'OMEGA Criteria/Guidance'. The third column then contains an appraisal of the LTC project in response to the criteria. The current phase of the project, with no definitive location, route or form, means that some of the activities of relevance to these lessons have not been conducted in full, or to the necessary level of detail. In most instances the need for additional work is recognised within the relevant documents. In this respect the tables are presented as a tool to inform and improve the future directions of the project in this regard, and to ensure that all the necessary issues are taken into consideration.

The appraisal described in the third column, whilst employing the OMEGA Lessons, has been carried out by The Systems Centre, University of Bristol.

31 OMEGA Centre, Decision making in the Planning, Appraisal and Delivery of Mega Transport

Projects: Lessons for Decision-Makers (OMEGA 2 Study), 2012 
$1.1 \quad$ MTPs frequently become (either by design or by virtue of the nature and extent of their impacts) critical 'agents of change' that have multiple spatial, economic, environmental and other implications - but 'agent of change' objectives are not always a part of their initial raison d'etre;
- The project planning and appraisal process must spatial and sectoral change.

- As a consequence, such planning and appraisal processes must view MTPs as more than simply infrastructure providers examine its potential to function as an agent of

- The LTC Project is in reaction to congestion on the existing Dartford crossing being forecast to exceed acceptable limits, possibly leading to negative effects for the local and national economy. In this way it has been considered in terms of how without it, positive change (much of it planned regeneration) may be hindered if it does not go ahead.

- While the LTC Project's appraisal has thus far considered its effects on the environment (as a result of easing congestion) and some regeneration in the region (in terms of agglomeration), it has not been explicitly viewed or appraised as a proactive agent for change. Generally, wider costs and benefits have not been considered beyond direct impacts on traffic and the coupled knock-on effects this is thought to have.

1.2 - Similarly, the potential for such projects to change the context into which they are placed is often under-appreciated by decision-makers resulting

ces
unexpected/unintended consequences (which may be beneficial and/or problematic);

and/or

- $\quad$ MTP planning and appraisal processes need to thoroughly examine their potential impacts on the contexts into which they are inserted.

- A key part of these processes is the building and testing of scenarios and the formulation of futureproofing strategies in response to forecast/potential changes in context.

- The modelling used in assessing site options has somewhat considered the impacts of different scenarios, and the impacts the crossing will have on the local areas, especially in terms of traffic flow.

- Given the regeneration planned in the region, there are many scenarios which could affect the use and impacts of the crossing.

- Given the current phase in the project, once a location is decided, there may be additional scope to consider the impacts on land use, and how this will change the context of the problem.

1.3 - MTP planning, appraisal and delivery agents therefore need to be clear about:

o whether, how and over what spatial and temporal dimensions a MTP is expected to function as an 'agent of change' (e.g. in terms of territorial, sectoral or other type of strategy) o which forces of change the projects should be trying to influence or harness and over what timeframe

o what resources (financial, institutional, personnel, legal, etc.) and policy frameworks are likely to be needed

- There is a need for clarity by MTP planning, appraisal and delivery agents therefore need to be clear about:

- whether, how and over what spatial and temporal dimensions a MTP is expected to function as an 'agent of change' (e.g. in terms of territorial, sectoral or other type of strategy)

- which forces of change the projects should be trying to influence or harness and over what timeframe

- what resources (financial, institutional, personnel, legal, etc.) and policy frameworks are likely to be needed
- The region of interest and timescales are relatively explicit.

- Traffic project extend to 2084 in some cases (AECOM LTC Model), and the impact on national economy is considered.

- There is arguably additional scope to consider the proactive regional economic impacts 
2 MTPs are 'Open Systems' - planning, appraisal and delivery agents need to recognise that MTPs are phenomena that require 'open systems' treatment in light of their complex and fluid relationship with the areas/sectors/communities they serve, traverse and impact upon.

2.1 - MTPs are 'open systems' that continuously interact with the changing 'context(s)' they serve, traverse and impact upon - including environmental, social, economic, physical, institutional and political contexts.
- MTPs must be seen as 'open systems' that continuously interact with the changing 'context(s)' they serve, traverse and impact upon - including environmental, social, economic, physical, institutional and political contexts.

- This calls for the establishment of project planning and appraisal processes that enable MTPs to be properly treated as open systems.

- By contrast, MTP planning and delivery agents need to be aware that MTPs which are treated as 'closed systems' during the project planning and appraisal stages cannot be adequately considered as a constituent of the wider, and hence more complex, context into which they are placed. This raises the real possibility that potential project impacts will be seriously underestimated and/or lead to significant lost opportunities and downside risk

2.2 - Closed system treatment will undoubtedly be needed once a MTP is deemed ready for implementation. However, the timing of this 'project freezing' is critical in that choices about the project will inevitably be locked in and may be prejudiced by future contextual change.

2.3 - It should be acknowledged that many outcomes of MTPs are difficult to identify precisely, much less quantify - and may only emerge many years after the project has been completed. This is because MTPs are themselves complex (often innovative) systems which interact in multiple and complex ways over time and space.
- The timing of 'project freezing' needs to be carefully considered in that choices about the project will inevitably be locked in and may be prejudiced by future contextual change.

- MTP planning, appraisal and delivery processes need to acknowledge that many project outcomes/impacts are difficult to identify precisely, much less quantify - and may only emerge many years after the project has been completed.
Once minor short and medium term actions at the existing Dartford Crossing had been considered, there is little evidence that the solution was considered as anything other than an element of hard transport infrastructure.

- Interactions within the transport sector (general and freight traffic, rail and public transport) were considered across the boundary of a crossing and the impacts these may have on other systems have been briefly discussed in the appraisal.

- Interactions with other infrastructure systems beyond the transport sector do not appear to have been significantly considered at this stage.

- In this respect the problem is conceived as a relatively closed system beyond immediate intra-sector interdependencies

- $\quad$ No evidence has been found that the downside risks associated with project freezing have been considered.

- While the project is seemingly tied to a transport crossing, there is still scope to consider this.

- Data is collected for the existing Dartford Crossing relating to traffic volumes, delays etc. and the appraisal for the new crossing is very closely linked to these. No evidence has been found that a process for the continual future evaluation of these outcome measures has been discussed in detail. 
3 MTPs are 'Organic' Phenomena - MTPs are 'organic' phenomena (rather than static engineering artefacts) that often need 'time to breathe'. This time to

breathe can present special opportunities that should be seized and exploited by key decision-makers.

3.1 - Most MTPs are subject to an 'organic', evolutionary - MTP planning and appraisal agents, and the process that often produces fundamental change in their raison d'etre, their scope/scale and/or the thinking behind plans for the areas they impact upon.

- Given the organic characteristics of MTPs, they often need a period of reflection (a 'time to breathe') to allow for more consistent and comprehensive decision-making. This addition to the project's gestation period need not be seen as ineffective if used wisely to reconsider and reconfigure the raison d'etre and scale/scope of the project.

- By contrast, in some cases, the fast tracking of projects can prove very problematic if insufficient time has been allowed to absorb/deal with the numerous issues they need to address.

- Planning, appraisal and delivery agents need to acknowledge the evolutionary nature of many/most MTPs and in so doing recognise:

$\circ$ that many MTPs and the plans, programmes and projects they spawn will often need to evolve in response to changing contextual influences that exert themselves over the (often lengthy) project lifecycle;

over the (olten lengthy) project in reficated periods of reflection into the project planning and appraisal process - which should faciltate the involvement of all interested stakeholders and allow for the advent of new 'emergent' objectives or visions;

o that opportunities may present themselves when contextual influences are 'right' (i.e., when the 'planets are aligned') to take decisive action

that the ability to control every aspect of project planning and delivery is often fundamentally undermined by 'happenstance' (i.e. unforeseen circumstance);

o that preparing flexible, robust and adaptable strategies for MTP developments that are able to address and respond to the complexities they pose, especially in relation to their interaction with the areas and sectors they impact upon, is of critical importance; and

othat the fundamental raison d'etre must not necessarily remain unchanged over time.
MTP planning and appraisal agents, and the
processes they establish for this purpose need to be aware that most such projects are subject to an 'organic', evolutionary process that often produces fundamental change in their raison d'etre, their scope/scale and/or the thinking behind plans for the areas they impact upon.

- MTP planning and appraisal agents should consider whether, and how, a period of reflection (a 'time to breathe') is needed to allow for more consistent and comprehensive decision-making.

- By contrast, there is a need to consider whether the fast tracking of projects could prove to be very problematic if insufficient time has been allowed to absorb/deal with the numerous issues they need to address.

- Planning, appraisal and delivery agents need to acknowledge the evolutionary nature of many/most MTPs and in so doing recognise:

o that many MTPs and the plans, programmes and projects they spawn will often need to evolve in response to changing contextual influences that exert themselves over the (often lengthy) project lifecycle:

of dedicated periods of reflection into the project planning and apprais - which should faciltate the involvement of all intereste - which should faciltate the involvement of all interested stakeholders and allow for the advent of new 'emergent'
objectives or visions;

that opportunities may present themselves when contextual influences are 'right' (i.e., when the 'planets are aligned') to take decisive action;

o that the ability to control every aspect of project planning and delivery is often fundamentally undermined by 'happenstance' (i.e. unforeseen circumstance);

o that preparing flexible, robust and adaptable strategies for MTP developments that are able to address and respond to the complexities they pose, especially in relation to their interaction with the areas and sectors they impact upon, is of critical importance; and

0 that the fundamental raison d'etre of MTPs must not necessarily remain unchanged over time.
- The project has been in gestation for some time, having first been discussed in 1990. The need for additional capacity, and solution of a new crossing, was established and has remained throughout more recent appraisals.

The solution as a new crossing, and perhaps more importantly, its bounding as a transport problem/solution has been fixed

The project has been through several appraisals and consultations and will go through several more stages of planning.

There is no evidence that the raison d'etre has yet been through a period of proactive reflection.

While there is no suggestion the project has been fast tracked in any way, it is included as one of the National Infrastructure Plans key projects.

- While the general solution concept may be fixed, the project is still in the relatively early stages with regard to engineering a crossing and the specific route it will take.

- $\quad$ Future steps in the project will need to ensure that robust and adaptable strategies are in place should there be significant changes in land use or demand.

- The process should include opportunities for reflection on the impact of the changes.

- This is especially true given the large number of regeneration activities planned for the surrounding region. 
4 The Framing of MTPs - the changing demands placed on MTPs can make it excruciatingly difficult to judge their successes and failures. This makes it

imperative to ensure proper project framing so as to enable their appraisal to be based upon a fair and transparent foundation.

4.1 - The most common criteria employed for judging MTP 'success' remain those associated with completing projects on time, on budget, and as per specifications. This focus is, however, capable of only providing a partial (albeit important) basis for such judgements. Indeed, to make a sound judgement about a project's 'success' or 'failure' it is critically important to also understand contextual influences that prevailed at the time the project was conceived, planned, appraised and implemented.

4.2 - Careful thought should be given to the nature and clarity of MTP visions, goals and objectives - whether these relate to the project itself, associated spatial and sectoral transformational initiatives or a combination of the two. In this connection it is suggested that: o there should be a clear early statement of project roles, goals and objectives, together with key assumptions, appraisal criteria and anticipated impacts which need to be disseminated to (and thoroughly discussed with) impacted key stakeholders:

having such clarity could be harmful if there is reluctance to change/inertia even when fluid contextual forces suggest the need to accommodate emergent objectives;

0 objectives relating to agent of change roles and functions are often insufficiently developed at the outset and will need time to fully articulate in terms of more concrete action.

4.3 - Sound judgement about the 'success' (or failure) of MTPs is more likely to be achieved when projects are presented to key decision-makers in a manner that lays out all key financial and non-financial costs and benefits in a transparent way against different time-lines and within a policy-led multi-criteria framework to assess progress. This assists the setting of priorities and helps make trade-offs among different project objectives and stakeholder interests much clearer. As part of this process, it should be acknowledged (once again) that the achievement of project completion on time, to cost and to specification, though very important, does not necessarily represent the raison d'être for undertaking MTPs.
- The planning and appraisal of MTPs needs to recognise
that judgements about project success will almost that judgements about project success will almost considerations than whether the project was delivered on time, on budget and to specification.

- Given that the planning, appraisal and delivery process will almost inevitably be influenced by contextual forces, it is critically important to establish clear (and transparent) project objectives (whether original or emergent) against which project success can be measured.

- Careful thought should be given to the nature and clarity of MTP visions, goals and objectives - whether these relate to the project itself, associated spatial and sectoral transformational initiatives or a combination of the two. In this connection it is suggested that: o there should be a clear early statement of project roles, goals and objectives, together with key assumptions, appraisal criteria and anticipated impacts which need to be disseminated to (and thoroughly discussed with) impacted key stakeholders:

- having such clarity could be harmful if there is reluctance to change/inertia even when fluid contextual forces suggest the need to accommodate emergent objectives; and

- objectives relating to agent of change roles and functions are often insufficiently developed at the outset and will need time to fully articulate in terms of more concrete action.

- Projects should be presented to key decision-makers in a manner that lays out all key financial and nonfinancial costs and benefits in a transparent way against different time-lines and within a policy-led multi-criteria framework to assess progress. This assists the setting of priorities and helps make tradeoffs among different project objectives and stakeholder interests much clearer.
- The most recent project appraisal (Aecom, 2013) looks at a range of success measures across four general areas (including environmental, wider economic and regeneration).

- The appraisal is conducted in accordance with HM (Green Book) and DfT (WebTAG) guidance - However these are all assessed as an impact of relieved congestion.

- There needs to be a robust process to reflect on the applicability of these measures as the project evolves.

- The overall objective of the project is relatively clear, and has been so for some considerable time.

- Consultation undertaken by Parsons Brinkerhoff (2009) did consider stakeholder views on objectives of LTC Project.

- The current consultation does not explicitly enquire about the objectives or the individual success measures and their importance to stakeholders.

- Some aspect (Business user impacts, wider economic impacts, noise, air quality ,greenhouse gasses, commuter impacts, accidents) have been monetised for a cost benefit analysis

- Other impacts (reliability, regeneration, landscape, biodiversity, physical activity, journey quality, security etc.) have not been monetised at this time. 
5 The Power of Context - context awareness and sensitivity to context on the part of project decision-makers is vital for both the successful planning

appraisal and delivery of MTPs and suitable treatment of contextual risks, uncertainties and complexities.

$5.1 \quad \bullet$ The context of individual decisions and events - The context of individual decisions and events impacting impacting on MTP planning appraisal and delivery is essentially unique for each project and therefore reference to past/best practice can be very misleading.

5.2 - The contexts in which MTPs are planned, appraised and delivered are changing at an ever increasing pace due, among other things, to rapid technological improvements, global financial and environmental instabilities and forces of globalisation - especially for those MTPs that have a transnational function. Careful attention also needs to be paid to the governmental (and spatial/territorial planning) contexts into which MTPs are to be inserted as mismatches in expectations and outcomes are frequently experienced.

5.3 - MTP planning, appraisal and delivery agents faced with this reality consequently need to acknowledge the importance of:

o undertaking periodic sensitivity analyses of the context(s) of such projects over the entire project lifecycle contextual change often drives pivotal decisions;

- key project stakeholders need to identify and analyse the critical contexts (and interdependencies) that surround pivotal project decision making;

pivotal project decision making; recognising the likelihood (perhaps inevitability) that the
constant ebb and flow of context will almost certainly constant ebb and flow of context will almost certainly result in the need to adjust project objectives, appraisal
methods/approaches and delivery plans and methods/app

acknowledging that there are occasions of serendipity ('happenstance') in MTP decision-making when unique opportunities present themselves that need to be seized by key stakeholders who are keen to influence project outcomes;

acknowledging that 'mega events' (such as major political change, World Cup Finals and Olympic Games) may have both positive and negative impacts on the contextual risk, unce contextual iss, uncertainty and complexity of MTPs; and recognising that the scale, cost and often controversial nature of MTPs means that political influence/support will remain a critical contextual factor over the entire project on MTP planning appraisal and delivery is essentially unique for each project and therefore reference to past/best practice can be very misleading.

The Commercial Case and Financial Case make reference to previous river crossing funding models and past experience of procuring such projects is used.

The contexts in which MTPs are planned, appraised and delivered are changing at an ever increasing pace due, among other things, to rapid technological improvements, global financial and environmental instabilities and forces of globalisation - especially for those MTPs that have a transnational function.

- Careful attention also needs to be paid to the governmental (and spatial/territorial planning) contexts into which MTPs are to be inserted as mismatches in expectations and outcomes are frequently experienced.

- MTP planning, appraisal and delivery agents faced with this reality consequently need to acknowledge the importance of:

- undertaking periodic sensitivity analyses of the context(s) of such projects over the entire project lifecycle - contextual change often drives pivotal decisions;

- key project stakeholders need to identify and analyse the critical contexts (and interdependencies) that surround pivotal project decision making;

- recognising the likelihood (perhaps inevitability) that the constant ebb and flow of context will almost certainly result in the need to adjust project objectives, appraisal methods/approaches and delivery plans and programmes;

- acknowledging that there are occasions of serendipity ('happenstance') in MTP decision-making when unique opportunities present themselves that need to be seized by key stakeholders who are keen to influence project outcomes. - acknowlodging that 'mega eve (such as major polical change, World Cup Finals and Olympic Games) may have both positive and negative impacts on the contextual risk, - recognising that the scale, cost and often controversial nature of MTPs means that political influence/support will remain a critical contextual factor over the entire project lifecycle.

- The Management Case also refers to the DfT's experience in delivering similar projects.

No evidence has yet been found that there has been an explicit consideration of external contextual influences from the outset, certainly beyond the traffic modelling

- Some consideration of wider risks in Commercial Case

Uncertain

Perhaps too early in planning stage to assess whether these issues have or will be taken into account. 
OMEGA Lessons \& Insights

OMEGA Criteria/Guidance

Analysis of LTC in Response to Criteria

6 Role of Sustainable Development Visions - the lack of a clear and shared vision of the meaning of 'sustainable development' threatens to seriously undermine the potential for, and use of, MTPs to make a positive contribution to its achievement. Simultaneously, it is readily apparent that there is a

widespread lack of clarity about the capability of such projects to support sustainable development visions (despite the rhetoric that exists in this respect)

$6.1 \quad$ - The lack of clarity and consensus regarding the operationalisation of sustainable development visions as they concern MTP planning, appraisal and delivery poses questions about whether they can effectively meet the needs of intra and inter-generational equity of sustainable social, economic and environmental development - including global concerns about energy consumption, carbon footprints, climate change, greenhouse gases and Co2 emissions.

- There needs to be greater clarity and consensus regarding the operationalisation of sustainable development visions as they concern MTP planning, appraisal and delivery poses questions about they can effectively meet the needs of intra and intergenerational equity of sustainable social, economic and environmental development - including global concerns about energy consumption, carbon footprints, climate change, greenhouse gases and Co2 emissions.

- MTP planning and appraisal processes need to be clear about the relative aspirations associated with the different dimensions of sustainability and how the needs associated with each dimension are to be achieved/balanced in a mutually acceptable manner.

6.2 - There are significant institutional/organisational and professional barriers and silos that often inhibit the application of 'holistic' visions of sustainability to MTP developments.

6.3 - Certain MTPs (especially those with major highway components) are characterised by an inbuilt conflict between concerns for environmental sustainability and the manner in which they are designed and funded i.e. their continued financial sustainability is frequently dependent on revenues that require ever increasing patronage/rising traffic levels.

- MTP planning, appraisal and delivery processes need to facilitate the application of 'holistic' visions of sustainability and thereby overcome existing institutional, professional and organisational barriers.

- MTP planning, appraisal and delivery processes need to facilitate a measured approach to address the inbuilt conflict between concerns for environmental sustainability and the manner in which such projects are designed and funded - i.e. their continued financial sustainability should not be dependent on revenues that require ever increasing patronage/rising traffic levels.

- In planning and appraising proposed MTPs, priority should always be given to those projects that comprise components of transit-orientated developments (ToDs) as these potentially have far-reaching positive sustainability benefits that go well beyond their immediate line-haul operations by virtue of the positive urban agglomerations they can attract and the reduced private motorcar dependency they can encourage.

6.4 - Sustainable development visions require long-term appraisal and evaluation cycles which in turn need to be supported by sustained political support and institutional frameworks which share the same vision.

- Sustainable development visions require long-term appraisal and evaluation cycles which in turn need to be supported by sustained political support and institutional frameworks which share the same vision.
- Environmental impacts, noise, air quality and greenhouse gas emissions have been a central part of the appraisal process.

It is not clear whether energy consumption has been factored into the financial appraisals

- The 2013 Strategic Case is set out in the context of the wider Government vision for a sustainable transport system

Uncertain

No evidence available on how sustainability has been planned for across organisational silos.

Evidence of consideration of wider impacts, but seemingly little available on any explicit tradeoffs with sustainability objectives. 


\section{OMEGA Lessons \& Insights}

OMEGA Criteria/Guidance

Analysis of LTC in Response to Criteria

7 Engaging with MTP Stakeholders - effective and early engagement with key stakeholders is seen as critical in MTP planning, appraisal and delivery. This presents important opportunities to manage/mitigate risk, uncertainty and complexity in project developments and more specifically to assist in the adjustment of project objectives to address manifold contextual influences (and changes thereto), manage expectations and help progress the project delivery process.

7.1 • Discerning and analysing key stakeholder motives/agendas and levels of influence on MTP developments is never easy - not least, because they are subject to change over time and the likelihood that relationships between

- MTP planning, appraisal and delivery processes should acknowledge that discerning and analysing key stakeholder motives/agendas and levels of influence on project developments is never easy - not least, because they are subject to change over time and the likelihood that relationships between will alter during the MTP lifecycle.

- MTP planning, appraisal and delivery processes need to establish mechanisms that enable the building of effective relations with key project stakeholders.

- This is dependent upon the establishment of trust, credibility and transparency - which, in turn, represent important factors in creating consensus in decision-making, especially necessary in turbulent and uncertain times.

- Trust, credibility and transparency is more usually achieved if project stakeholders are involved at an early stage in the setting of project objectives.

- In turn, access by key stakeholders to all relevant, high quality, information is seen as critically important in building trust and consensus.
- Many of the relevant documents are in the public domain, these include documents at national, regional and local government levels.

- The project has been discussed, with many documents in the public domain, for a considerable period

- The project is currently undertaking its second consultation in five years including open public engagement

- The project has a stakeholder advisory panel which collectively represent a broad range of private and public organisations. 
8 Institutional, Policy and Legislative Support - MTPs are unlikely to be able to deliver the full range of agent of change benefits unless accompanied by a suitable institutional, policy and legislative framework that remains in place throughout the project lifecycle.

8.1 - Whether or not a MTP's institutional framework is bespoke or represents an adaptation/extension of currently available institutional, policy or legislative arrangements, it is critically important that they are transparent, accountable and sustainable over the long-term - including during the project operations phase.

8.2 - Such frameworks also need to address the wide-ranging variety of stakeholder expectations and aspirations that MTPs inevitably engender; and the multiple territorial, sectoral and stakeholder interfaces with which project planning, appraisal and delivery processes have to deal.

8.3 • MTPs benefit greatly from sustained political support and leadership, particularly to the point of their political approval and commencement of construction - such support helps to maintain both consensus and momentum.
- It is critically important that MTP's institutional frameworks are transparent, accountable and sustainable over the long-term - including during the project operations phase.
Planning and appraisal appear transparent thus far

- Transparent process for moving to operation

- Such frameworks also need to address the wide-ranging variety of stakeholder expectations and aspirations that MTPs inevitably engender; and the multiple territorial, sectoral and stakeholder interfaces with which project planning, appraisal and delivery processes have to deal.

- MTPs benefit greatly from sustained political support and leadership, particularly to the point of their political approval and commencement of construction - such support helps to maintain both consensus and momentum.
- A wide variety of stakeholders have been identified and involved in the process

- Sectoral focus very much on transport
LTC Project has been gestating for over 20 years, with a significant process in the last 5 (i.e. though successive governments)

Evidence of strong commitment to project (e.g. NIP)

\section{OMEGA Lessons \& Insights} 9 Lesson Learning and Sharing - It is apparent that systematic, widespread lesson-learning and sharing is not currently a significant feature of MTP planning, of project performance. Furthermore, there is evidence to suggest that knowledge acquired by the private sector in the field of MTP developments is frequently jealously guarded for commercially competitive gain, often ultimately at the expense of the public purse.

9.1 - In light of the above, MTP planning, appraisa and delivery agents should seek to ensure that the findings of more extensive and systematic lesson-learning and sharing are integrated into project decision-making practice world-wide.
- MTP planning, appraisal and delivery agents should seek to ensure that the findings of more extensive and systematic lessonlearning and sharing are integrated into project decision-making practice world-wide. 


\section{Method for Application of IP\&MF Associated Tools}

This chapter describes the method used throughout the rest of this report to apply a tool assoiated with the Interdependency Planning and Management Framework (IP\&MF) for the systematic identification, structuring and characterisation of necessary and potnetial interdependencies between a new Lower Thames Crossing and other infrastructure (both existing and proposed). This trial application invoves three phases:

1. An initial desk study of the existing reports and documents concerning the proposed Lower Thames Crossing as detailed in the previous chapters

2. The application of a matrix-based tool to systematically and holistically identify and extract the key necessary, planned and potential interdependencies between the LTC and other infrastructures

3. The characterisation and evaluation of the identified interdependencies

The key pronciples of the IP\&MF are applied across these phases. In particular the consideration of an open-systems view of the Lower Thames Crossing infrastructure project.

A workshop was initially proposed to identify and assess potential interdependencies, however, discussions with the relevant personnel involvoed with the project concluded that, as the project had recently been openend to public consultation over the crossing site, it was not the correect phase in the lifecycle to hold such a workshop.

As the location of the LTC has yet to be decided, the IP\&MF could be used to assess the interdepdnencies of each location option in order to advise on the location choice. However, the routing options for each location are also yet to be decided, leaving a great deal of uncertainty over the nature of the crossing. Once a location was decided, the IP\&MF could be used to inform more specific routing decisions by identifying valuable and hazardous interdependencies.

This application of the framework aims to look at the LTC options in generic terms in order to identify the interdependeicnes that may become relevant once the location has been decided. While this work may not directly impact the location decision, it will assist the application of the IP\&MF during this later phase by highlighting a preliminary catalogue of interdependeices at play in the in the LTC region, given the issues disucussed in the first part of this report.

\section{Matrix-Based Tool}

The matrix-based tool has been developed from the $\mathrm{N}^{2}$ Chart tool created by R. J. Lano ${ }^{32}$ for the analysis of interfaces and relationships. He describes it as "a visual aid which can be effectively employed to communicate functional or physical interface and interrelationship information to a large group and/or mixed discipline audience in a very short time period" (p1). To this he adds that "it provides the user with an effective tool for the definition, tabulation, design and analysis of these interfaces."

32 R. J. Lano, 1979, A technique for software and system design, Elsevier North Holland Publishing Co. 
At its most basic, the $\mathrm{N}^{2}$ Chart consists of matrix showing the interactions between $\mathrm{N}$ functions. It gets its name from the fact there will be $\mathrm{N}^{2}$ locations in the matrix which contain a function or an interaction between two functions. The functions are located along the diagonal of the matrix, leaving the remaining locations to illustrate the interactions between them. This is best demonstrated by example as shown in Figure 15.

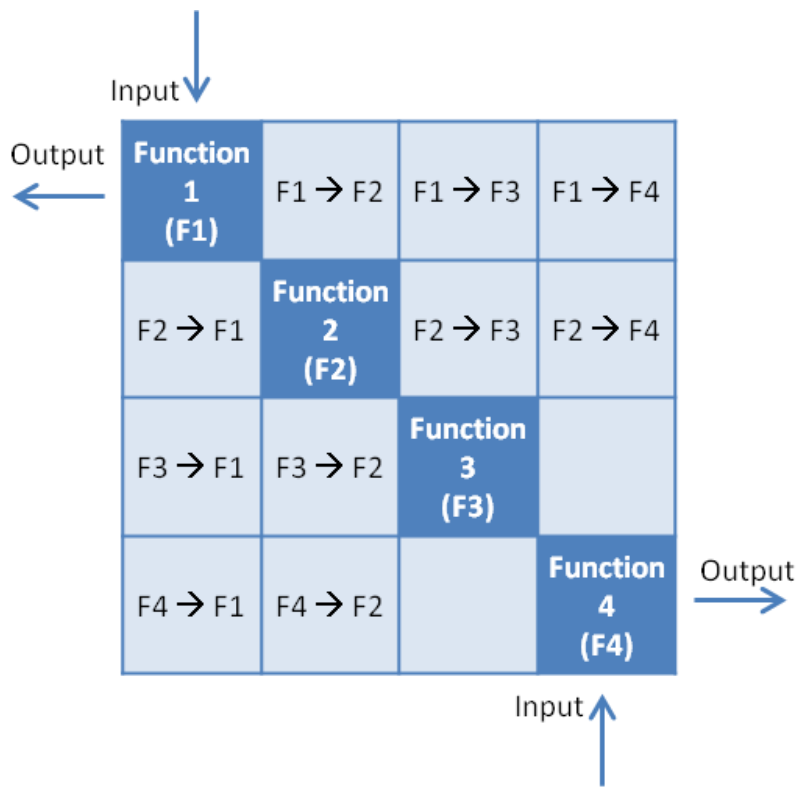

Figure 15 - Example N-Squared Chart (after Lano, 1979)

In this example, the functions F1, F2, F3 and F4 can be seen in the darker boxes running from the top left corner to the bottom right corner. The off-diagonal boxes show the relationships between these functions. The box labelled "F1 $\rightarrow$ F2", for example, indicates a one-directional relationship from Function 1 to Function 2 . In its original form these off-diagonal boxes are conceived as outputs and inputs, such that the box labelled "F1 $\rightarrow$ F2" shows that an output of Function 1 becomes an input to Function 2. The squares in horizontal rows therefore become the outputs of the Function in that row. The squares in the vertical columns show the inputs to the Function in that column.

When discussing the dependencies and interdependencies between two infrastructure projects or policies, this functional view of inputs and outputs may not be wholly adequate. For example two policies may be interdependent if they share the same owner. Two projects may be interdependent if their physical manifestations are co-located in the same geographical space. Two projects may be interdependent if they fulfil the same capabilities, even if the systems which fulfil them are completely different. There are many other examples which do not fit into this model of inputs and outputs, and as such the matrix-based tool applied in line with the IP\&MF is not fixed to the this functionalist view. The off-diagonal boxes can be used to record shared ownership or geographical co-location.

\section{Characterising and Evaluating Interdependencies}

Following the systematic identification of interdependencies using the Matrix-Based Tool, the next step is to characterise and evaluate those interdependencies.

The characterisation is performed qualitatively in order to better understand the interdependencies. It does not claim to be definitive, and as discussed below, there is often 
significant overlap between the sub-categories. The categories used for characterising the interdependencies are: Nature, Necessity, Result, Chronology and Scale of Impact. The most relevant stakeholders are also identified as per Table 5. Due to a lack of information the evaluation of the interdependencies is also performed qualitatively. The PESTE (Political, Environmental, Social, Technological and Economic) framework is used as the basis for this.

\section{Nature}

Several methods have been proposed to capture the different types of interdependency specific to infrastructure. The method used here categorises interdependency into four broad types drawn from those suggested by Rinaldi et al. $^{33}$, Ventura et al. $^{34}$, the National Infrastructure Plan 2012 and a report on infrastructure interdependency by Frontier Economics $^{35}$ (which referred to these types as classifying the 'nature' of the interdependency). These four types of interdependency are Physical (e.g. a transfer of material between elements, or one element's physical reliance on the function of another), Digital (e.g. a transfer of information), Geographic (e.g. co-location) and Organisational (e.g. linked through a mechanism of finance or governance). It is possible to classify an interdependency in terms of many of these types. A physical interdependency may for example mean colocation and therefore geographic interdependency. It may also be governed by an organisational relationship.

\section{Necessity}

It is also useful to consider whether the interdependencies are functionally Necessary or whether they are not necessary, but could provide Potential, additional benefits or risks. Identifying, cataloguing, characterising and evaluating necessary interdependencies could help in managing their benefits and risks. Similarly, identifying, characterising and evaluating potential interdependencies could lead to more efficient infrastructure projects. Some potential interdependencies may in practice be extremely common, but the distinction is made from those which are required for the system to operate.

\section{Result}

In this context, the result of an interdependency refers to whether it primarily offers and additional opportunity for Benefit or simply provides additional risk of $\underline{\text { Hazard }}$ or disbenefit.

An interdependency which provides additional opportunity for benefits may well bring with it a set of risks. The interdependencies will be characterised in terms of their principal trait (relevant to the LTC) but this should not be interpreted to mean that they do not come with any additional risks if they are seen as opportunities, or indeed could not be used in a beneficial way if they are seen as risks.

A necessary interdependency may present the opportunities for additional benefits, beyond their core necessary role, or they may only provide that necessary role in which case the result of the interdependency, in this context, may not be relevant.

\section{Chronology}

\footnotetext{
33 Rinaldi SM, Peerenboom JP, Kelly TK., 2001, Identifying, understanding, and analyzing critical infrastructure interdependencies, IEEE Control Systems Magazine; 21:11-25.

34 Ventura CE, Juarez Garcia H, Marti JM., 2010, Understanding Interdependencies among Critical Infrastructures, Proceedings of the 9th U.S. National and 10th Canadian Conference on Earthquake Engineering, Toronto

35 Frontier Economics, 2012, Systemic Risks and Opportunities in UK Infrastructure - A Report Prepared for HM Treasury \& Infrastructure UK, January 2012
} 
The chronology refers to the broad phase during which the impact of the interdependency is of most importance. Some interdependencies only have an impact during the Planning or Construction phase, others are important during the normal phase of Operation or at infrastructure element's 'End of Life'. Additionally, some interdependencies are only relevant under particular Scenarios (such as during accidental failure or during extreme weather events). Construction is not limited to the physical construction of asset; it could also refer to the design of a service.

An interdependency may be of use during an infrastructure elements operation, for example a by-product from operation may be usable as an input to another infrastructure element. It may be beneficial to acknowledge this and discuss it during the planning stages, but the impact of the interdependency, its benefit or risk, are felt during operation. Hence, this characteristic aims to capture the phase in which the impact is felt. Other interdependencies may provide benefits during the planning stage (e.g. shared design teams) or during construction (e.g. shared personnel or recycled construction materials).

\section{Scale of Impact}

In this context the 'Scale of Impact' refers to the geographical area over which the primary Result or impacts of the identified interdependency are felt. This ranges from Local (villages, towns, districts etc.) and Regional (a collection of districts, counties, etc.) to National and International. While any interdependency will have an impact on the crossing, the results of some interdependencies may be limited to the LTC Project itself, hence this can also be highlighted in the characterisation.

\section{PESTE Evaluation}

Once characterised, the interdependencies are evaluated in terms of their Political, Environmental, Social, Technological and Economic value. In many cases the information required to make this sort of assessment is not available. As such, the process looks to assess whether the value is thought to be broadly positive $(\underline{ \pm})$, negative $(\Xi)$, neutral $(\underline{I})$ or unknown ( $\underline{?})$.

\section{Type: Inter- and Intra- System Interdependencies}

In discussing cascade risks (that is one event causing or influencing another) as a potential output of interdependency, Frontier Economic ${ }^{35}$ identifies two broad 'types' of interdependency: inter-system and intra-system. However, their definition of a system, and where the system boundary is drawn very wide. For example, they describe inter-system risk with the example of the energy system affecting the communications network. Intra-system risk is described with the example of one part of the road network affecting another part. The first example implies that the system is synonymous with the sector. This is reinforced by their use of the terms in practice. The interdependency between the A14 and Felixstowe port are described as an intra-system interdependency as they both exist within the transport sector.

In the following study the interdependencies are considered sector by sector. Therefore, as the LTC is perceived as a transport project, only those interdependencies with other transport infrastructure elements are intra-system interdependencies, the rest and inter-system interdependencies. 


\section{Interdependency Identification}

The Interdependency Planning and Management Framework's associated Matrix-Based Tool for the initial interdependency identification has been applied based on a desk study of the existing literature on the Lower Thames Crossing and surrounding areas.

In order to simplify this process and structure the identified infrastructure interdependencies a generic sector-level interdependency matrix is used, as shown in Figure 16.

This application has focused on the identfication of primary or first-order interdepdnecies. These are direct interdepdendencies between the LTC and other infrastructure elements. It has not sought to identify second-order interdepdnencies between multiple infrastructure elements. These chains of dependency can be potentially very important, and are also the most often overlooked. However, it was felt that with the LTC project at an ealry stage of development (with no fixed location) the level of granulairty would be too low to be of use.

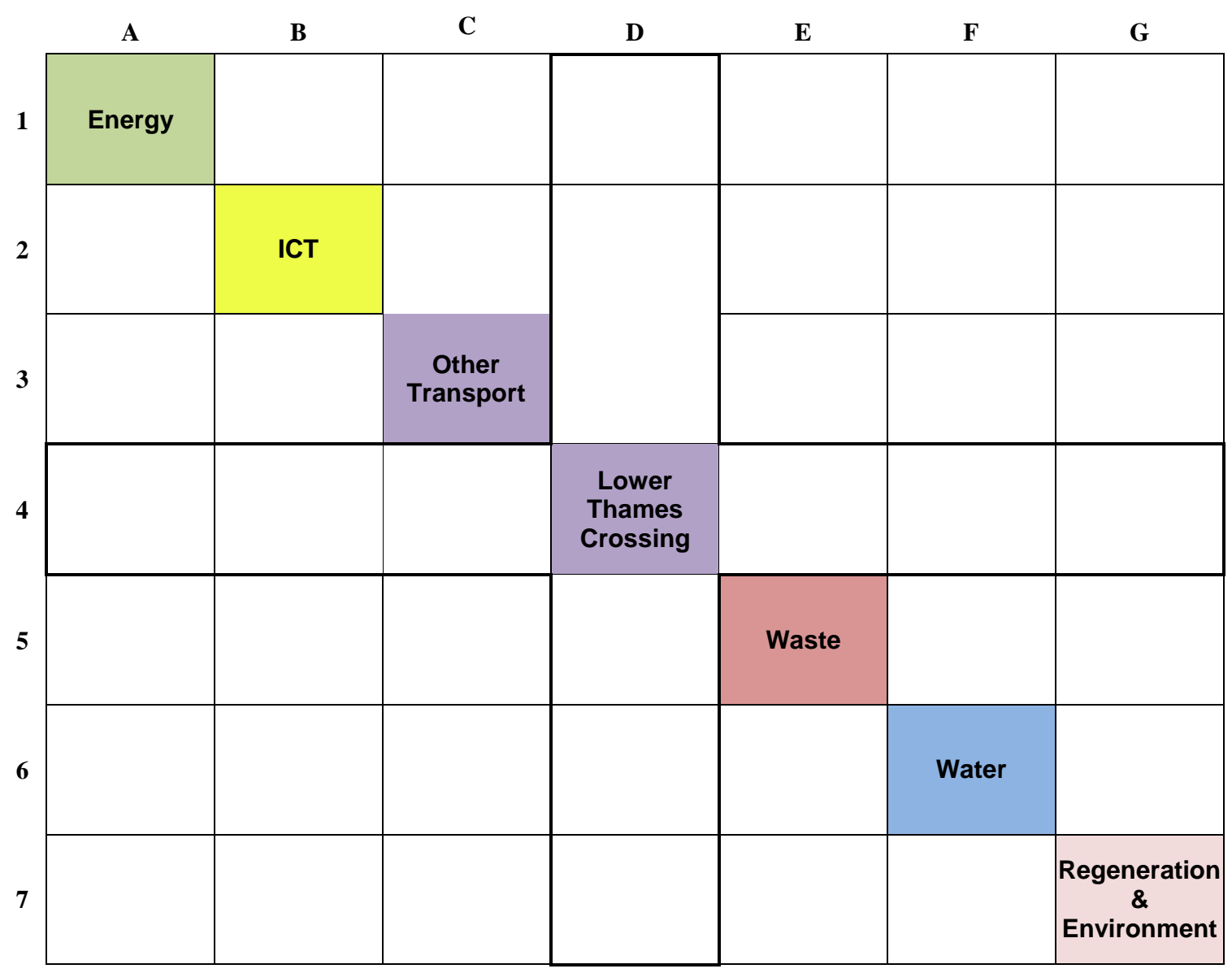

Figure 16 - Generic Sector-Level Infrastructure Interdependency Matrix

The collective output is shown in Appendix B, while the following sections look at the interdependencies between the Lower Thames Crossing and existing and proposed infrastructure elements in each of the main infrastructure sectors. 


\section{Energy Infrastructure \& the Lower Thames Crossing}

Energy infrastructure refers to the resources, assets, services and systems related to the harvesting, distribution and provision of energy. This could include everything from fossil fuel power stations to gas storage facilities and hydrogen distribution networks. There is some potential for overlap with the water infrastructure sector, for example in relation to tidal power. This may be particularly relevant for a river crossing.

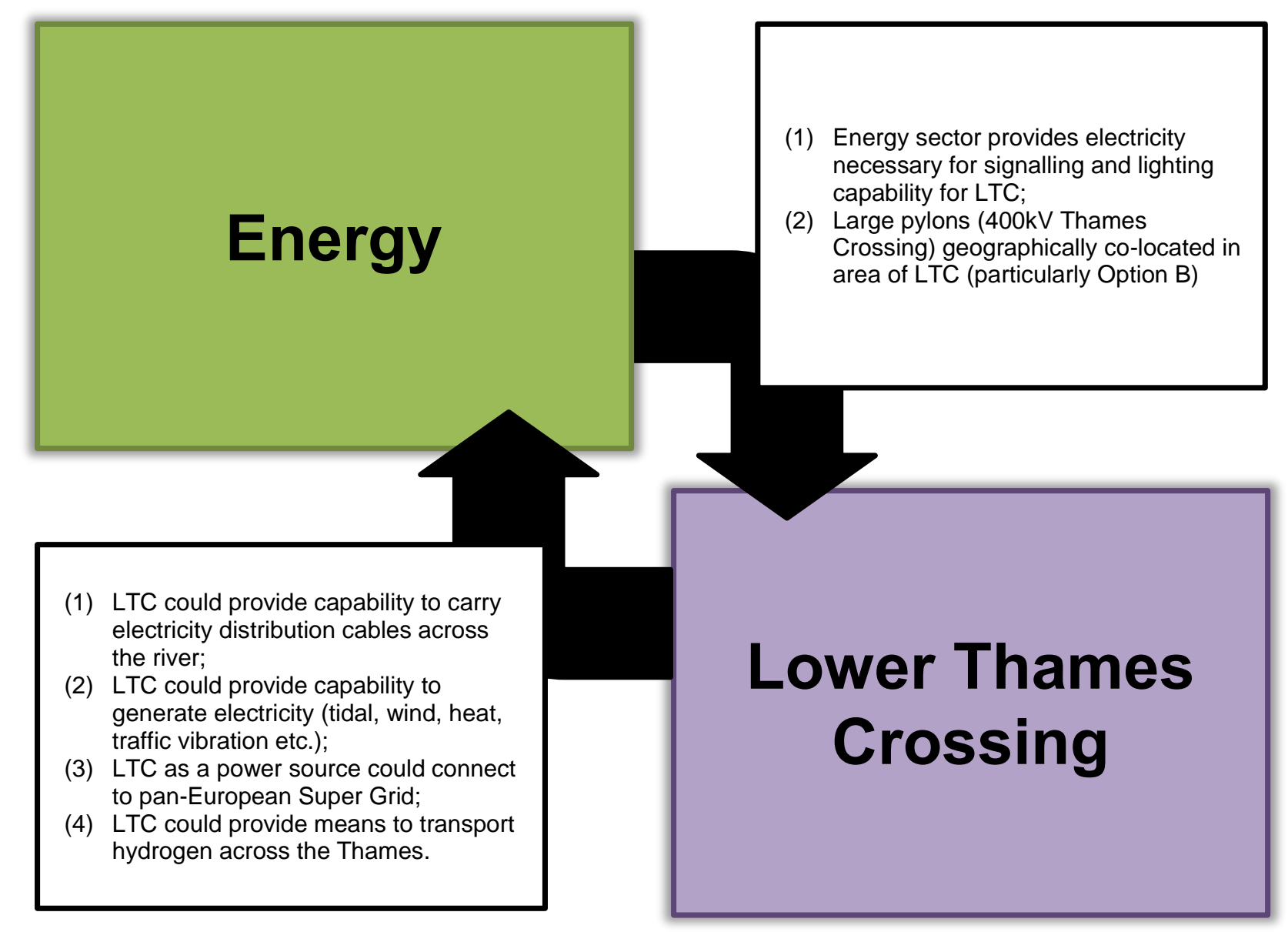

Figure 17 - Energy Infrastructure \& LTC Interdependencies

As Figure 17 shows, some of the identified interdependencies are necessary for the LTC to function (e.g. power for lighting), while others are potential opportunities (e.g. to generate electricity) or hazards (e.g. large pylons). This classification is further discussed in the following chapter (and Table 6). These are relatively general interdependencies; more specific interdependencies may be identified by consulting with a broad range of stakeholders with an open-systems perspective. 


\section{ICT Infrastructure \& the Lower Thames Crossing}

Figure 18 shows the identified interdependencies between information and communications technology sector infrastructure elements and the proposed LTC.

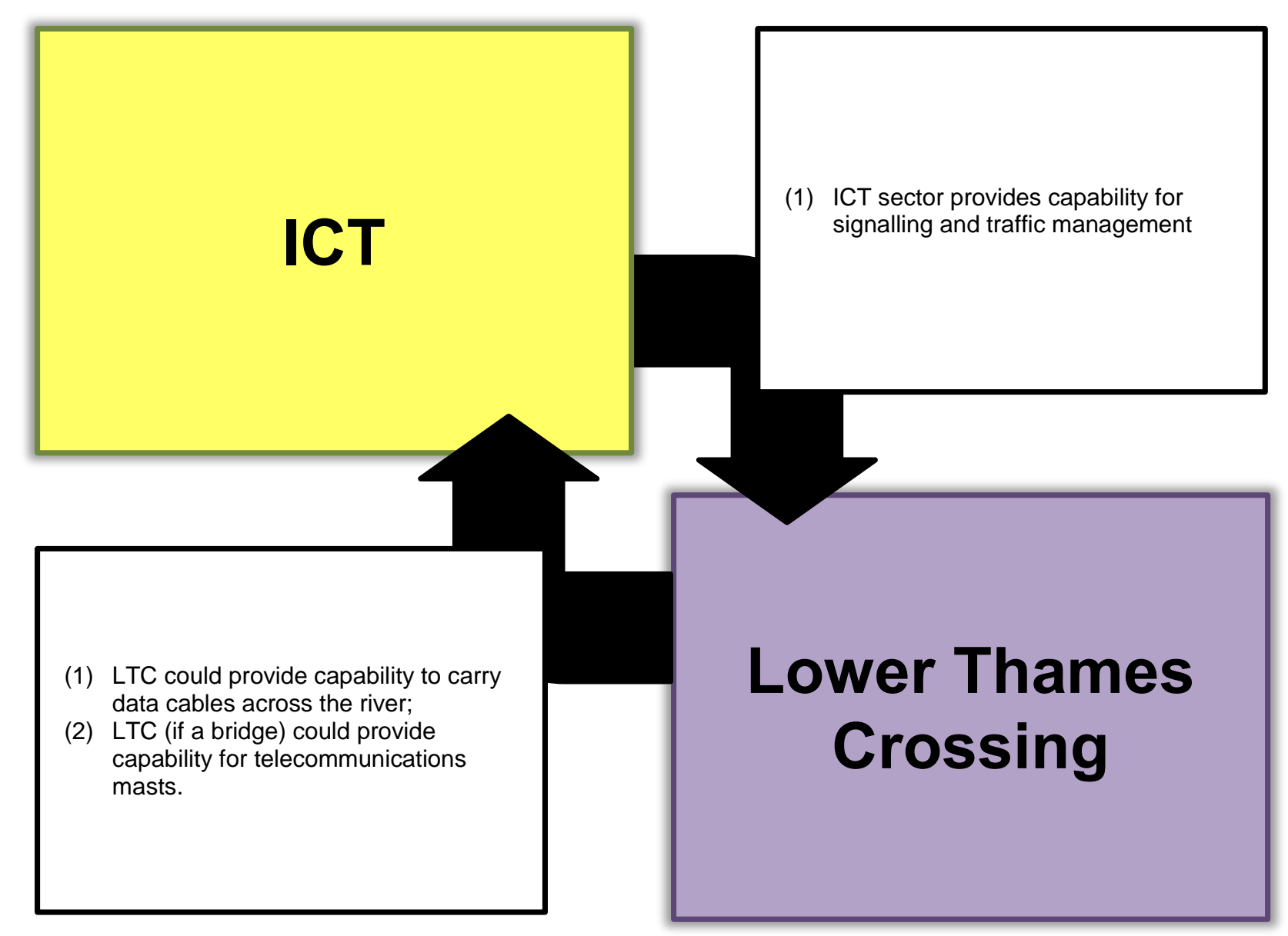

Figure 18 - ICT Infrastructure \& LTC Interdependencies

As with the previous example it is clear that some aspects of the LTC's operation are functionally dependent on services and assets provided by the ICT sector, but there are also opportunities which could arise for the ICT sector from the construction of the LTC. Particular scenarios, dependent on the location choice, could affect the feasibility and desire for leveraging the benefit of these interdependencies. For example, BT Openworld have discussed installing the UK's fastest broadband network in the Ebbsfleet Valley regeneration area, very close to crossing Option B. The LTC could provide an opportunity to carry this network over the Thames. If chosen, the two projects may have other positive and negative impacts on each other which would need to be considered once more information was available.

\section{Transport Infrastructure \& the Lower Thames Crossing}

Perhaps unsurprisingly, the most interdependencies which can be identified from the existing documentation arise between the LTC and other transport infrastructure elements (e.g. roads, 
railways, public transport services, etc.). This is to be expected given the nature of the physical asset identified as the solution to the perceived congestion and capacity problem, as it has to integrate with the existing crossing and road networks. While it is possible that the visibility of transport sector interdependencies is an artefact of the project boundary and its ownership as a transport problem, there is no evidence that this is necessarily the case. Figure 19 captures these interdependencies.

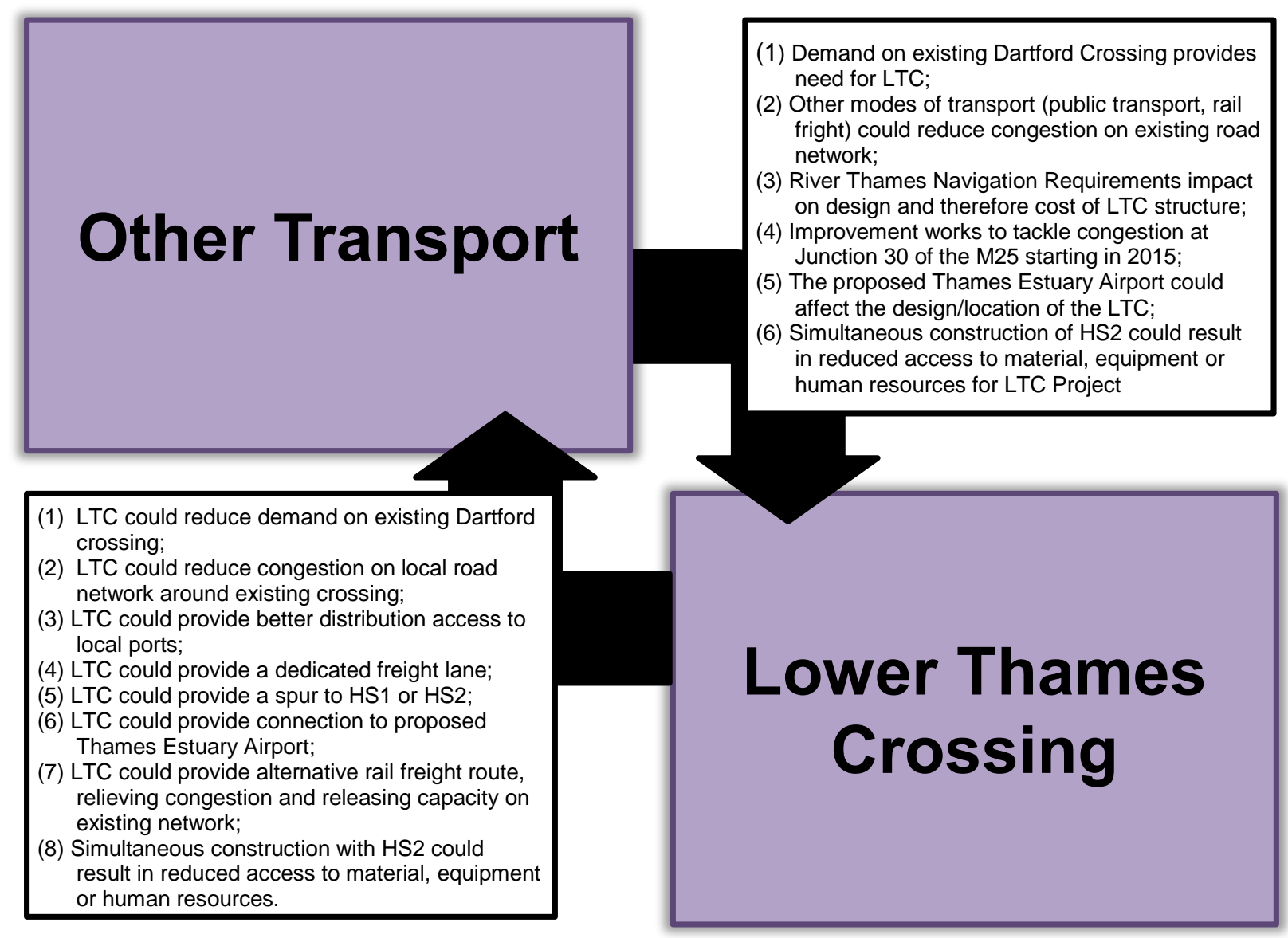

Figure 19 - Other Transport Infrastructure \& LTC Interdependencies

Some of the interdependencies here are at the core of the project's perceived problem and suggested solution. Congestion at the existing Dartford Crossing provides a great deal of the motivation for a Lower Thames Crossing, in response the Lower Thames Crossing provides a solution to reduce that congestion through the provision of additional crossing capacity.

\section{Waste Infrastructure \& the Lower Thames Crossing}

There were no interdependencies between waste infrastructure elements and the proposed LTC explicitly discussed in the reviewed documents, but it is possible to identify some potential interdependency opportunities from the wider literature which may become more relevant as the project develops. For example, the waste sector could provide materials for the road base or surface, and reciprocally the LTC could provide a means to 'dispose' of this material by 
putting it to use. This might be in the form of recycled aggregate, building materials or even car tyres ${ }^{36}$. These interdependencies are shown graphically in Figure 20

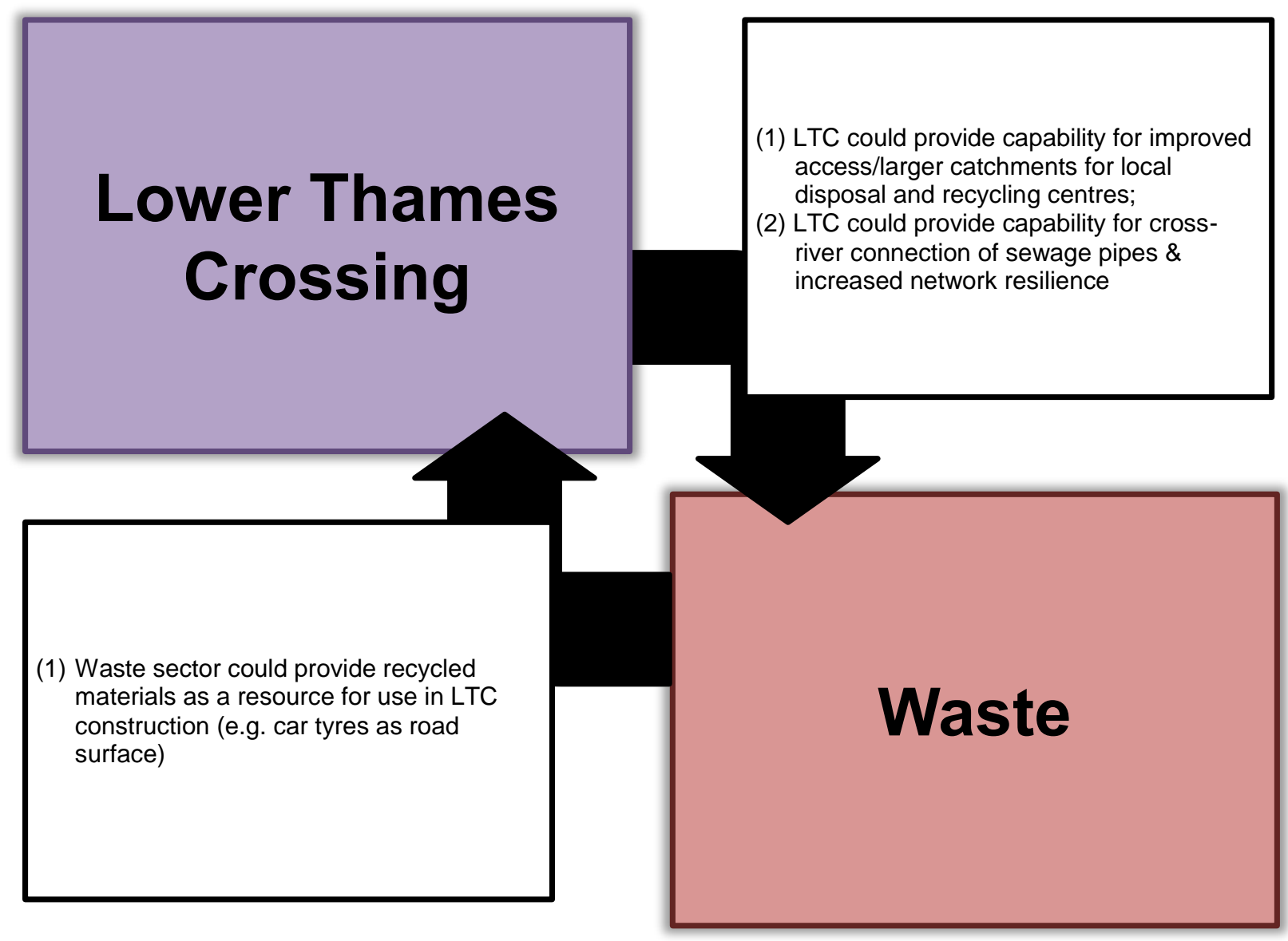

Figure 20 - Waste Infrastructure \& LTC Interdependencies

There may be more interdependencies with waste infrastructure assets and services that become more apparent as the location and design of the bridge are refined, but they should also be taken into account during the refining process. There of course may be issues with these interdependency opportunities which make them untenable or, for example, raise the risk profile to an unacceptable level. This evaluation will be discussed in the following chapter.

\section{Water Infrastructure \& the Lower Thames Crossing}

As with transport infrastructure, it is perhaps unsurprising that a river crossing has a number of necessary interdependencies with the water sector, as well as additional interdependency opportunities and risks. As recorded in Figure 21 while the LTC may provide some opportunities for generally beneficial interdependencies, the two also present many challenges and risks through their interdependencies, mainly a result of sharing the same geographical location.

\footnotetext{
${ }^{36}$ As implemented on the A90 between Perth and Dundee: South Lanarkshie Council, 2013, 'Innovative approach to resurfacing road' published on $14^{\text {th }}$ January 2013 [Online: http://www.southlanarkshire.gov.uk/press/article/686/innovative_approach_to_resurfacing_road], Accessed: 11th July 2013
} 


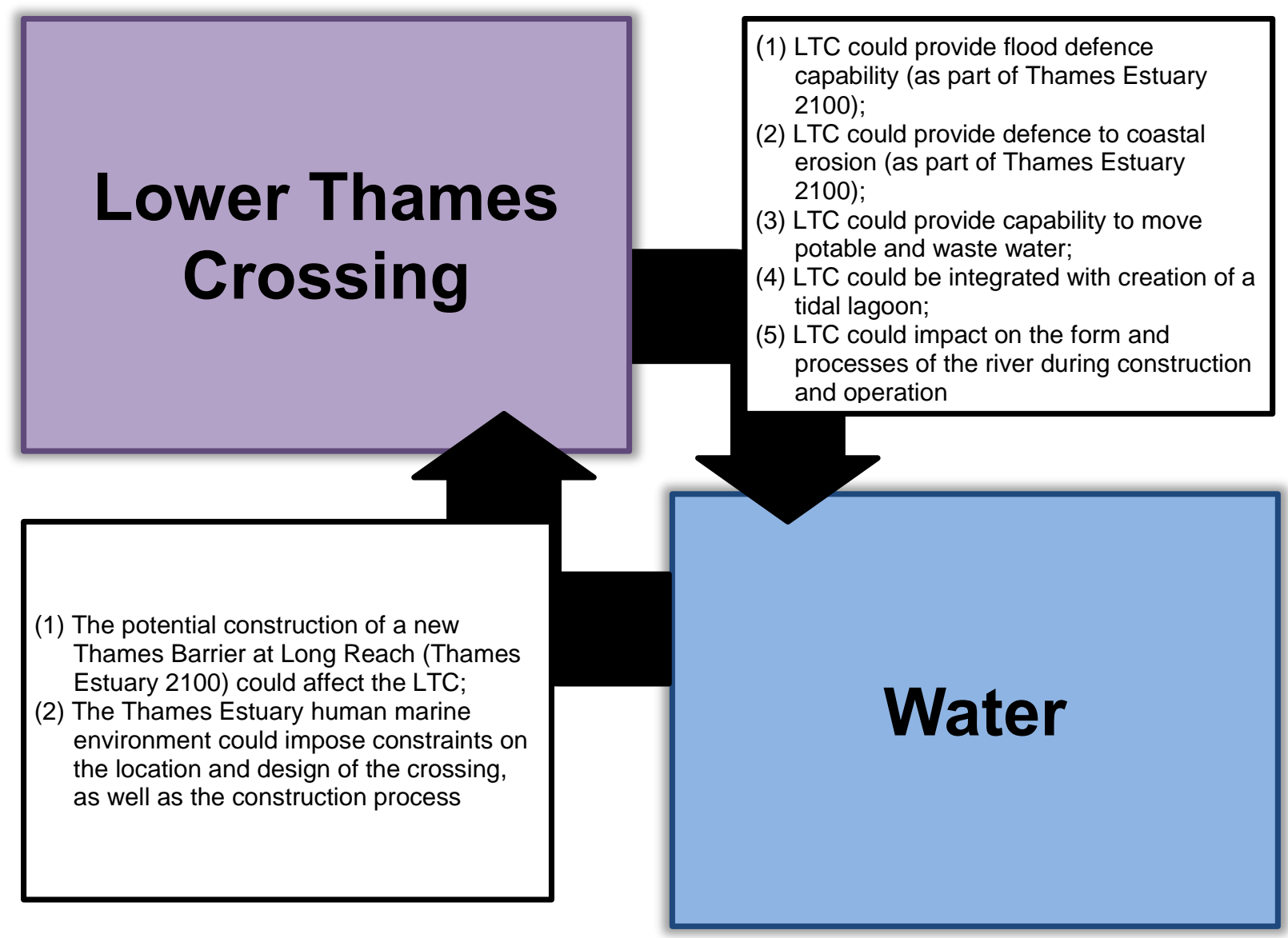

Figure 21 - Water Infrastructure \& LTC Interdependencies

\section{The Wider Community and Environment \& the Lower Thames Crossing}

The final group of interdependencies considered here concern social and environmental infrastructure specifically in relation to the proposed regeneration schemes in the region around the potential LTC sites. While a very broad area, there is a significant degree of overlap and interaction between the issues.

While Figure 22 identifies a large number of possible interdependencies between the LTC, the local natural and social environment, and regeneration project, it is not an exhaustive list. There are likely to be many more opportunities and risks presented by interdependencies apparent to those who live in the areas and those who are involved in the regeneration projects. These will hopefully come to light during the July 2013 consultation exercise, and yet more may become apparent once a location has been decided.

In general, the LTC's impact on the environment and biodiversity of the proposed sites has been considered, for example, as detailed in Aecom report. The purpose of acknowledging these necessary and potential interdependencies (and their impacts on the natural environment) in this study is therefore not to replicate an environmental impact assessment. Nevertheless, some examples of such interdependencies have been included to illustrate how these may fit in with the tool. 


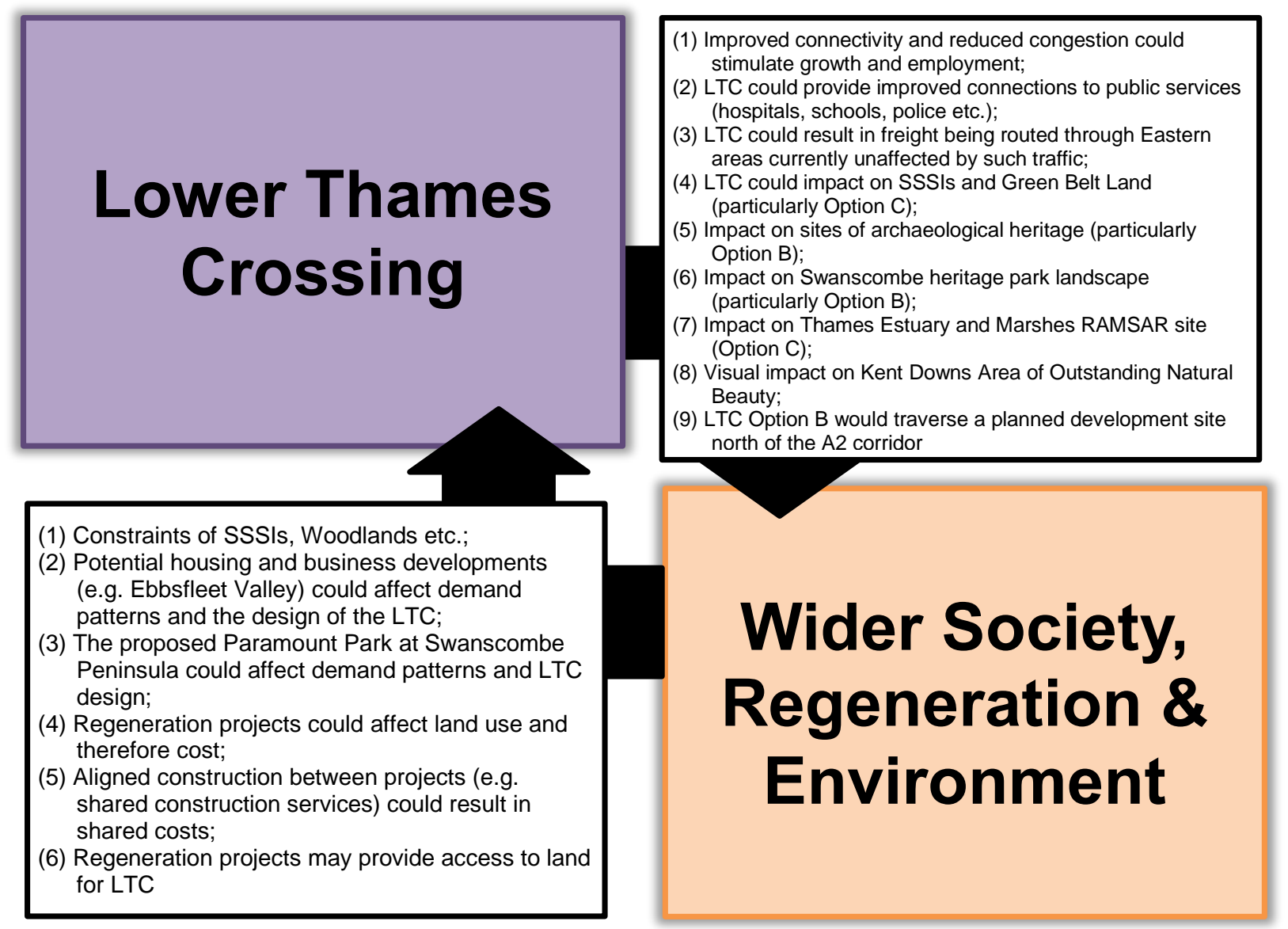

Figure 22 - Wider Society, Regeneration and Environment Infrastructure \& LTC Interdependencies

\section{Conclusions}

This chapter identified and presented the main interdependencies between the Lower Thames Crossing and other infrastructure elements (assets, services, resources and systems) across a broad division of infrastructure sectors.

While the project boundary is drawn around the transport sector, it is clear that there are opportunities and risks presented by necessary and potential interdependencies with elements that exist beyond this.

The list may not be exhaustive. It may be advantageous to seek further interdependencies with key stakeholders, as identified earlier in this report.

The following chapter looks to further characterise and evaluating these interdependencies. 


\section{Interdependency Evaluation}

This chapter records the output of the third phase of the method, the characterisation and evaluation of the interdependencies identified and discussed in the previous chapter. The interdependencies are characterised as per the schema set out in the method. The tables on the following pages captured this assessment.

As with the previous chapter the interdependencies are addressed on a per-sector basis, thus identifying inter-system and intra-system interdependencies. The first column identifies the primary nature of the interdependency while the second assess whether it is necessary for normal operation (of the LTC) or is optional. The third and fourth columns look at whether the interdependencies primarily provide additional opportunity or hazards, and the phase of the project lifecycle in which they are most relevant. The fifth column assesses the geographical scale of the impact of the interdependency. The penultimate column records a high-level evaluation of the interdependency using the PESTE framework. It looks at whether the interdependency is broadly positive, negative or neutral to each of the PESTE factors. It also explicitly captures uncertainty over the position. The final column in each of the tables records the main stakeholders of relevance to the interdependency.

The tables do not explicitly capture the evidence for or against the interdependency, or whether they are supported by policy or need. They also do not provide a monetary or quantitative assessment. These are both options for further work.

\section{Energy Infrastructure \& the Lower Thames Crossing}

The first table below (Table 6) characterises and attempts a high level evaluation of the interdependencies recognised between energy sector infrastructure and the Lower Thames Crossing project. These interdependencies are therefore inter-system interdependencies. Many potential interdependencies have been identified which could provide additional benefits, during the crossings operation to the local and regional surrounding areas. Most of these examples would require collaboration between the crossing operator, utilities companies and distribution companies, as well as the necessary governing bodies.

\section{ICT Infrastructure \& the Lower Thames Crossing}

As discussed in the previous chapter, two potential interdependency opportunities have been identified as a result of geographically co-locating ICT assets with the LTC asset. These would be of benefit during the crossing's operation and would impact on the local and potentially regional areas. These would see the crossing used to provide additional communications capabilities either by carrying data cables across the river, or (if a bridge) providing communications masts. Although none of the surrounding areas are known to have poor telecommunications connectivity, it could provide a simple and inexpensive means of improving capabilities. These interdependencies are therefore generally thought to have a positive impact in terms of the PESTE factors, delivering additional capacity to services with less cost or impact of a stand-alone installation. 


\section{Transport Infrastructure \& the Lower Thames Crossing}

This would constitute intra-system interdependencies using the Frontier Economics classification. The majority of the interdependencies are characterised in Table 8 as Physical interdependencies. This is because they involve a physical transfer of people, goods or vehicles. Some of these are necessary, such as the interdependency with the surrounding road network, while others provide opportunities for additional benefits, or in some cases the potential for new hazards which would affect the operation of the crossing. Most of the impacts are restricted to the local and regional areas around the crossing, but the improvement of access to local ports could have an international impact.

As with the inter-system interdependencies it can be very hard to evaluate the interdependencies captured under this heading. If the interdependencies reduce congestion and further improve connectivity and journey time reliability then they generally have a positive economic value and political value, these being key goals for the LTC project. Their social and environmental values are far harder to judge without extensive stakeholder consultation.

\section{Waste Infrastructure \& the Lower Thames Crossing}

The characterisation of the waste infrastructure interdependencies shown in Table 9 indicate all three of those identified could provide additional benefits to the surrounding local and regional areas. The use of recycled material during the construction phase could be of environmental and social value.

\section{Water Infrastructure \& the Lower Thames Crossing}

As a river crossing, the LTC could have interdependencies with the existing water infrastructure, or provide the opportunity to become an important part of water infrastructure (Table 10). These interdependencies tend to have strong positive and negative environmental values.

\section{The Wider Community and Environment \& the Lower Thames Crossing}

There are any necessary and potential inter-system interdependencies between the Lower Thames Crossing project, the wider community and the environment, as characterised and evaluated in Table 11. The LTC has the potential to generate interdependencies of significant negative value in this area during construction and operation. The developments and regeneration in the region, at a general level, could also present many complications to the LTC project through their interdependencies with one another, both during construction and operation. In particular the way in which they could change the demand patterns on the crossing. There are also opportunities for interdependencies of positive value, particularly with regard to integrating and aligning elements of the LTC's construction with other construction and regeneration projects in the region. 
Table 6 - Energy Infrastructure \& LTC Interdependencies Characterisation and Evaluation

\begin{tabular}{|c|c|c|c|c|c|c|c|c|c|c|c|c|c|c|c|c|c|c|c|c|c|c|c|c|c|}
\hline \multirow[b]{2}{*}{ Interdependency } & \multicolumn{5}{|c|}{ Nature } & \multicolumn{2}{|c|}{ Necessity } & \multicolumn{2}{|c|}{ Result } & \multicolumn{5}{|c|}{ Chronology } & \multicolumn{5}{|c|}{ Scale } & \multicolumn{5}{|c|}{ PESTE } & \multirow[b]{2}{*}{$\begin{array}{c}\text { Relevant } \\
\text { Stakeholders }\end{array}$} \\
\hline & 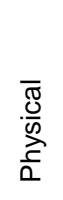 & $\frac{\bar{\pi}}{\overline{0}}$ & 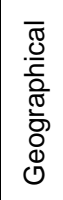 & 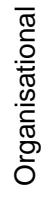 & 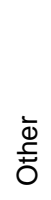 & 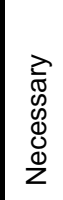 & 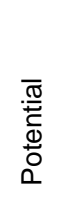 & $\begin{array}{l}\frac{1}{0} \\
\stackrel{\overline{0}}{\Phi} \\
\infty\end{array}$ & 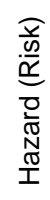 & 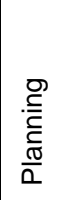 & 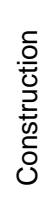 & $\begin{array}{l}\text { 음 } \\
\frac{0}{\pi} \overline{0} \\
\frac{0}{0}\end{array}$ & 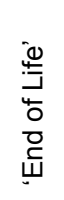 & 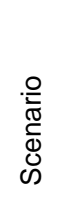 & $\begin{array}{l}\frac{\tilde{d}}{0} \\
\frac{0}{2} \\
\frac{0}{2}\end{array}$ & 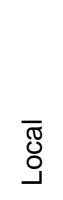 & 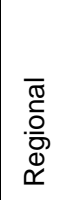 & $\begin{array}{l}\overline{\widetilde{\sigma}} \\
\stackrel{0}{0} \\
\stackrel{0}{\bar{\pi}} \\
z\end{array}$ & 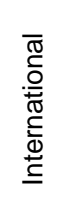 & 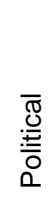 & 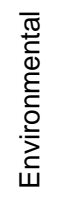 & $\begin{array}{l}\overline{\bar{\pi}} \\
\bar{\delta} \\
\infty\end{array}$ & 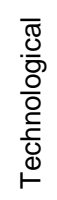 & 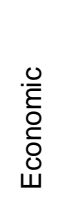 & \\
\hline $\begin{array}{l}\text { Energy sector provides electricity necessary for } \\
\text { signalling and lighting capability for LTC }\end{array}$ & & & & & & & & & & & & & & & & & & & & I & - & + & 1 & 1 & $\begin{array}{l}\text { Utilities Companies, LTC } \\
\text { Operator }\end{array}$ \\
\hline $\begin{array}{l}\text { Large pylons (400kV Thames Crossing) } \\
\text { geographically co-located in area of LTC } \\
\text { (particularly Option B) }\end{array}$ & & & & & & & & & & & & & & & & & & & & & & & - & - & $\begin{array}{l}\text { Distribution Companies, } \\
\text { Nat. Grid, LTC } \\
\text { Construction Companies }\end{array}$ \\
\hline $\begin{array}{l}\text { LTC could provide capability to carry electricity } \\
\text { distribution cables across the river }\end{array}$ & & & & & & & & & & & & & & & & & & & & + & + & + & + & + & $\begin{array}{l}\text { LTC Operator, } \\
\text { Distribution Companies, } \\
\text { Nat. Grid }\end{array}$ \\
\hline $\begin{array}{l}\text { LTC could provide capability to generate } \\
\text { electricity (tidal, wind, heat, traffic vibration etc.) }\end{array}$ & & & & & & & & & & & & & & & & & & & & + & + & + & $?$ & + & $\begin{array}{l}\text { LTC Operator, Utilities } \\
\text { Companies }\end{array}$ \\
\hline $\begin{array}{l}\text { LTC as a power source could connect to pan- } \\
\text { European Super Grid }\end{array}$ & & & & & & & & & & & & & & & & & & & & + & + & + & $?$ & + & \begin{tabular}{|l} 
LTC Operator, \\
Distribution Companies, \\
Nat. Grid
\end{tabular} \\
\hline $\begin{array}{l}\text { LTC could provide means to transport hydrogen } \\
\text { across the Thames }\end{array}$ & & & & & & & & & & & & & & & & & & & & $?$ & + & + & $?$ & $?$ & $\begin{array}{l}\text { LTC Operator, } \\
\text { Distribution Companies }\end{array}$ \\
\hline
\end{tabular}

Table 7 - ICT Infrastructure \& LTC Interdependencies Characterisation and Evaluation

\begin{tabular}{|c|c|c|c|c|c|c|c|c|c|c|c|c|c|c|c|c|c|c|c|c|c|c|c|c|c|}
\hline \multirow[b]{2}{*}{ Interdependency } & \multicolumn{5}{|c|}{ Nature } & \multicolumn{2}{|c|}{ Necessity } & \multicolumn{2}{|c|}{ Result } & \multicolumn{5}{|c|}{ Chronology } & \multicolumn{5}{|c|}{ Scale } & \multicolumn{5}{|c|}{ PESTE } & \multirow[b]{2}{*}{$\begin{array}{l}\text { Relevant } \\
\text { Stakeholders }\end{array}$} \\
\hline & $\begin{array}{l}\overline{\mathbb{N}} \\
\frac{\mathbb{N}}{\mathbb{N}} \\
\stackrel{\vec{D}}{\alpha}\end{array}$ & $\begin{array}{l}\overline{\widetilde{\pi}} \\
. \overline{0} \\
\overline{0}\end{array}$ & 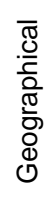 & 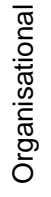 & $\stackrel{\bar{\Phi}}{\overline{ \pm}}$ & 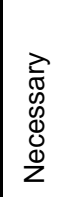 & $\begin{array}{l}\stackrel{\bar{\sigma}}{=} \\
\stackrel{ \pm}{\Phi} \\
0 \\
0\end{array}$ & 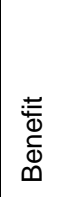 & $\begin{array}{l}\widehat{x} \\
\underline{\underline{D}} \\
\mathbb{N} \\
\frac{0}{0} \\
\mathbb{N} \\
\mathbb{N} \\
\mathbb{T}\end{array}$ & 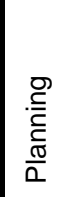 & 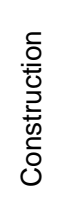 & 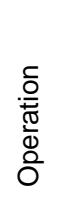 & 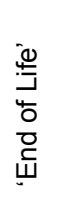 & 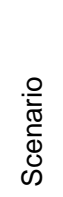 & 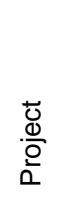 & ర్త్ర & $\begin{array}{l}\overline{\widetilde{\varpi}} \\
\widetilde{0} \\
\stackrel{0}{\mathbb{D}} \\
\widetilde{\simeq}\end{array}$ & 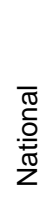 & 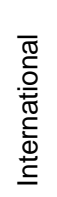 & 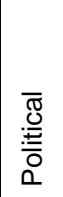 & 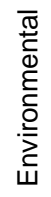 & $\begin{array}{l}\overline{\widetilde{\pi}} \\
\bar{O} \\
\text { க) }\end{array}$ & 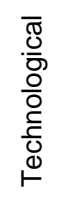 & 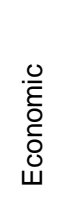 & \\
\hline $\begin{array}{l}\text { ICT sector provides capability for signalling and } \\
\text { traffic management }\end{array}$ & & & & & & & & & & & & & & & & & & & & I & + & + & I & + & $\begin{array}{l}\text { ICT Providers, LTC } \\
\text { Operator }\end{array}$ \\
\hline $\begin{array}{l}\text { LTC could provide capability to carry data } \\
\text { cables across the river }\end{array}$ & & & & & & & & & & & & & & & & & & & & + & + & + & I & + & $\begin{array}{l}\text { ICT Providers, LTC } \\
\text { Operator }\end{array}$ \\
\hline $\begin{array}{l}\text { LTC (if a bridge) could provide capability for } \\
\text { telecommunications masts. }\end{array}$ & & & & & & & & & & & & & & & & & & & & $?$ & + & + & I & + & $\begin{array}{l}\text { LTC Providers, LTC } \\
\text { Operator }\end{array}$ \\
\hline
\end{tabular}


Table 8 - Other Transport Infrastructure \& LTC Interdependencies Characterisation and Evaluation

\begin{tabular}{|c|c|c|c|c|c|c|c|c|c|c|c|c|c|c|c|c|c|c|c|c|c|c|c|c|c|}
\hline \multirow[b]{2}{*}{ Interdependency } & \multicolumn{5}{|c|}{ Nature } & \multicolumn{2}{|c|}{ Necessity } & \multicolumn{2}{|c|}{ Result } & \multicolumn{5}{|c|}{ Chronology } & \multicolumn{5}{|c|}{ Scale } & \multicolumn{5}{|c|}{ PESTE } & \multirow[b]{2}{*}{$\begin{array}{c}\text { Relevant } \\
\text { Stakeholders }\end{array}$} \\
\hline & 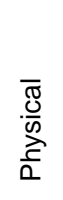 & $\frac{\bar{\pi}}{\stackrel{0}{\frac{\pi}{0}}}$ & $\begin{array}{l}\overline{\widetilde{J}} \\
\frac{0}{\bar{E}} \\
\overline{0} \\
\overline{0} \\
\overline{0} \\
\mathbb{0} \\
\widetilde{0}\end{array}$ & 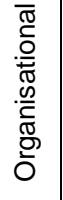 & $\begin{array}{l}\bar{\Phi} \\
\stackrel{ \pm}{ \pm}\end{array}$ & $\begin{array}{l}\text { 离 } \\
\text { d } \\
\mathbb{d} \\
\mathbb{d} \\
z\end{array}$ & 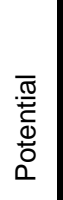 & 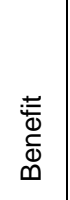 & 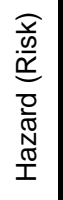 & 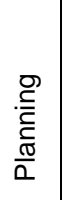 & 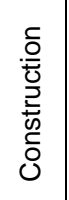 & 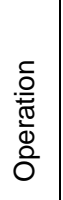 & 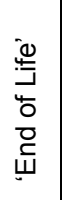 & 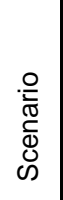 & $\begin{array}{l}\frac{1}{0} \\
\frac{\mathscr{Q}}{2} \\
\dot{0}\end{array}$ & ত্రু & 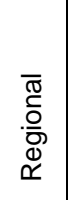 & $\begin{array}{l}\bar{\pi} \\
\frac{0}{0} \\
\frac{0}{\pi} \\
Z\end{array}$ & 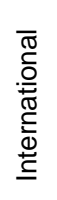 & 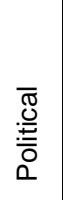 & 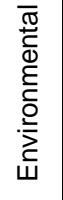 & $\begin{array}{l}\frac{\bar{\sigma}}{\bar{\delta}} \\
\dot{\infty}\end{array}$ & 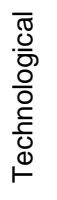 & 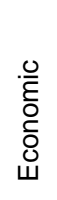 & \\
\hline $\begin{array}{l}\text { Demand on existing Dartford Crossing provides } \\
\text { need for LTC }\end{array}$ & & & & & & & & & & & & & & & & & & & & $?$ & $?$ & $?$ & $?$ & $?$ & \begin{tabular}{|l|} 
LTC Planners, \\
Construction and \\
Operators, DfT, HA
\end{tabular} \\
\hline $\begin{array}{l}\text { Other modes of transport (public transport, rail } \\
\text { fright) could reduce congestion on existing road } \\
\text { network }\end{array}$ & & & & & & & & & & & & & & & & & & & & + & + & + & l & $?$ & $\begin{array}{l}\text { Public Transport } \\
\text { Operators, DfT, HA }\end{array}$ \\
\hline $\begin{array}{l}\text { River Thames Navigation Requirements impact } \\
\text { on design and therefore cost of LTC structure }\end{array}$ & & & & & & & & & & & & & & & & & & & & $?$ & $?$ & $?$ & $?$ & $?$ & $\begin{array}{l}\text { LTC Planners, } \\
\text { Construction and DfT }\end{array}$ \\
\hline $\begin{array}{l}\text { Improvement works to tackle congestion at } \\
\text { Junction } 30 \text { of the M25 starting in } 2015\end{array}$ & & & & & & & & & & & & & & & & & & & & + & $?$ & + & l & + & DfT, HA \\
\hline $\begin{array}{l}\text { The proposed Thames Estuary Airport could } \\
\text { affect the design/location of the LTC }\end{array}$ & & & & & & & & & & & & & & & & & & & & $?$ & ? & $?$ & $?$ & $?$ & \begin{tabular}{|l|} 
TfL, GLA, LTC \\
Operators, DfT, HA, \\
Airport Operators
\end{tabular} \\
\hline $\begin{array}{l}\text { Simultaneous construction of HS2 could result } \\
\text { in reduced access to material, equipment or } \\
\text { human resources for LTC Project }\end{array}$ & & & & & & & & & & & & & & & & & & & & & $?$ & $?$ & ? & $?$ & $\begin{array}{l}\text { HS2 Ltd., LTC } \\
\text { Construction, DfT }\end{array}$ \\
\hline $\begin{array}{l}\text { LTC could reduce demand on existing Dartford } \\
\text { crossing }\end{array}$ & & & & & & & & & & & & & & & & & & & & + & $?$ & $?$ & l & + & $\begin{array}{l}\text { DfT, HA, Dartford } \\
\text { Operators }\end{array}$ \\
\hline $\begin{array}{l}\text { LTC could reduce congestion on local road } \\
\text { network around existing crossing }\end{array}$ & & & & & & & & & & & & & & & & & & & & + & $?$ & $?$ & l & + & $\begin{array}{l}\text { DfT, HA, Local Council } \\
\text { and Communities }\end{array}$ \\
\hline $\begin{array}{l}\text { LTC could provide better distribution access to } \\
\text { local ports }\end{array}$ & & & & & & & & & & & & & & & & & & & & + & $?$ & $?$ & 1 & + & $\begin{array}{l}\text { National and } \\
\text { International Port } \\
\text { Operators and Haulage } \\
\text { Companies }\end{array}$ \\
\hline LTC could provide a dedicated freight lane & & & & & & & & & & & & & & & & & & & & $?$ & $?$ & $?$ & 1 & $?$ & $\begin{array}{l}\text { DfT, HA, Haulage } \\
\text { Companies, Commuters }\end{array}$ \\
\hline LTC could provide a spur to HS1 or HS2 & & & & & & & & & & & & & & & & & & & & $?$ & $?$ & $?$ & 1 & $?$ & \begin{tabular}{|l|} 
DfT, LTC Planners, \\
Network Rail, Rail \\
Operators \\
\end{tabular} \\
\hline $\begin{array}{l}\text { LTC could provide connection to proposed } \\
\text { Thames Estuary Airport }\end{array}$ & & & & & & & & & & & & & & & & & & & & $?$ & $?$ & $?$ & $?$ & $?$ & $\begin{array}{l}\text { TfL, GLA, LTC } \\
\text { Operators, DfT, Airport } \\
\text { Operator }\end{array}$ \\
\hline $\begin{array}{l}\text { LTC could provide alternative rail freight route, } \\
\text { relieving congestion and releasing capacity on } \\
\text { existing network }\end{array}$ & & & & & & & & & & & & & & & & & & & & $?$ & + & - & l & $?$ & $\begin{array}{l}\text { DfT, Network Rail, Rail } \\
\text { Operators, Local Industry }\end{array}$ \\
\hline $\begin{array}{l}\text { Simultaneous construction with HS2 could result } \\
\text { in reduced access to material, equipment or } \\
\text { human resources. }\end{array}$ & & & & & & & & & & & & & & & & & & & & - & $?$ & $?$ & $?$ & $?$ & $\begin{array}{l}\text { HS2 Ltd., LTC } \\
\text { Construction, DfT }\end{array}$ \\
\hline
\end{tabular}

* Ruled out by 2009 Parsons Brinkerhoff Study 
Table 9 - Waste Infrastructure \& LTC Interdependencies Characterisation and Evaluation

\begin{tabular}{|c|c|c|c|c|c|c|c|c|c|c|c|c|c|c|c|c|c|c|c|c|c|c|c|c|c|}
\hline \multirow[b]{2}{*}{ Interdependency } & \multicolumn{5}{|c|}{ Nature } & \multicolumn{2}{|c|}{ Necessity } & \multicolumn{2}{|c|}{ Result } & \multicolumn{5}{|c|}{ Chronology } & \multicolumn{5}{|c|}{ Scale } & \multicolumn{5}{|c|}{ PESTE } & \multirow[b]{2}{*}{$\begin{array}{c}\text { Relevant } \\
\text { Stakeholders }\end{array}$} \\
\hline & $\begin{array}{l}\overline{\mathbb{N}} \\
\frac{\mathscr{N}}{\sqrt[N]{ }} \\
\overline{\mathbb{a}}\end{array}$ & $\frac{\bar{\pi}}{\stackrel{\bar{T}}{0}}$ & 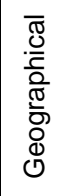 & 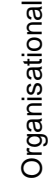 & $\begin{array}{l}\bar{\Phi} \\
\stackrel{ \pm}{ \pm}\end{array}$ & 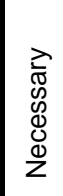 & 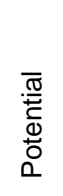 & 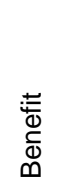 & 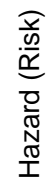 & 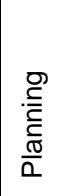 & 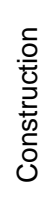 & $\begin{array}{l}\frac{.}{0} \\
\frac{0}{0} \\
\frac{0}{0} \\
0\end{array}$ & 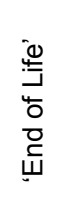 & $\begin{array}{l}\text { 을 } \\
\frac{0}{d} \\
\text { d } \\
\text { ஸ }\end{array}$ & $\begin{array}{l}\frac{\overline{0}}{\mathscr{Q}} \\
\frac{\Phi}{2}\end{array}$ & ত్ర్ & 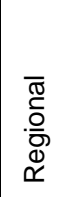 & $\begin{array}{l}\overline{\widetilde{J}} \\
\stackrel{0}{\bar{T}} \\
\frac{\mathrm{O}}{2}\end{array}$ & 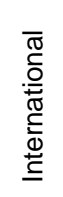 & 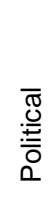 & 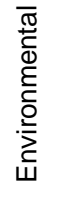 & $\begin{array}{l}\frac{\bar{\pi}}{\mathrm{d}} \\
\dot{\infty}\end{array}$ & 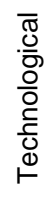 & $\begin{array}{l}\stackrel{0}{E} \\
\bar{\delta} \\
\bar{\delta} \\
\dot{U}\end{array}$ & \\
\hline $\begin{array}{l}\text { LTC could provide capability for improved } \\
\text { access/larger catchments for local disposal and } \\
\text { recycling centres }\end{array}$ & & & & & & & & & & & & & & & & & & & & $?$ & + & + & I & $?$ & \begin{tabular}{|l|} 
Local Communities, \\
Councils and Waste \\
Management Companies
\end{tabular} \\
\hline $\begin{array}{l}\text { LTC could provide capability for cross-river } \\
\text { connection of sewage pipes \& increased } \\
\text { network resilience }\end{array}$ & & & & & & & & & & & & & & & & & & & & $?$ & ? & ? & $?$ & $?$ & $\begin{array}{l}\text { Local Communities, } \\
\text { Councils and Waste } \\
\text { Management Companies }\end{array}$ \\
\hline $\begin{array}{l}\text { Waste sector could provide recycled materials } \\
\text { as a resource for use in LTC construction (e.g. } \\
\text { car tyres as road surface) }\end{array}$ & & & & & & & & & & & & & & & & & & & & $?$ & + & + & ? & + & \begin{tabular}{|l} 
LTC Construction, Waste \\
Management Companies
\end{tabular} \\
\hline
\end{tabular}

Table 10 - Water Infrastructure \& LTC Interdependencies Characterisation and Evaluation

\begin{tabular}{|c|c|c|c|c|c|c|c|c|c|c|c|c|c|c|c|c|c|c|c|c|c|c|c|c|c|}
\hline \multirow[b]{2}{*}{ Interdependency } & \multicolumn{5}{|c|}{ Nature } & \multicolumn{2}{|c|}{ Necessity } & \multicolumn{2}{|c|}{ Result } & \multicolumn{5}{|c|}{ Chronology } & \multicolumn{5}{|c|}{ Scale } & \multicolumn{5}{|c|}{ PESTE } & \multirow[b]{2}{*}{$\begin{array}{c}\text { Relevant } \\
\text { Stakeholders }\end{array}$} \\
\hline & 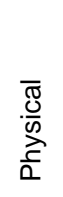 & $\frac{\bar{\pi}}{\stackrel{0}{0}}$ & $\begin{array}{l}\overline{\mathbb{U}} \\
\frac{0}{\bar{t}} \\
\overline{0} \\
\overline{0} \\
\overline{0} \\
0 \\
0\end{array}$ & 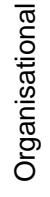 & $\begin{array}{l}\bar{\Phi} \\
\stackrel{ \pm}{ \pm}\end{array}$ & 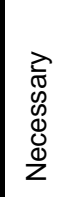 & 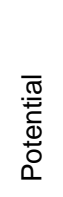 & 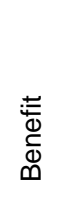 & $\begin{array}{l}\widehat{x} \\
\frac{\mathbf{w}}{\tilde{N}} \\
\mathbb{N} \\
\overline{0} \\
\mathbb{N} \\
\mathbb{N} \\
\mathbb{I}\end{array}$ & 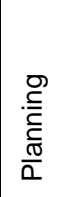 & 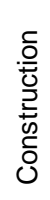 & $\begin{array}{l}\frac{.}{0} \\
\frac{\pi}{\pi} \\
\frac{0}{0}\end{array}$ & 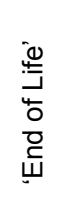 & $\begin{array}{l}\frac{0}{\overline{0}} \\
\stackrel{0}{0} \\
\text { d } \\
\infty\end{array}$ & $\begin{array}{l}\frac{1}{0} \\
\frac{\Phi}{0} \\
\dot{0}\end{array}$ & $\overline{\mathscr{ల}}$ & 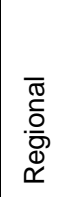 & $\begin{array}{l}\overline{\widetilde{\sigma}} \\
\stackrel{0}{\overline{ \pm}} \\
\frac{\pi}{Z}\end{array}$ & 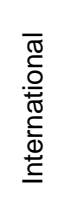 & 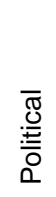 & 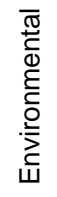 & $\begin{array}{l}\frac{\bar{\pi}}{\mathrm{d}} \\
\dot{8}\end{array}$ & 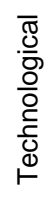 & $\begin{array}{l}\stackrel{0}{\bar{E}} \\
\stackrel{0}{0} \\
\text { Uू }\end{array}$ & \\
\hline $\begin{array}{l}\text { LTC could provide flood defence capability (as } \\
\text { part of Thames Estuary 2100) }\end{array}$ & & & & & & & & & & & & & & & & & & & & $?$ & $?$ & + & $?$ & + & $\begin{array}{l}\text { Environment Agency, } \\
\text { Thames Water, GLA, } \\
\text { Local Councils }\end{array}$ \\
\hline $\begin{array}{l}\text { LTC could provide defence to coastal erosion } \\
\text { (as part of Thames Estuary 2100) }\end{array}$ & & & & & & & & & & & & & & & & & & & & $?$ & $?$ & + & $?$ & + & $\begin{array}{l}\text { Environment Agency, } \\
\text { Local Councils }\end{array}$ \\
\hline $\begin{array}{l}\text { LTC could provide capability to move potable } \\
\text { and waste water }\end{array}$ & & & & & & & & & & & & & & & & & & & & + & + & + & I & + & $\begin{array}{l}\text { Thames Water, Local } \\
\text { Councils }\end{array}$ \\
\hline $\begin{array}{l}\text { LTC could be integrated with creation of a tidal } \\
\text { lagoon }\end{array}$ & & & & & & & & & & & & & & & & & & & & $?$ & $?$ & ? & $?$ & $?$ & $\begin{array}{l}\text { Environment Agency, } \\
\text { Local Councils }\end{array}$ \\
\hline $\begin{array}{l}\text { LTC could impact on the form and processes of } \\
\text { the river during construction and operation }\end{array}$ & & & & & & & & & & & & & & & & & & & & - & - & - & I & - & $\begin{array}{l}\text { Environment Agency, } \\
\text { Thames Water, Maritime } \\
\text { Users }\end{array}$ \\
\hline $\begin{array}{l}\text { The potential construction of a new Thames } \\
\text { Barrier at Long Reach (Thames Estuary 2100) } \\
\text { could affect the LTC } \\
\end{array}$ & & & & & & & & & & & & & & & & & & & & $?$ & $?$ & ? & $?$ & $?$ & \begin{tabular}{|l|} 
LTC Planners \& \\
Construction, Barrier \\
Planners \& Construction
\end{tabular} \\
\hline $\begin{array}{l}\text { The Thames Estuary human marine } \\
\text { environment could impose constraints on the } \\
\text { location and design of the crossing, as well as } \\
\text { the construction process }\end{array}$ & & & & & & & & & & & & & & & & & & & & $?$ & $?$ & - & I & - & $\begin{array}{l}\text { Thames Water, } \\
\text { Environment Agency, } \\
\text { LTC Construction }\end{array}$ \\
\hline
\end{tabular}


Table 11 - Wider Community and Environment \& LTC Interdependencies Characterisation and Evaluation

\begin{tabular}{|c|c|c|c|c|c|c|c|c|c|c|c|c|c|c|c|c|c|c|c|c|c|c|c|c|c|}
\hline \multirow[b]{2}{*}{ Interdependency } & \multicolumn{5}{|c|}{ Nature } & \multicolumn{2}{|c|}{ Necessity } & \multicolumn{2}{|c|}{ Result } & \multicolumn{5}{|c|}{ Chronology } & \multicolumn{5}{|c|}{ Scale } & \multicolumn{5}{|c|}{ PESTE } & \multirow[b]{2}{*}{$\begin{array}{c}\text { Relevant } \\
\text { Stakeholders }\end{array}$} \\
\hline & 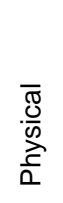 & $\frac{\bar{\pi}}{\overline{0}}$ & 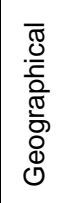 & 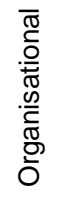 & $\begin{array}{l}\bar{\varpi} \\
\stackrel{ \pm}{ \pm}\end{array}$ & 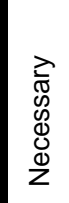 & 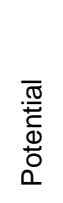 & $\begin{array}{l}\frac{1}{0} \\
\stackrel{\overline{0}}{\Phi} \\
\infty\end{array}$ & 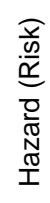 & 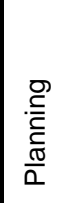 & 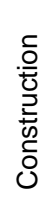 & 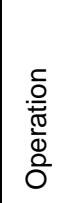 & 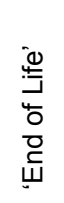 & 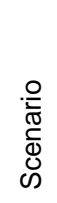 & $\frac{\bar{d}}{\frac{\Phi}{2}}$ & ס্ర్ & 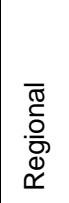 & $\begin{array}{l}\overline{\widetilde{\sigma}} \\
\stackrel{0}{0} \\
\stackrel{0}{\bar{\pi}} \\
z\end{array}$ & 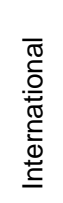 & 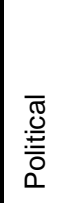 & 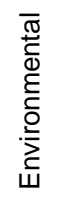 & $\begin{array}{l}\overline{\bar{T}} \\
\bar{\delta} \\
\infty\end{array}$ & 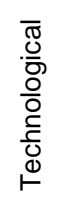 & $\begin{array}{l}\stackrel{.}{E} \\
\bar{\delta} \\
\bar{\partial} \\
\dot{U}\end{array}$ & \\
\hline $\begin{array}{l}\text { Improved connectivity and reduced congestion } \\
\text { could stimulate growth and employment }\end{array}$ & & & & & & & & & & & & & & & & & & & & + & $?$ & + & I & + & $\begin{array}{l}\text { Local Councils, } \\
\text { Government, Local } \\
\text { Industry }\end{array}$ \\
\hline $\begin{array}{l}\text { LTC could provide improved connections to public } \\
\text { services (hospitals, schools, police etc.) }\end{array}$ & & & & & & & & & & & & & & & & & & & & + & $?$ & + & / & + & $\begin{array}{l}\text { Local Councils and } \\
\text { Social Service Providers }\end{array}$ \\
\hline $\begin{array}{l}\text { LTC could result in freight being routed through } \\
\text { Eastern areas currently unaffected by such traffic }\end{array}$ & & & & & & & & & & & & & & & & & & & & - & - & - & / & - & $\begin{array}{l}\text { Local Councils, Haulage } \\
\text { Companies }\end{array}$ \\
\hline $\begin{array}{l}\text { LTC could impact on SSSIs and Green Belt Land } \\
\text { (particularly Option C) }\end{array}$ & & & & & & & & & & & & & & & & & & & & - & - & - & 1 & - & $\begin{array}{l}\text { Environment Agency, } \\
\text { Local Councils }\end{array}$ \\
\hline $\begin{array}{l}\text { Impact on sites of archaeological heritage } \\
\text { (particularly Option B) }\end{array}$ & & & & & & & & & & & & & & & & & & & & - & - & - & / & I & Environment Agency \\
\hline $\begin{array}{l}\text { Impact on Swanscombe heritage park landscape } \\
\text { (particularly Option B) }\end{array}$ & & & & & & & & & & & & & & & & & & & & - & - & - & I & I & $\begin{array}{l}\text { Environment Agency, } \\
\text { Local Councils }\end{array}$ \\
\hline $\begin{array}{l}\text { Impact on Thames Estuary and Marshes RAMSAR } \\
\text { site (Option C) }\end{array}$ & & & & & & & & & & & & & & & & & & & & - & - & - & I & - & $\begin{array}{l}\text { Environment Agency, } \\
\text { Local Councils }\end{array}$ \\
\hline $\begin{array}{l}\text { Visual impact on Kent Downs Area of Outstanding } \\
\text { Natural Beauty }\end{array}$ & & & & & & & & & & & & & & & & & & & & - & - & - & 1 & I & $\begin{array}{l}\text { Environment Agency, } \\
\text { Local Councils }\end{array}$ \\
\hline $\begin{array}{l}\text { LTC Option B would traverse a planned } \\
\text { development site north of the A2 corridor }\end{array}$ & & & & & & & & & & & & & & & & & & & & - & I & - & 1 & - & $\begin{array}{l}\text { Local Councils and } \\
\text { Developers }\end{array}$ \\
\hline Constraints of SSSIs, Woodlands etc. & & & & & & & & & & & & & & & & & & & & l & l & l & / & - & $\begin{array}{l}\text { Environment Agency, } \\
\text { LTC Planners }\end{array}$ \\
\hline $\begin{array}{l}\text { Potential housing and business developments } \\
\text { (e.g. Ebbsfleet Valley) could affect demand } \\
\text { patterns and the design of the LTC }\end{array}$ & & & & & & & & & & & & & & & & & & & & $?$ & $?$ & ? & $?$ & $?$ & $\begin{array}{l}\text { LTC Planners, } \\
\text { Operators, Local } \\
\text { Developers } \\
\end{array}$ \\
\hline $\begin{array}{l}\text { The proposed Paramount Park at Swanscombe } \\
\text { Peninsula could affect demand patterns and } \\
\text { LTC design }\end{array}$ & & & & & & & & & & & & & & & & & & & & $?$ & $?$ & ? & $?$ & $?$ & LTC Planners, Operators \\
\hline $\begin{array}{l}\text { Regeneration projects could affect land use and } \\
\text { therefore cost }\end{array}$ & & & & & & & & & & & & & & & & & & & & $?$ & $?$ & - & / & - & $\begin{array}{l}\text { LTC Planners, Local } \\
\text { Developers }\end{array}$ \\
\hline $\begin{array}{l}\text { Aligned construction between projects (e.g. } \\
\text { shared construction services) could result in } \\
\text { shared costs }\end{array}$ & & & & & & & & & & & & & & & & & & & & + & + & + & + & + & $\begin{array}{l}\text { LTC Construction, Local } \\
\text { Developers }\end{array}$ \\
\hline $\begin{array}{l}\text { Regeneration projects may provide access to } \\
\text { land for LTC }\end{array}$ & & & & & & & & & & & & & & & & & & & & + & + & + & + & + & $\begin{array}{l}\text { LTC Construction, Local } \\
\text { Developers. }\end{array}$ \\
\hline
\end{tabular}




\section{Conclusions}

The existing Dartford to Thurrock Thames River crossing is an important part of the national, regional and local road networks. Traffic forecasts have indicated a need for increased future river crossing capacity.

There are many complex issues surrounding the capacity problem, the needs for a new crossing and delivery of a solution. The literature concerning the LTC indicates that it is broadly conceived as a transport problem; albeit one that can influence regional and national economies. This perspective can influence the way in which a solution is developed and the way in which interdependencies with other infrastructure systems are identified and valued.

There are a large number of urban regeneration projects proposed for the area around the LTC. These can have an impact on the need for a new crossing and the demands that will be placed upon it. In turn, the existing and new crossing can impact on the delivery and success of these regeneration activities. Desirable and undesirable interdependencies may emerge between the LTC project and these regeneration projects either by design or by accident.

The application of the IP\&MF to this project has provided a means through which to explore the necessary and potential interdependencies, along with their emergent benefits and effects on risk.

The application of a Matrix-Based Tool for the systematic identification of cross-sector interdependencies highlights a number of necessary and potential interdependencies. These can then be evaluated in terms of Political, Environmental, Social, Technological and Economic factors. Additional, potentially valuable interdependency opportunities include:

- Using the crossing to generate electricity;

- Using the crossing to carry electricity, telecommunications, water and waste infrastructure elements;

- Using the crossing as a flood defence;

- Using recycled materials in the construction of the crossing; and

- Sharing resources between the construction of the crossing and local regeneration projects

At this stage in the frameworks development the desk-study has insufficient evidence to claim with any certainty whether the identified interdependencies are of value or if there is an appetite to pursue them amongst the stakeholders. However, it does demonstrate that further consideration of the interdependecies and their impacts arising from the Lower Thames Crossing Project could lead to the identification and realisation of economic, environmantal and social benefits as well as the improved management of risk. Achieving this requires an open-systems approach, appropriate exploration of the perceived system boundaries and wide sstakeholder engagement. 


\section{Appendix A - Lower Thames Crossing Document Roadmap}

\begin{tabular}{|c|c|c|c|}
\hline Date & Author & Title & Notes \\
\hline 1989 & $\begin{array}{l}\text { Department for } \\
\text { Transport }\end{array}$ & Roads for Prosperity & $\begin{array}{l}\text { White Paper proposing large UK road construction programme (many projects of which did } \\
\text { not go ahead) based on traffic growth forecasts of between } 83 \% \text { and } 142 \% \text { by } 2025 \text {. It } \\
\text { included relief measures for the junctions around the existing crossing and proposed a study } \\
\text { into a Lower Thames Crossing. }\end{array}$ \\
\hline 1990 & $\begin{array}{l}\text { Department for } \\
\text { Transport }\end{array}$ & $\begin{array}{l}\text { Private Finance Road } \\
\text { Schemes - Information on } \\
\text { Proposed Options }\end{array}$ & $\begin{array}{l}\text { Describes how LTC would increase opportunity for journeys, improve communications, } \\
\text { movements to Europe, and reduce pressure on M25. }\end{array}$ \\
\hline 1994 & $\begin{array}{l}\text { G Maunsell and } \\
\text { Partners }\end{array}$ & $\begin{array}{l}\text { Lower Thames Crossing } \\
\text { Study }\end{array}$ & $\begin{array}{l}\text { Conducted for the Highways Agency, Identified four potential crossing locations ( } 25 \text { options in } \\
\text { total). }\end{array}$ \\
\hline 1998 & $\begin{array}{l}\text { Halcrow Fox and } \\
\text { Associates }\end{array}$ & $\begin{array}{l}\text { East Thames River } \\
\text { Crossings: Appraisal } \\
\text { Framework }\end{array}$ & \\
\hline 1998 & $\begin{array}{l}\text { Department for } \\
\text { Transport }\end{array}$ & $\begin{array}{l}\text { A New Deal for Transport: } \\
\text { Better for Everyone }\end{array}$ & White Paper \\
\hline 1998 & $\begin{array}{l}\text { Halcrow Fox and } \\
\text { Associates }\end{array}$ & $\begin{array}{l}\text { The Dartford Local } \\
\text { Crossing Study }\end{array}$ & $\begin{array}{l}\text { Parsons Brinkerhoff report notes that many of the options would not now be possible due to } \\
\text { subsequent development in the area. }\end{array}$ \\
\hline 2002 & Mott MacDonald & $\begin{array}{l}\text { London to Ipswich Multi } \\
\text { Modal Study (LOIS) - } \\
\text { Preferred Strategy } \\
\text { Development Report }\end{array}$ & $\begin{array}{l}\text { Rejects LTC on environmental an economic grounds, states need is dependent on land use } \\
\text { changes. }\end{array}$ \\
\hline 2002 & KBR & $\begin{array}{l}\text { Orbit: transport solutions } \\
\text { around London }\end{array}$ & $\begin{array}{l}\text { Conducted for the Government Office for the South East (GOSE) in order to develop a long- } \\
\text { term sustainable management strategy for the M25. Quotes Highways Agency figures stating } \\
\text { existing crossing has } 10 \text { years remaining life before it reaches capacity. }\end{array}$ \\
\hline 2004 & $\begin{array}{l}\text { Strategic Rail } \\
\text { Authority }\end{array}$ & Lower Thames Crossing & \\
\hline 2004 & Jacobs Babtie & $\begin{array}{l}\text { Getting the most out of the } \\
\text { Dartford Crossing }\end{array}$ & $\begin{array}{l}\text { Identified drivers of increased traffic on existing crossing and opportunities to manage demand } \\
\text { in short and medium term. Supports LTC mentioning regeneration will affect ability to } \\
\text { safeguard land. }\end{array}$ \\
\hline 2006 & Sir Rod Eddington & $\begin{array}{l}\text { The Eddington Transport } \\
\text { Study - The case for action: } \\
\text { Sir Rod Eddington's advice } \\
\text { to Government }\end{array}$ & Sets out an argument linking transport to economic growth. \\
\hline
\end{tabular}




\begin{tabular}{|c|c|c|c|}
\hline Date & Author & Title & Notes \\
\hline 2007 & Thames Gateway & $\begin{array}{l}\text { Thames Gateway Delivery } \\
\text { Plan }\end{array}$ & $\begin{array}{l}\text { Links transport to support for job growth in the Thames Gateway area, and identifies that DfT } \\
\text { will shortly be consulting on the need for a LTC. Provides details of some specific projects } \\
\text { planned for the area. }\end{array}$ \\
\hline 2007 & $\begin{array}{l}\text { Department for } \\
\text { Transport }\end{array}$ & $\begin{array}{l}\text { Towards a Sustainable } \\
\text { Transport System (TaSTS) }\end{array}$ & Sets out five high level goals against which transport project are to be judged. \\
\hline 2008 & $\begin{array}{l}\text { Department for } \\
\text { Transport }\end{array}$ & $\begin{array}{l}\text { Delivering a Sustainable } \\
\text { Transport System (DaSTS) }\end{array}$ & $\begin{array}{l}\text { Replaces the above TaSTS. Referenced by Parsons Brinkerhoff as shaping the scheme. } \\
\text { Includes five goals: supporting economic competitiveness and growth through transport, } \\
\text { reducing emissions, contribute to safety and health, promote equality of opportunity and } \\
\text { improve quality of life. }\end{array}$ \\
\hline 2008 & $\begin{array}{l}\text { Government } \\
\text { Office for the East } \\
\text { of England }\end{array}$ & East of England Plan & Includes the Regional Transport Strategy for the East of England. \\
\hline 2008 & $\begin{array}{l}\text { Government } \\
\text { Office for the } \\
\text { South East }\end{array}$ & $\begin{array}{l}\text { South East Plan: Regional } \\
\text { Spatial Strategy }\end{array}$ & $\begin{array}{l}\text { Secretary of State comments that A2/A282/M2 corridor (including Thames Crossing Options) } \\
\text { is a priority transport link coming under increasing pressure from underlying traffic growth. }\end{array}$ \\
\hline 2009 & $\begin{array}{l}\text { Gifford, MVA } \\
\text { Consultancy, } \\
\text { Capita }\end{array}$ & $\begin{array}{l}\text { Assessment of Lower } \\
\text { Thames Crossing Capacity }\end{array}$ & $\begin{array}{l}\text { Summarises the need for a new crossing and assess the location and design options using a } \\
\text { framework looking at National Policy, Regional Spatial Strategies, Regional Transport } \\
\text { Strategies, Sub-Regional Strategies and Local Transport Plans. }\end{array}$ \\
\hline 2010 & HM Treasury & Spending Review 2010 & $\begin{array}{l}\text { Comprehensive Spending Review in which Department for Transport committed to short and } \\
\text { medium term measures to address congestion at the existing Dartford Crossing, and review } \\
\text { options for longer term capacity. }\end{array}$ \\
\hline 2010 & $\begin{array}{l}\text { Department for } \\
\text { Transport }\end{array}$ & Transport Spending Review & $\begin{array}{l}\text { As with above: "It is clear that additional capacity is needed at Dartford and that public funding } \\
\text { to provide it is unlikely to be available. Therefore, DfT will embark upon a review of the options } \\
\text { for future capacity increases at Dartford, funded by charges." }\end{array}$ \\
\hline 2010 & $\begin{array}{l}\text { Greater London } \\
\text { Authority }\end{array}$ & Mayor's Transport Strategy & Indicates support for the Government proposals to reduce congestion at the existing crossing. \\
\hline 2010 & $\begin{array}{l}\text { David Lock } \\
\text { Associates }\end{array}$ & $\begin{array}{l}\text { Swanscombe \& } \\
\text { Northfleet Riverside } \\
\text { Study - Revised Final } \\
\text { Output }\end{array}$ & Looks at land use in this region. \\
\hline 2011 & $\begin{array}{l}\text { Greater London } \\
\text { Authority }\end{array}$ & $\begin{array}{l}\text { London Plan: Spatial } \\
\text { Development Strategy for } \\
\text { Greater London }\end{array}$ & $\begin{array}{l}\text { Together with document above provide the policy framework for London Boroughs to develop } \\
\text { their own development frameworks. Stes out the vision to } 2031 \text {. Forecasts additional } \\
650,000 \text { jobs and } 1.2 \text { million population. } 37 \% \text { of additional employment and } 22 \% \text { of additional } \\
\text { population in east sub-region. Policy } 6.4,6.12 \text { and Table } 6.1 \text { set out need for additional river } \\
\text { crossings. }\end{array}$ \\
\hline
\end{tabular}




\begin{tabular}{|c|c|c|c|}
\hline Date & Author & Title & Notes \\
\hline 2011 & $\begin{array}{l}\text { Department for } \\
\text { Transport }\end{array}$ & $\begin{array}{l}\text { DfT Business Plan } 2012 \text { - } \\
2015\end{array}$ & Investment in roads to promote growth, reduce congestion and reduce carbon emissions. \\
\hline 2011 & Highways Agency & $\begin{array}{l}\text { HA Business Plan 2012- } \\
2013\end{array}$ & Sets out goals to tackle bottlenecks and increase capacity. \\
\hline 2011 & $\begin{array}{l}\text { HM Treasury, } \\
\text { Infrastructure UK }\end{array}$ & $\begin{array}{l}\text { National Infrastructure Plan } \\
2011\end{array}$ & Commitment to build a Lower Thames Crossing as a focused delivery item. \\
\hline 2012 & $\begin{array}{l}\text { Transport for } \\
\text { London }\end{array}$ & $\begin{array}{l}\text { East London River } \\
\text { Crossings: Assessment of } \\
\text { Need }\end{array}$ & $\begin{array}{l}\text { Does consider the Dartford Crossing and its impact on the Greater London Authority area, but } \\
\text { recognises that the majority of journey's originate and terminate beyond its boundary. }\end{array}$ \\
\hline 2012 & URS & $\begin{array}{l}\text { Third Thames Crossing } \\
\text { Regeneration Impact } \\
\text { Assessment - Final } \\
\text { Report }\end{array}$ & $\begin{array}{l}\text { Splits the region into several zones, identifies the nature of the regeneration and capacity for } \\
\text { jobs and homes in each. Looks at the impact each of the three crossing options may have on } \\
\text { these planned schemes. }\end{array}$ \\
\hline 2013 & Aecom & $\begin{array}{l}\text { Review of Lower Thames } \\
\text { Crossing Options: Final } \\
\text { Report }\end{array}$ & $\begin{array}{l}\text { Along with its supporting documents (traffic modelling and site impacts) summarises the need } \\
\text { for additional capacity and the three potential sites at which to provide it. }\end{array}$ \\
\hline 2013 & $\begin{array}{l}\text { South East Local } \\
\text { Enterprise } \\
\text { Partnership }\end{array}$ & $\begin{array}{l}\text { SE LEP response to the } \\
\text { Lower Thames Crossing } \\
\text { consultation }\end{array}$ & $\begin{array}{l}\text { A response to the public consultation. Expresses disappointment that options east of Option } \\
C \text { were not part of the consultation and reject Options } A \text { and } B \text { on the grounds that they do not } \\
\text { provide enough benefit to the local economies and their regeneration. }\end{array}$ \\
\hline
\end{tabular}




\section{Appendix B - Desk Study Output Matrix}

\begin{tabular}{|c|c|c|c|c|c|c|}
\hline \multirow[t]{3}{*}{ Energy } & & & 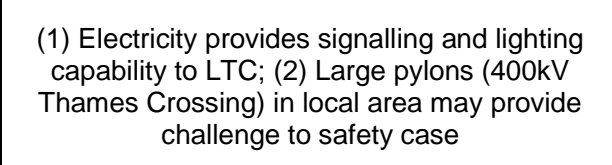 & & & \\
\hline & ICT & & $\begin{array}{l}\text { (1) ICT provides capability for signalling and } \\
\text { traftic management }\end{array}$ & & & \\
\hline & & Other Transport & 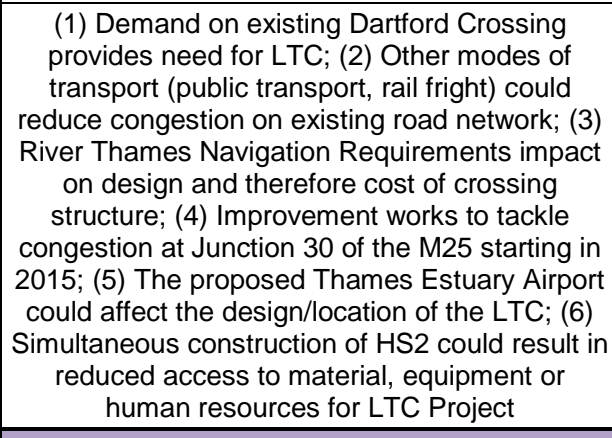 & & & \\
\hline \multirow[t]{4}{*}{ 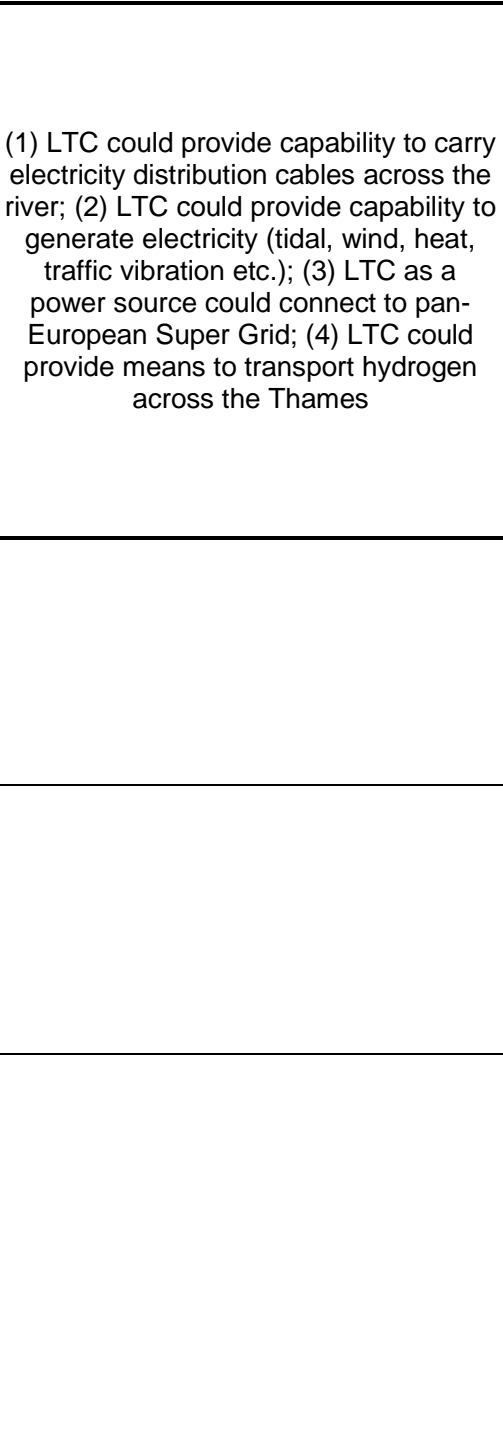 } & 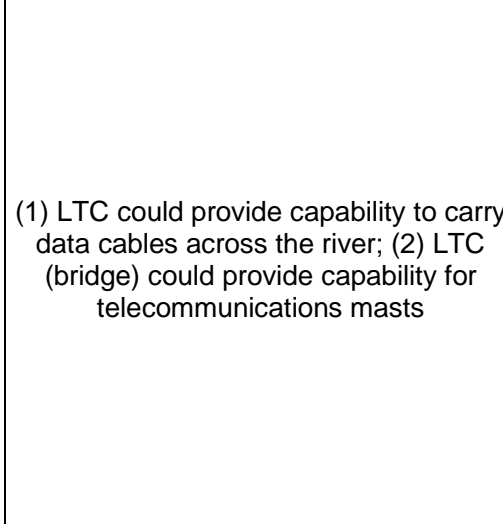 & 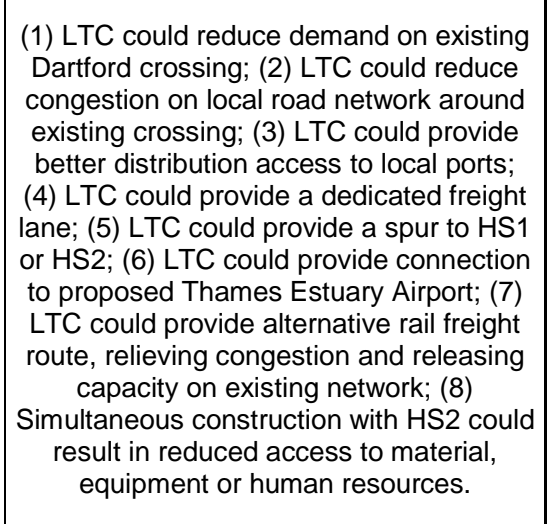 & $\begin{array}{l}\text { Lower Thames } \\
\text { Crossing }\end{array}$ & 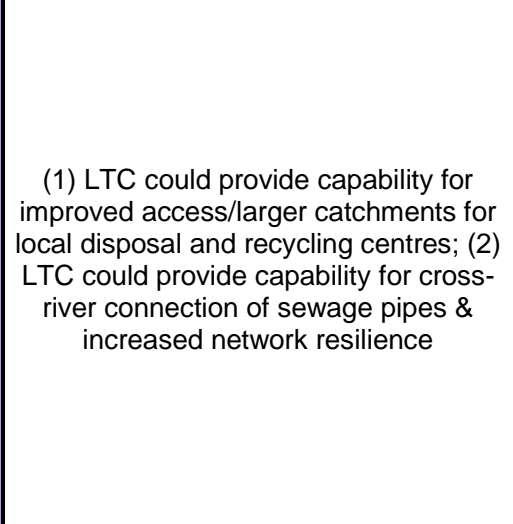 & 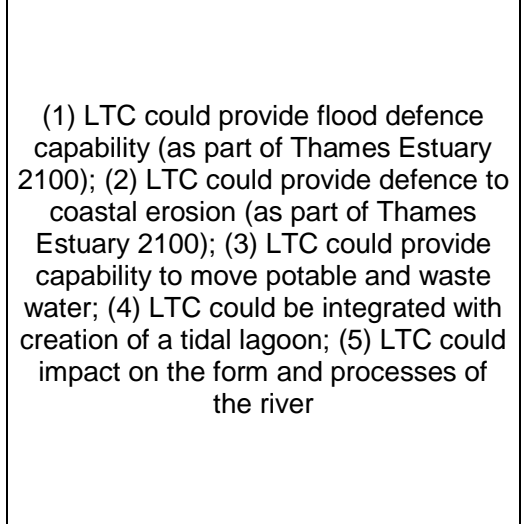 & 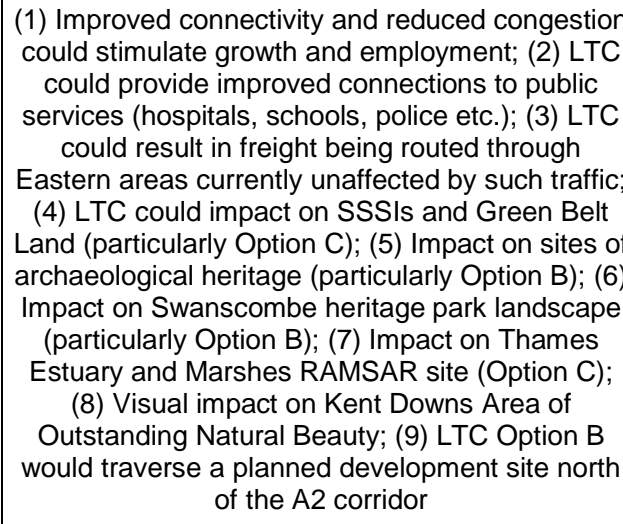 \\
\hline & & & 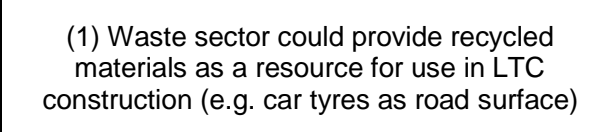 & Waste & & \\
\hline & & & 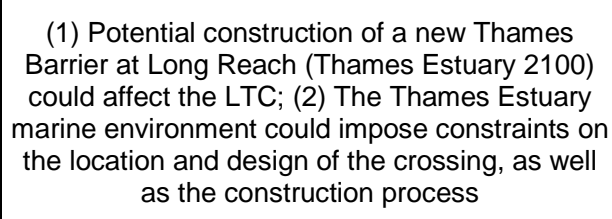 & & Water & \\
\hline & & & 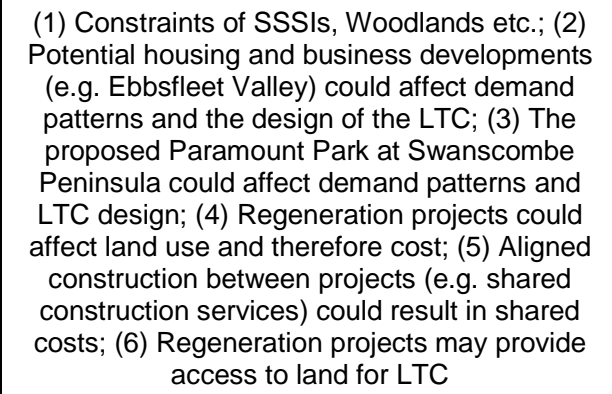 & & & $\begin{array}{c}\text { Wider Society, } \\
\text { Regeneration \& } \\
\text { Environment }\end{array}$ \\
\hline
\end{tabular}

